\title{
Amiaspochalasins A-H, undescribed aspochalasins with a C-21 ester carbonyl from Aspergillus micronesiensis
}

Zhaodi Wu, Xiaotian Zhang, Weaam Hasan Al Anbari, Mi Zhang, Xia Chen, Zengwei Luo, Xiao-Nian Li, Chunmei Chen, Junjun Liu, Jianping Wang, Hucheng Zhu,* and Yonghui Zhang*

Hubei Key Laboratory of Natural Medicinal Chemistry and Resource Evaluation, School of Pharmacy, Tongji Medical College, Huazhong University of Science and Technology, Wuhan 430030, Hubei Province, People's Republic of China

\section{* Corresponding Authors}

E-mails: zhangyh@mails.tjmu.edu.cn (Y. Zhang), zhuhucheng@hust.edu.cn (H. Zhu). 


\section{Table of contents}

Figure S1 X-ray crystallographic structure of 1 (displacement ellipsoids are drawn at $30 \%$ the

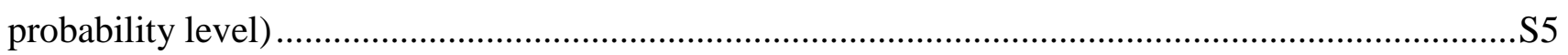

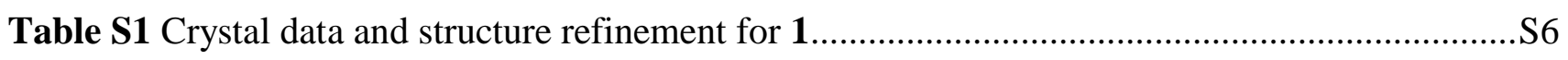

Figure S2 X-ray crystallographic structure of 5 (displacement ellipsoids are drawn at $30 \%$ the

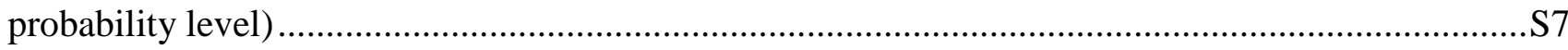

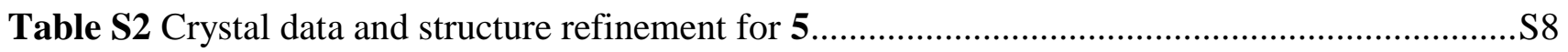

Figure S3 Key HMBC and ${ }^{1} \mathrm{H}-{ }^{1} \mathrm{H}$ COSY correlations of $\mathbf{4}$ and $\mathbf{5}$, and key NOESY correlations of $\mathbf{4}$,

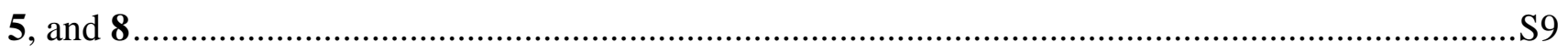

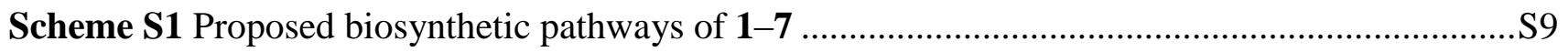

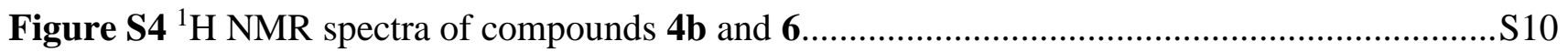

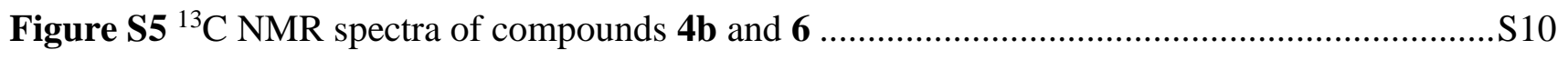

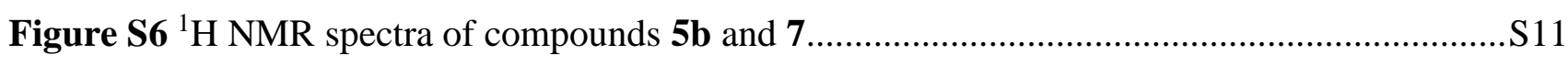

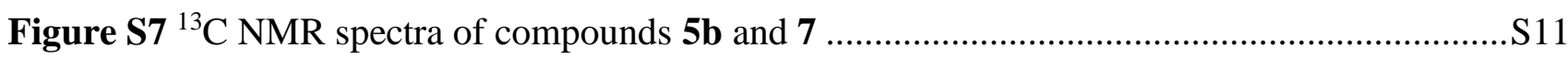

Figure S8 Dose-response viability curves of five cancer cell lines after treated with compound $\mathbf{4}$ for 48 h. Data represent mean \pm SD of three independent experiments............................................. 12

Figure S9 Dose-response viability curves of five cancer cell lines after treated with compound $\mathbf{5}$ for 48 h. Data represent mean \pm SD of three independent experiments..........................................S12

Figure S10 Dose-response viability curves of five cancer cell lines after treated with Taxol for $48 \mathrm{~h}$.

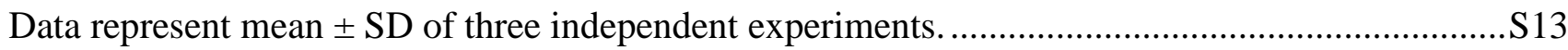

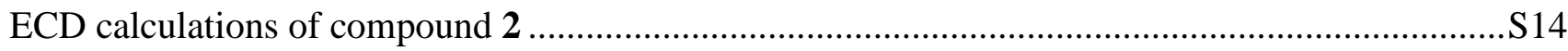

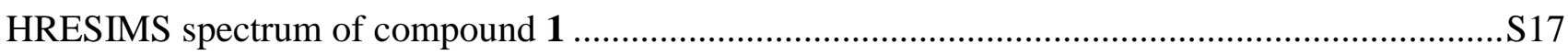

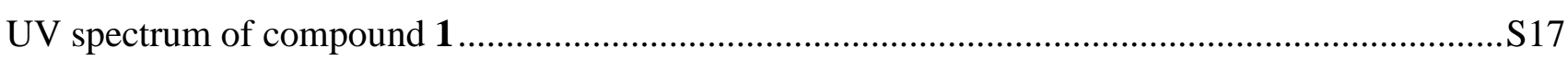

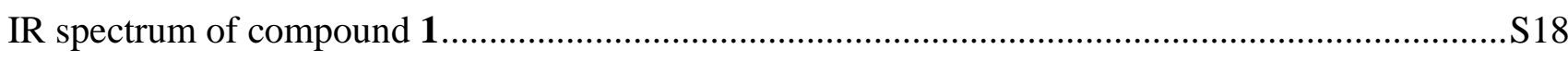

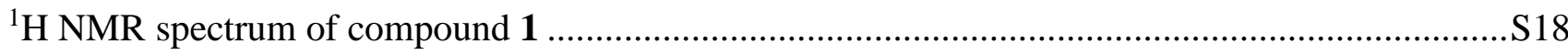

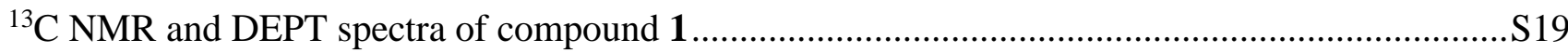

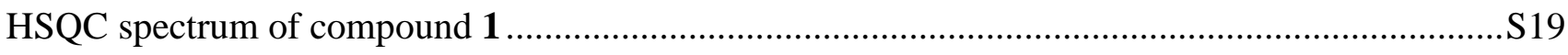

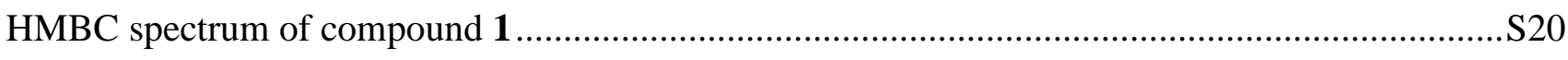

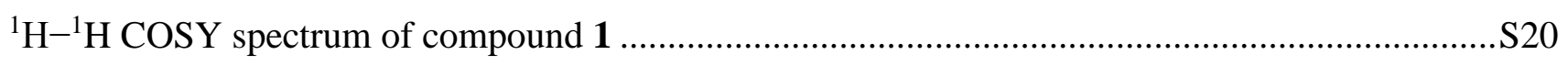

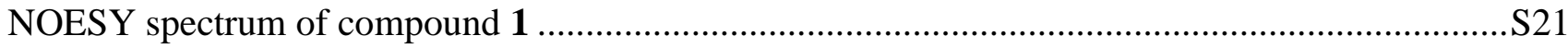

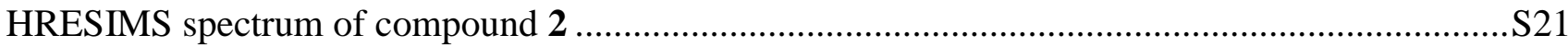

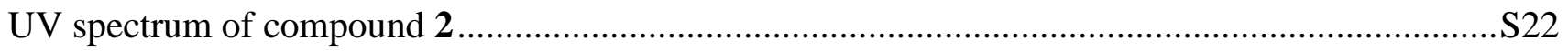




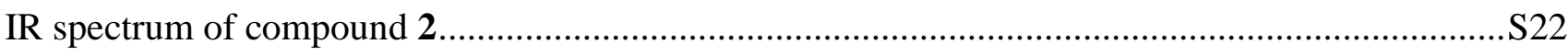

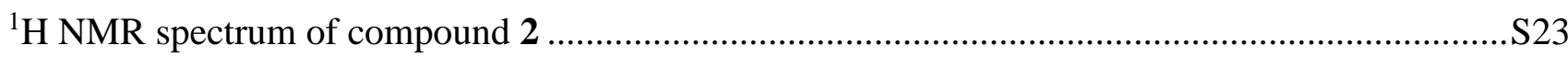

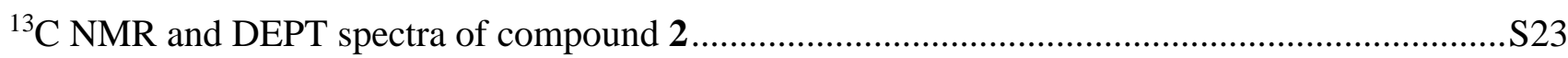

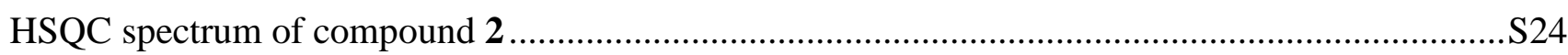

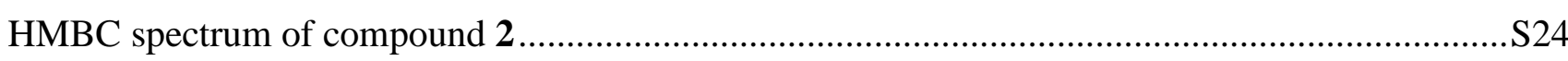

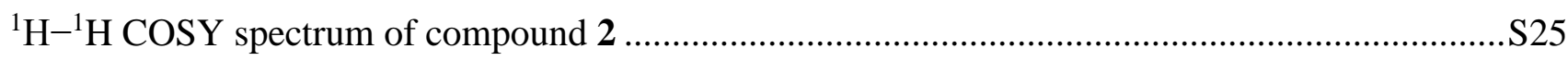

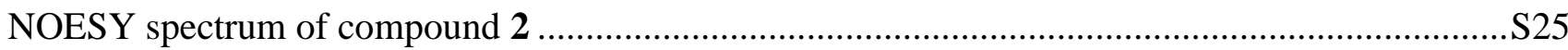

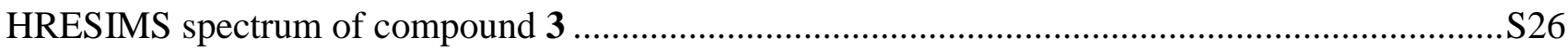

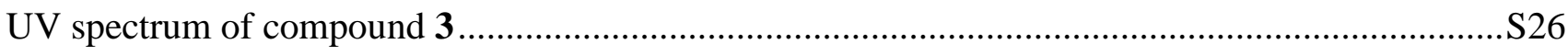

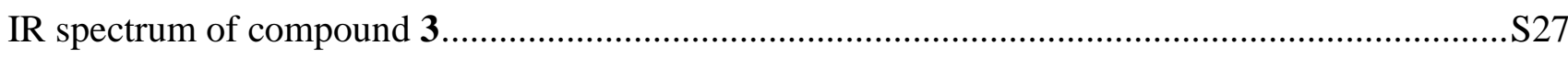

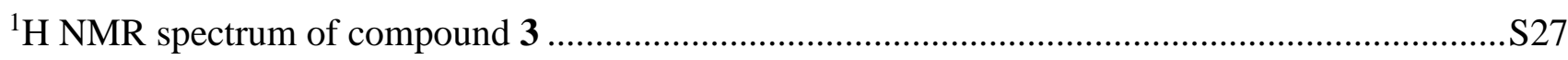

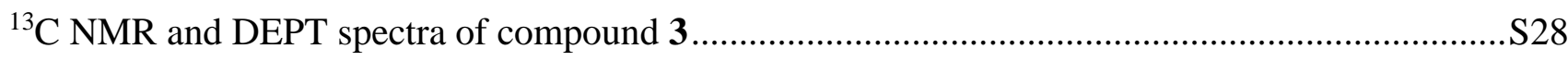

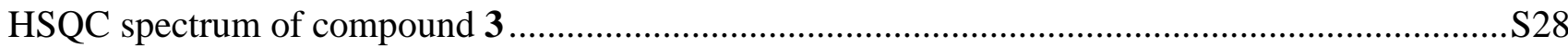

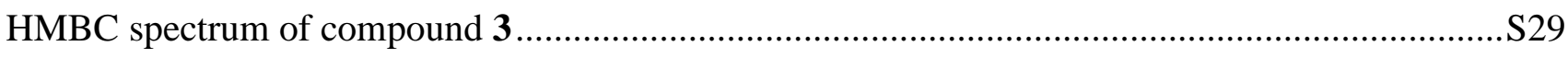

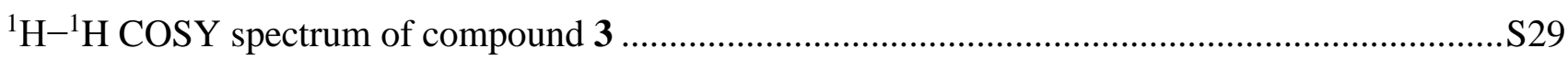

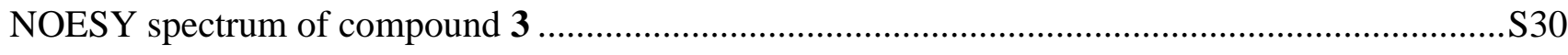

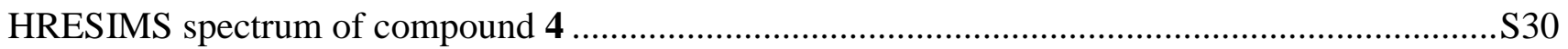

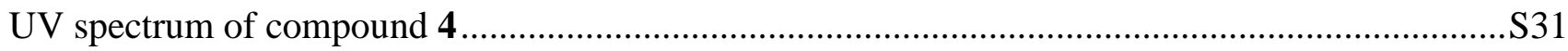

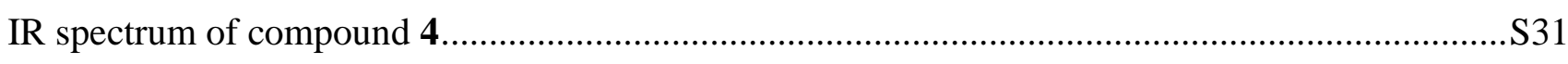

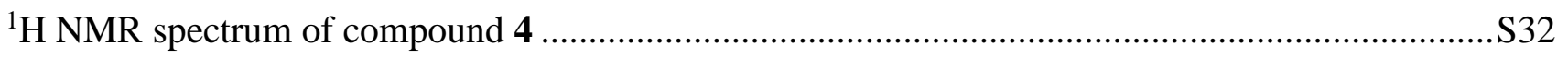

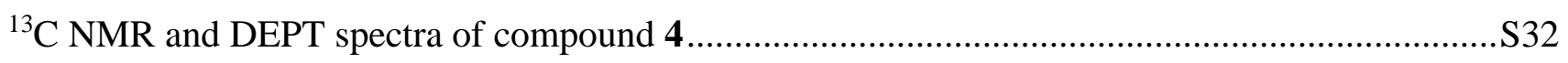

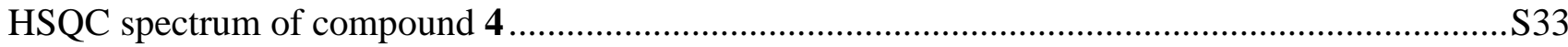

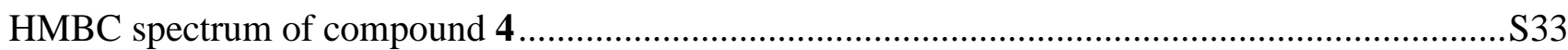

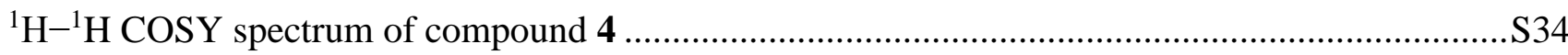

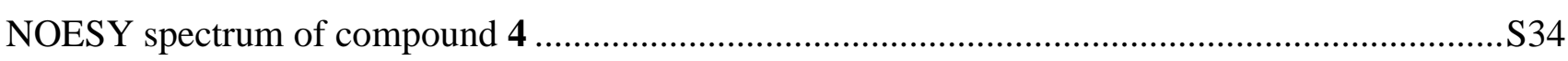

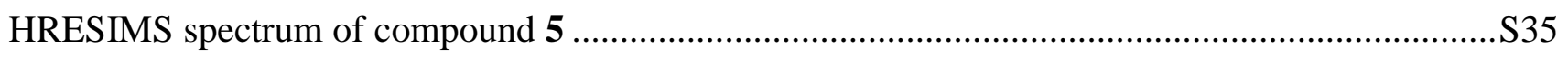

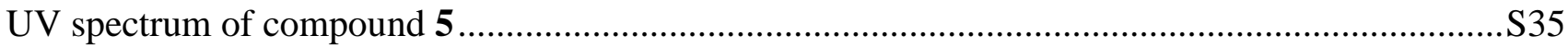

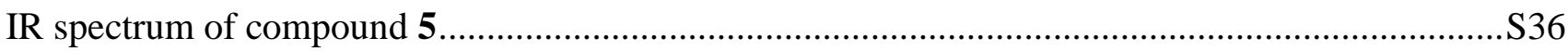

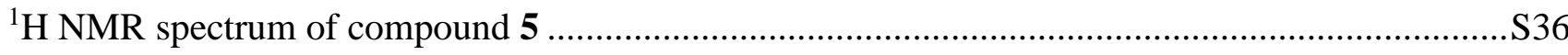

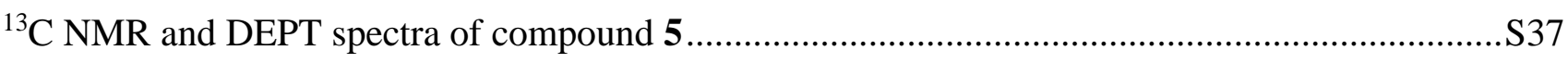

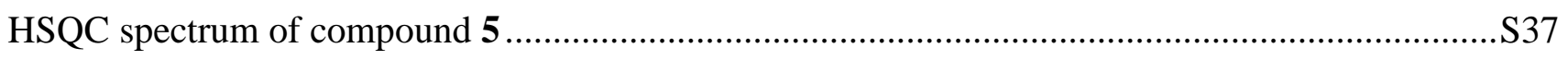

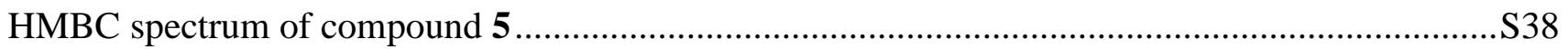

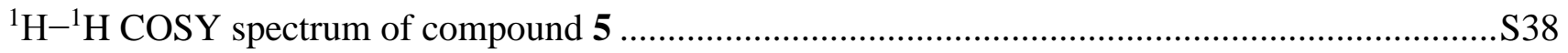




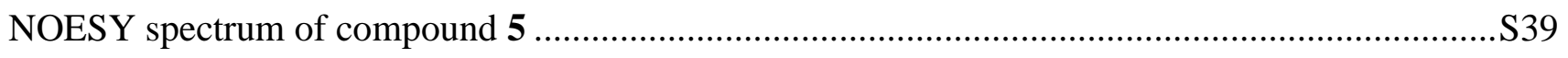

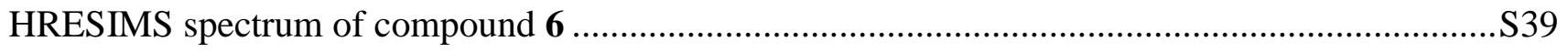

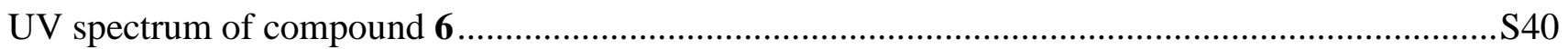

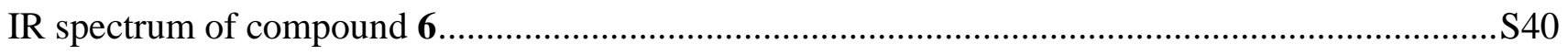

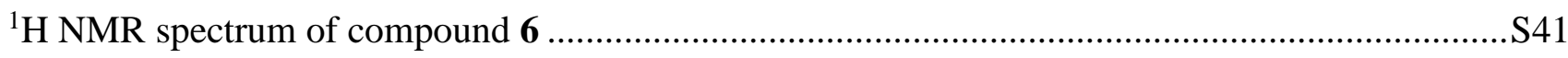

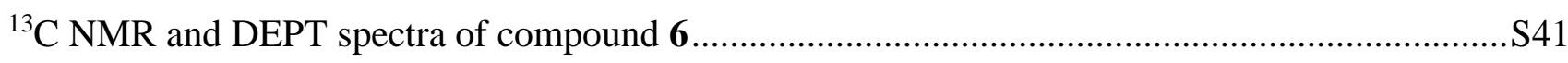

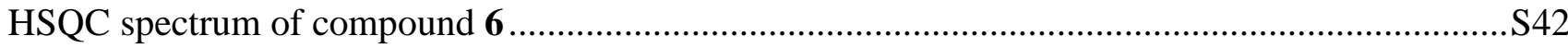

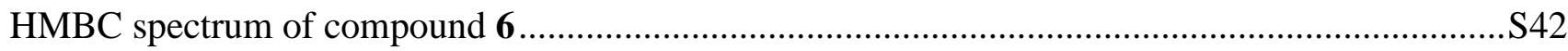

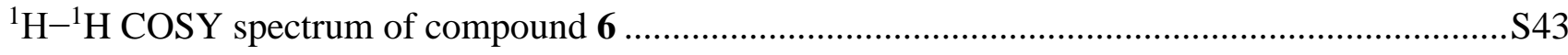

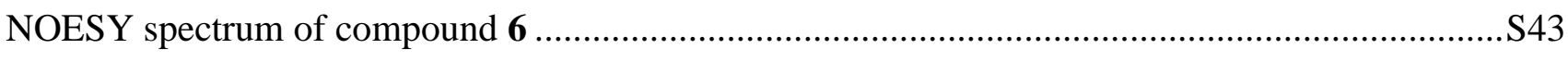

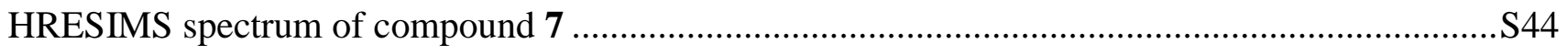

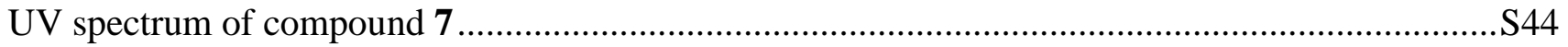

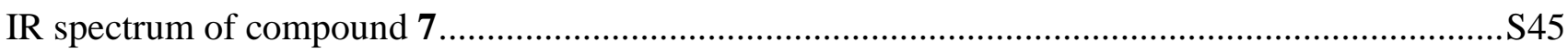

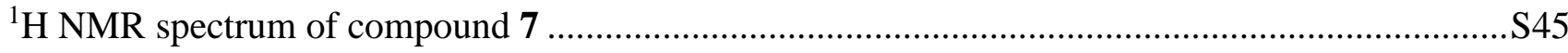

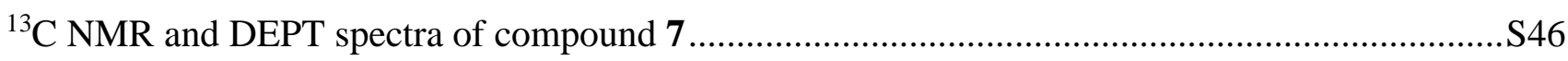

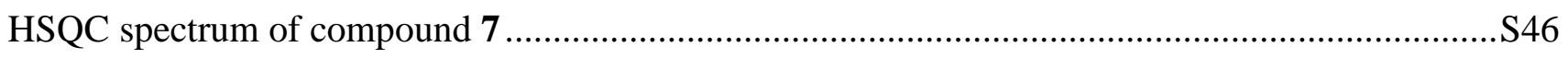

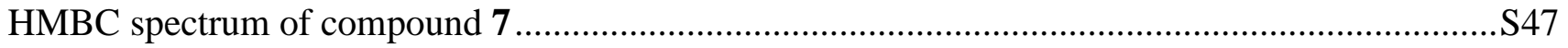

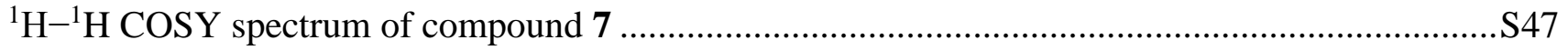

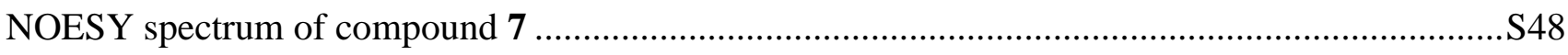

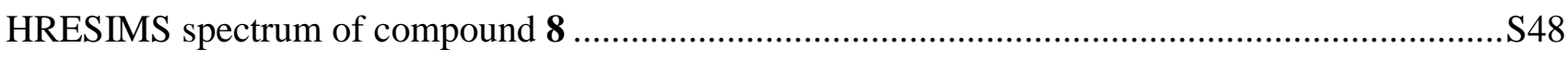

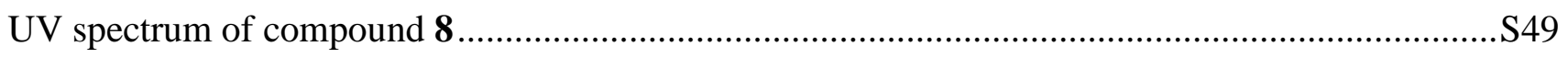

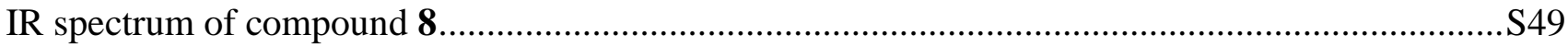

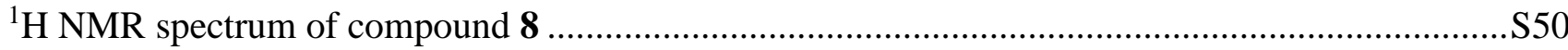

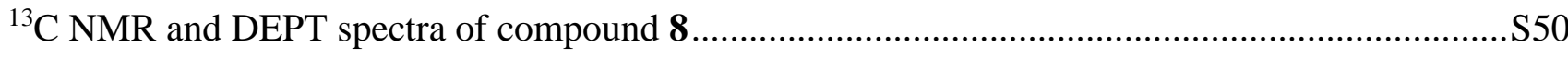

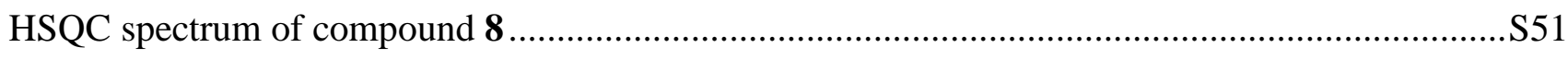

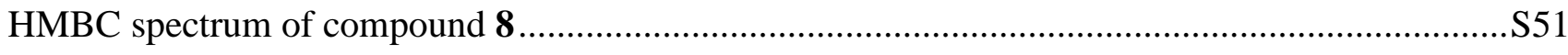

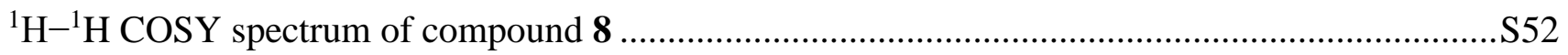

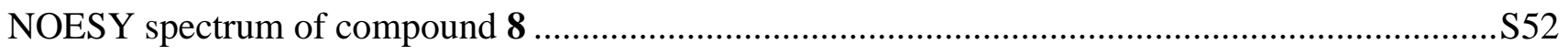

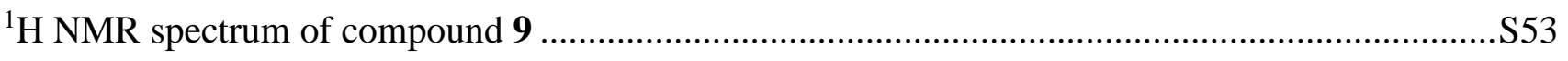

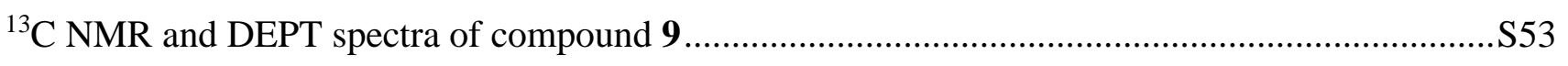




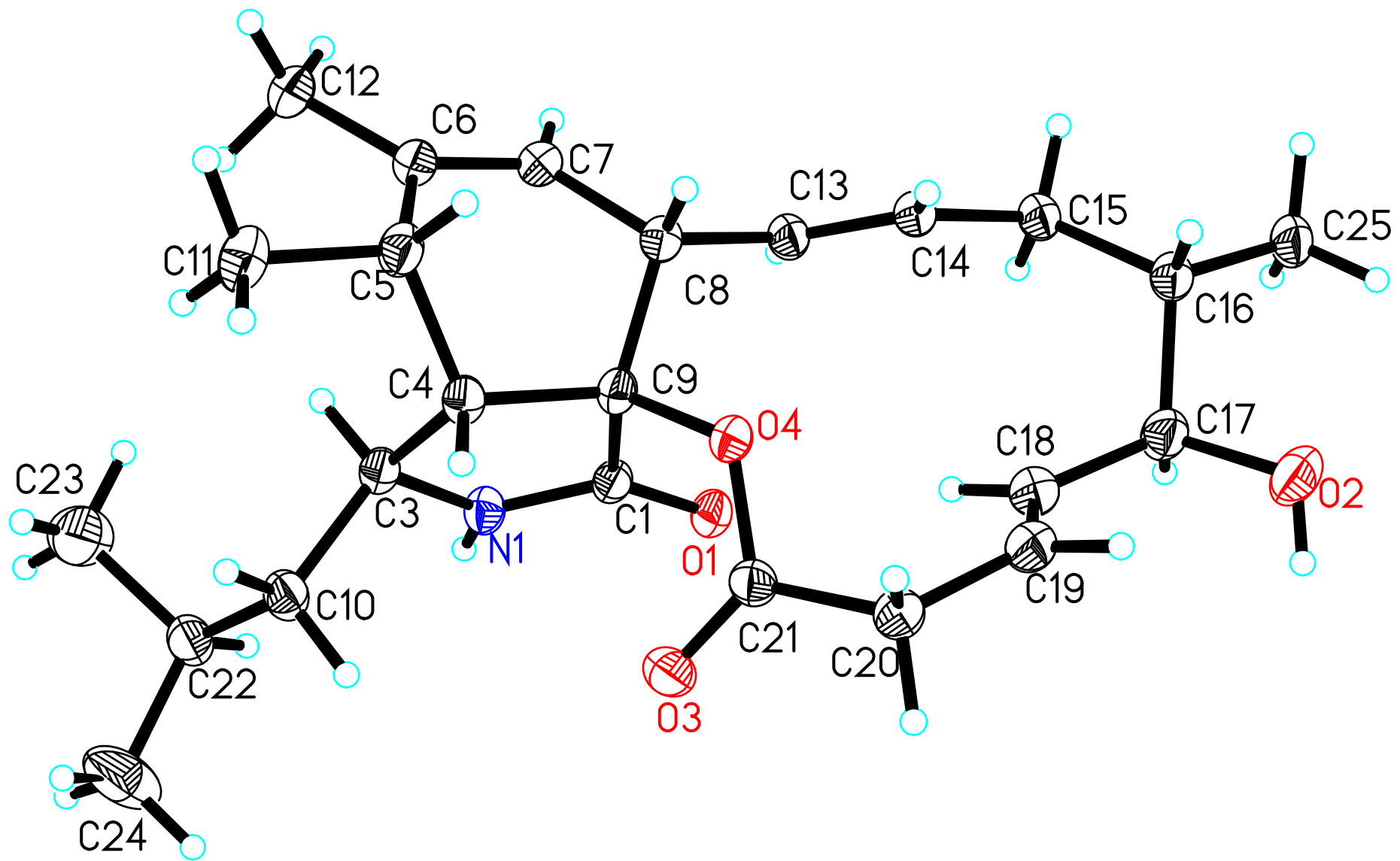

Crystal culture: $\mathrm{MeOH}$

Figure S1 X-ray crystallographic structure of $\mathbf{1}$ (displacement ellipsoids are drawn at $30 \%$ the probability level) 
Table S1 Crystal data and structure refinement for $\mathbf{1}$

Identification code

Empirical formula

Formula weight

Temperature

Wavelength

Crystal system

Space group

Unit cell dimensions

Volume

Z

Density (calculated)

Absorption coefficient

$\mathrm{F}(000)$

Crystal size

Theta range for data collection

Index ranges

Reflections collected

Independent reflections

Completeness to theta $=67.684^{\circ}$

Absorption correction

Max. and min. transmission

Refinement method

Data / restraints / parameters

Goodness-of-fit on $\mathrm{F}^{2}$

Final R indices [I>2sigma(I)]

$\mathrm{R}$ indices (all data)

Absolute structure parameter
D3-74-3

C24.25 H36 N O4.25

409.54

100(2) K

$1.54184 \AA$

monoclinic

P21

$a=13.09160(10) \AA \quad \alpha=90^{\circ}$.

$\mathrm{b}=27.1113(2) \AA \quad \beta=108.1070(10)^{\circ}$.

$\mathrm{c}=13.53230(10) \AA \quad \gamma=90^{\circ}$.

4565.17(6) $\AA^{3}$

8

$1.192 \mathrm{Mg} / \mathrm{m}^{3}$

$0.643 \mathrm{~mm}^{-1}$

1780

$0.360 \times 0.220 \times 0.220 \mathrm{~mm}^{3}$

3.260 to 74.086 .

$-16<=\mathrm{h}<=16,-33<=\mathrm{k}<=33,-16<=\mathrm{l}<=16$

85847

$18096[\mathrm{R}(\mathrm{int})=0.0418]$

$99.6 \%$

None

0.933 and 0.899

Full-matrix least-squares on $\mathrm{F}^{2}$

18096 / 109 / 1282

1.032

$\mathrm{R} 1=0.0532, \mathrm{wR} 2=0.1408$

$\mathrm{R} 1=0.0559, \mathrm{wR} 2=0.1431$

$-0.04(4)$ 


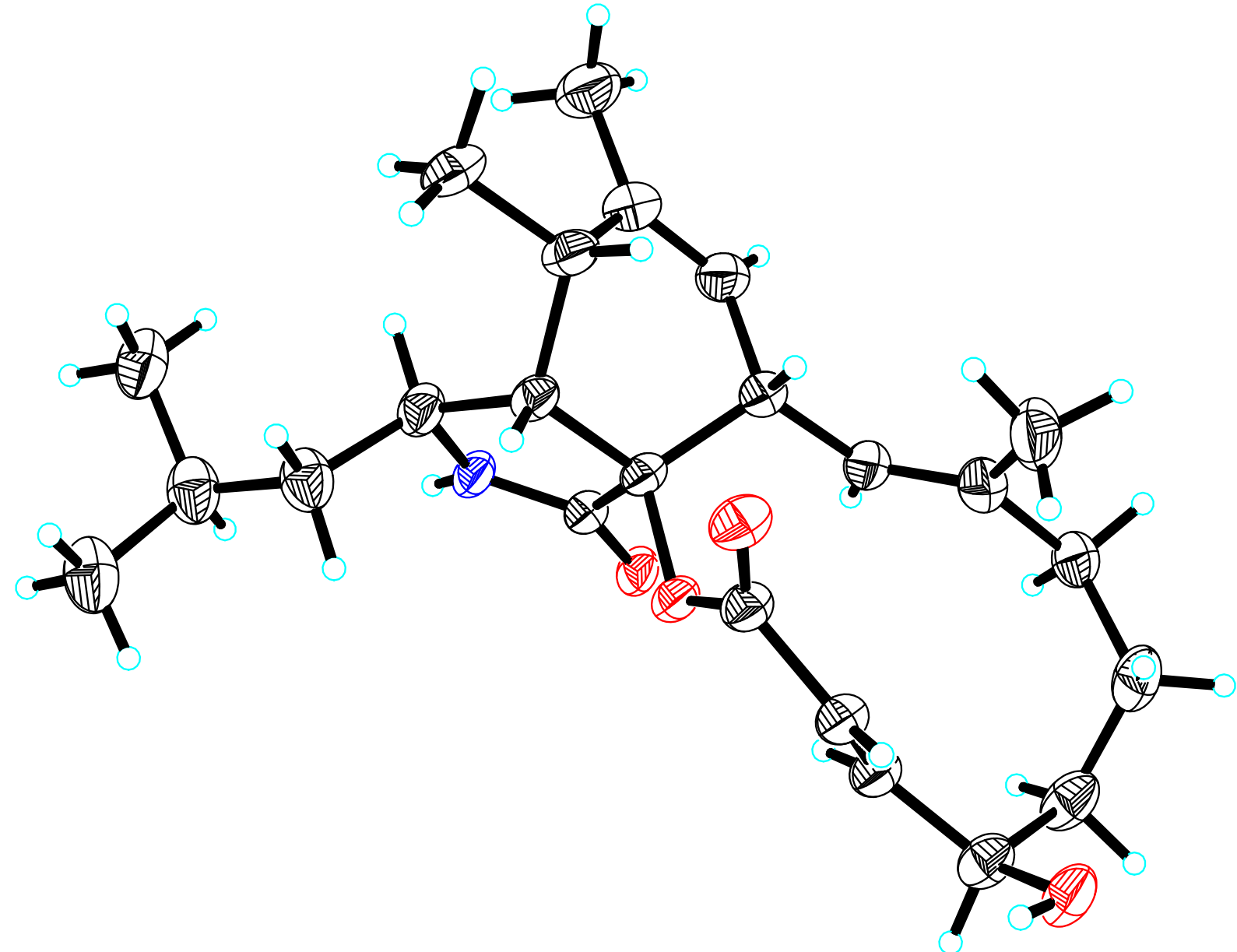

Crystal culture: $\mathrm{MeOH}$

Figure S2 X-ray crystallographic structure of $\mathbf{5}$ (displacement ellipsoids are drawn at 30\% the probability level) 
Table S2 Crystal data and structure refinement for $\mathbf{5}$

Identification code

Empirical formula

Formula weight

Temperature

Wavelength

Crystal system

Space group

Unit cell dimensions

Volume

Z

Density (calculated)

Absorption coefficient

$\mathrm{F}(000)$

Crystal size

Theta range for data collection

Index ranges

Reflections collected

Independent reflections

Completeness to theta $=72.30^{\circ}$

Absorption correction

Max. and min. transmission

Refinement method

Data / restraints / parameters

Goodness-of-fit on $\mathrm{F}^{2}$

Final $\mathrm{R}$ indices [I>2sigma(I)]

$\mathrm{R}$ indices (all data)

Absolute structure parameter global

C24 H35 N O4

401.53

100(2) K

$1.54178 \AA$

Orthorhombic

$\mathrm{P} 2{ }_{12} 2$

$\mathrm{a}=19.6655(19) \AA \quad \alpha=90^{\circ}$.

$\mathrm{b}=38.468(4) \AA \quad \beta=90^{\circ}$.

$\mathrm{c}=12.8796(10) \AA \quad \gamma=90^{\circ}$.

$9743.3(15) \AA^{3}$

16

$1.095 \mathrm{Mg} / \mathrm{m}^{3}$

$0.586 \mathrm{~mm}^{-1}$

3488

$0.360 \times 0.220 \times 0.220 \mathrm{~mm}^{3}$

2.30 to $72.30^{\circ}$.

$-24<=\mathrm{h}<=24,-47<=\mathrm{k}<=47,-15<=\mathrm{l}<=11$

89684

$19205[\mathrm{R}(\mathrm{int})=0.0578]$

$99.9 \%$

Semi-empirical from equivalents

0.88 and 0.75

Full-matrix least-squares on $\mathrm{F}^{2}$

19205 / 0 / 1069

0.967

$\mathrm{R} 1=0.0619, \mathrm{wR} 2=0.1828$

$\mathrm{R} 1=0.0742, \mathrm{wR} 2=0.1987$

$-0.03(6)$ 


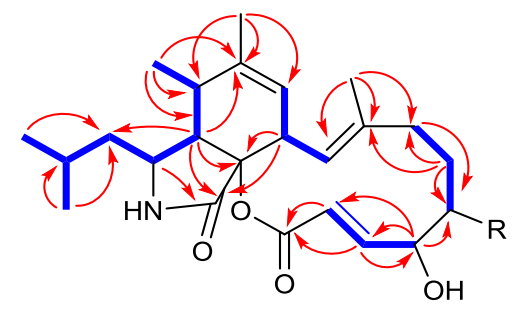

$4 \mathrm{R}=\mathrm{OH}$

$5 \mathrm{R}=\mathrm{H}$
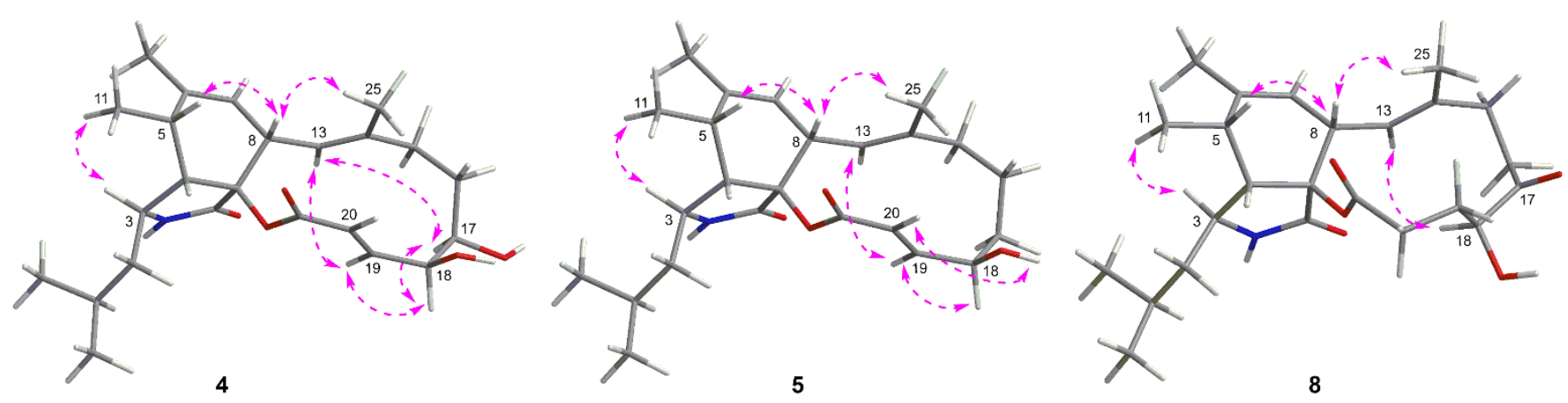

Figure S3 Key HMBC and ${ }^{1} \mathrm{H}-{ }^{1} \mathrm{H}$ COSY correlations of $\mathbf{4}$ and $\mathbf{5}$, and key NOESY correlations of 4, 5, and 8

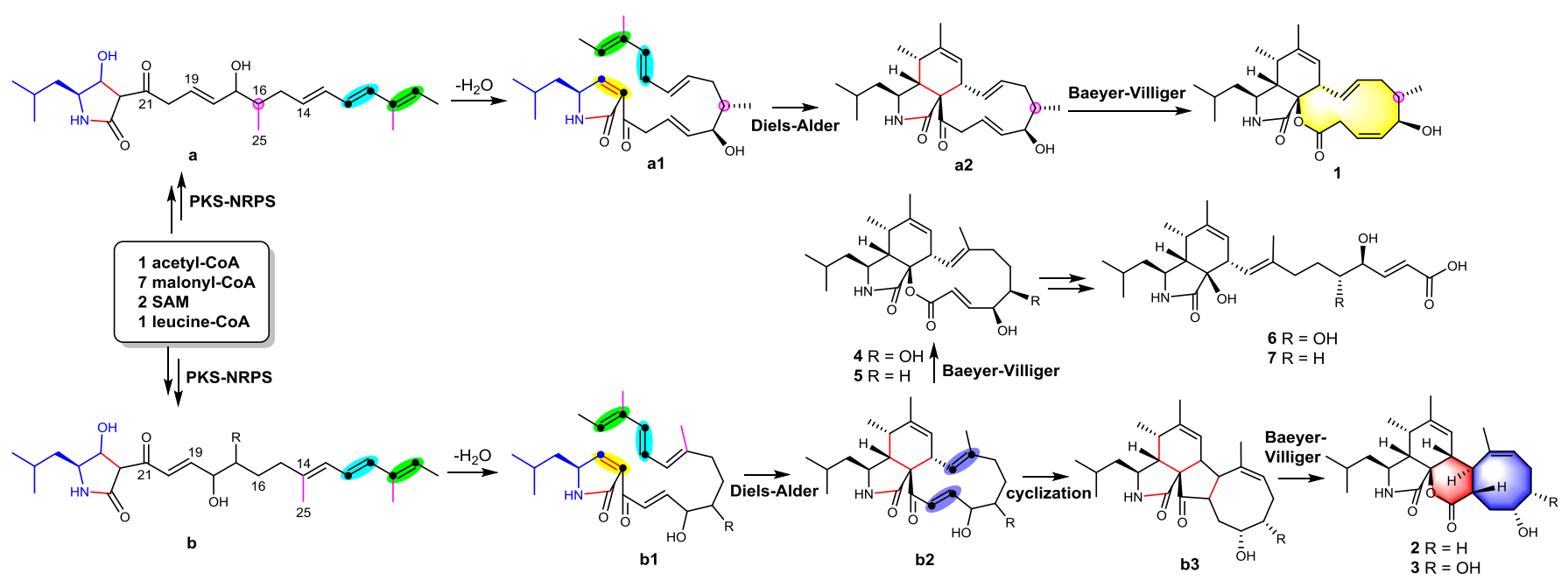

Scheme S1 Proposed biosynthetic pathways of 1-7 


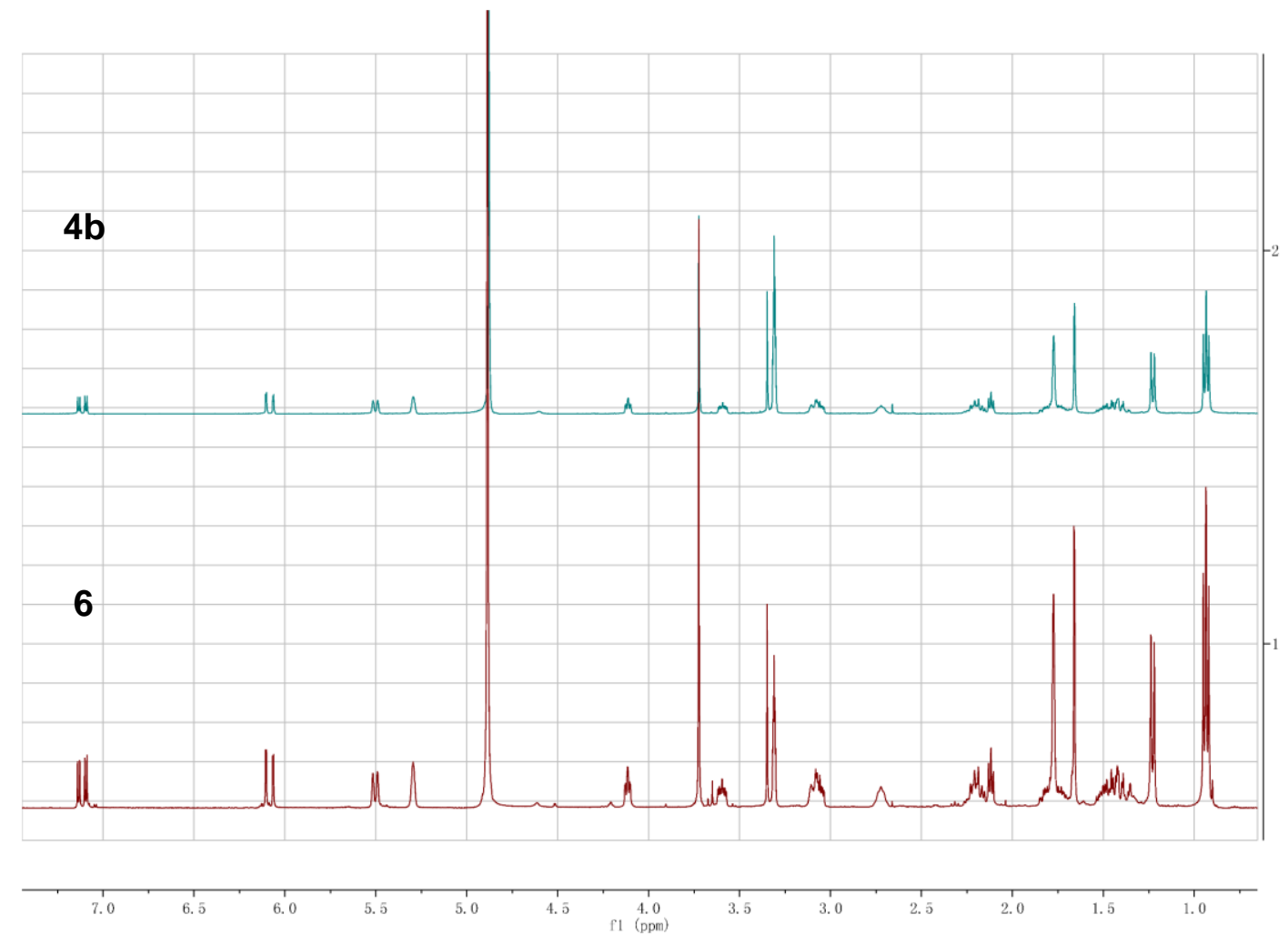

Figure S4 ${ }^{1} \mathrm{H}$ NMR spectra of compounds $\mathbf{4 b}$ and 6

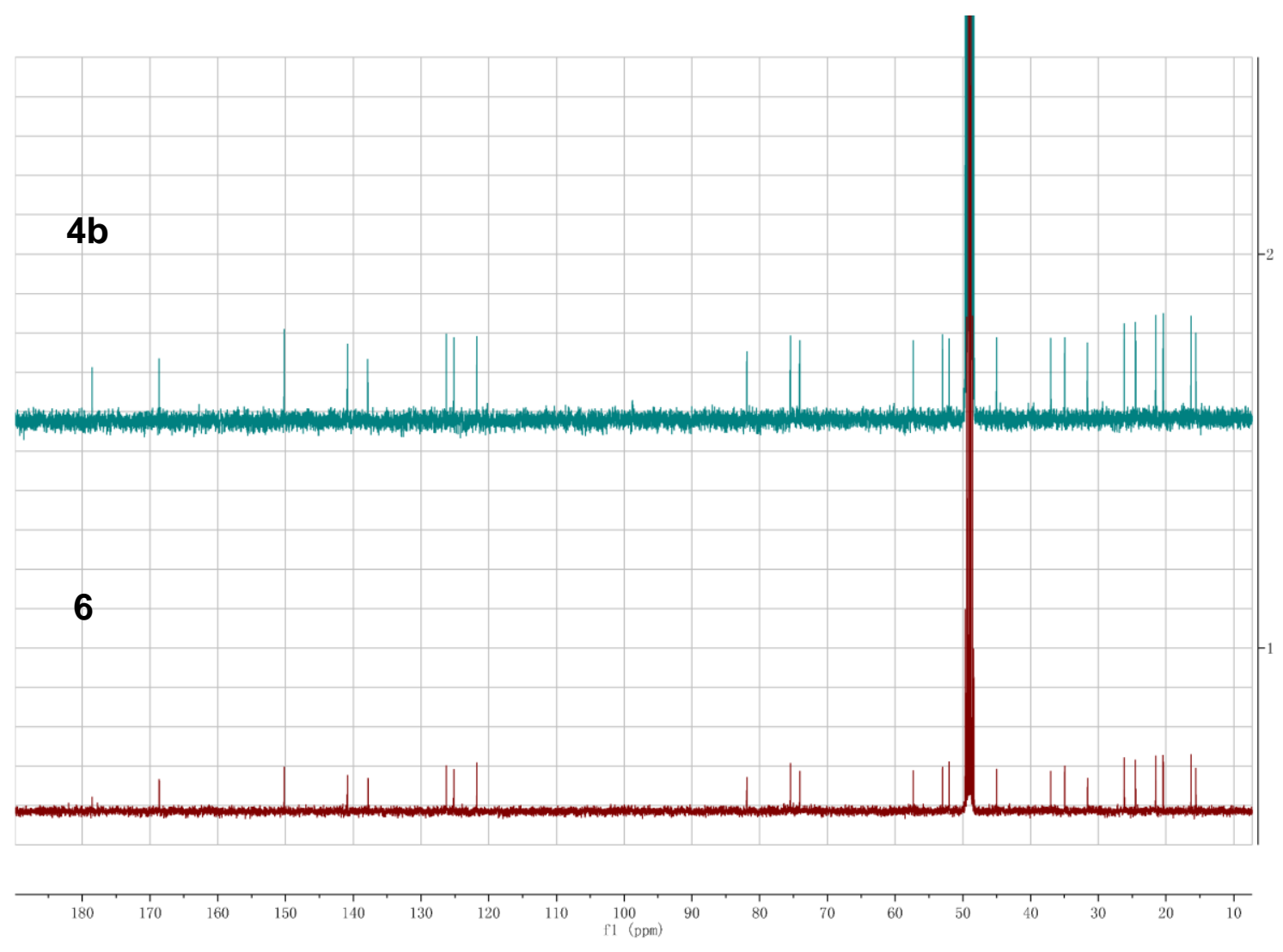

Figure S5 ${ }^{13} \mathrm{C}$ NMR spectra of compounds $4 \mathrm{~b}$ and 6 


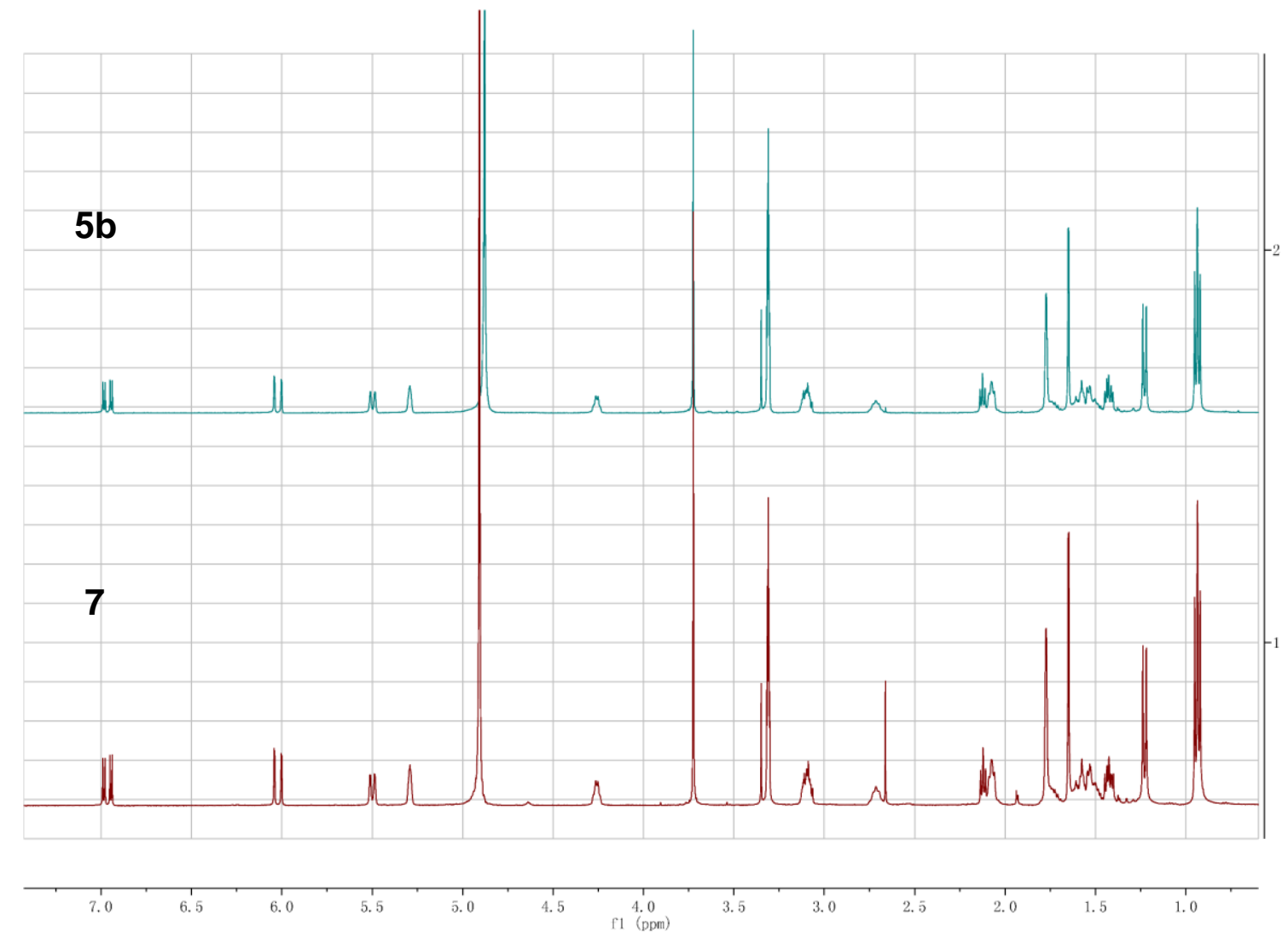

Figure S6 ${ }^{1} \mathrm{H}$ NMR spectra of compounds $\mathbf{5 b}$ and $\mathbf{7}$

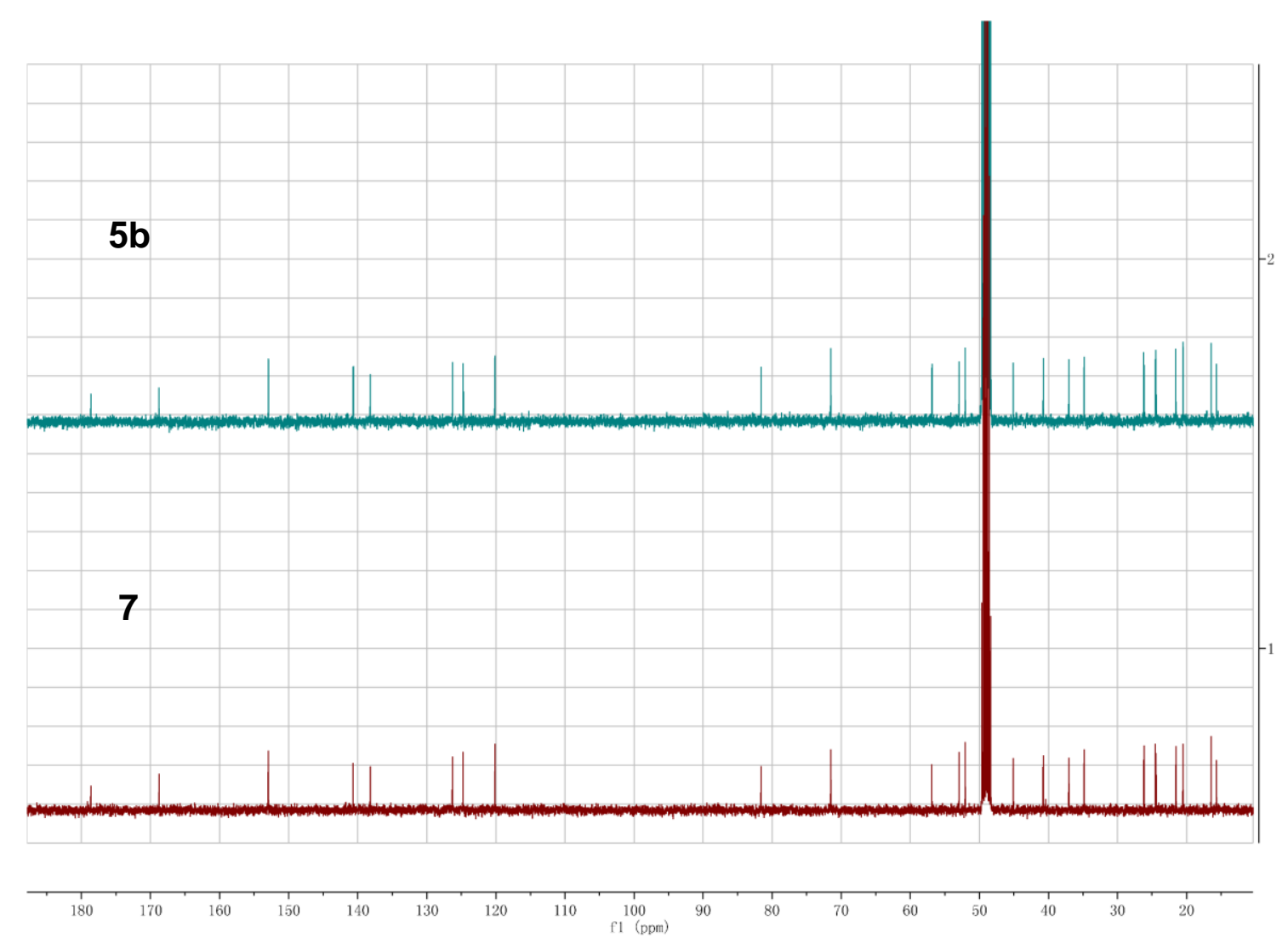

Figure $\mathbf{S 7}{ }^{13} \mathrm{C}$ NMR spectra of compounds $\mathbf{5 b}$ and $\mathbf{7}$ 


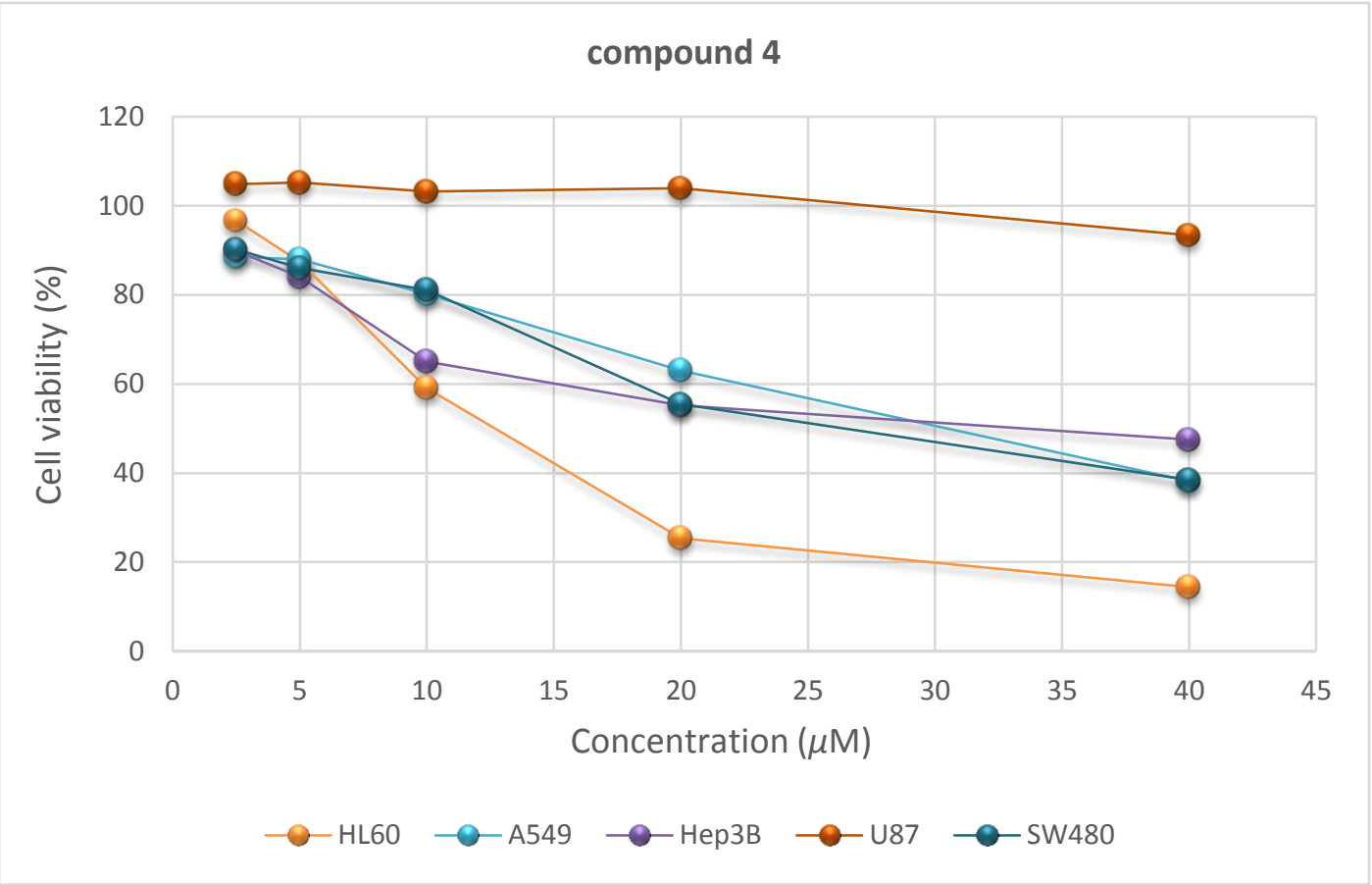

Figure S8 Dose-response viability curves of five cancer cell lines after treated with compound $\mathbf{4}$ for $48 \mathrm{~h}$. Data represent mean $\pm \mathrm{SD}$ of three independent experiments.

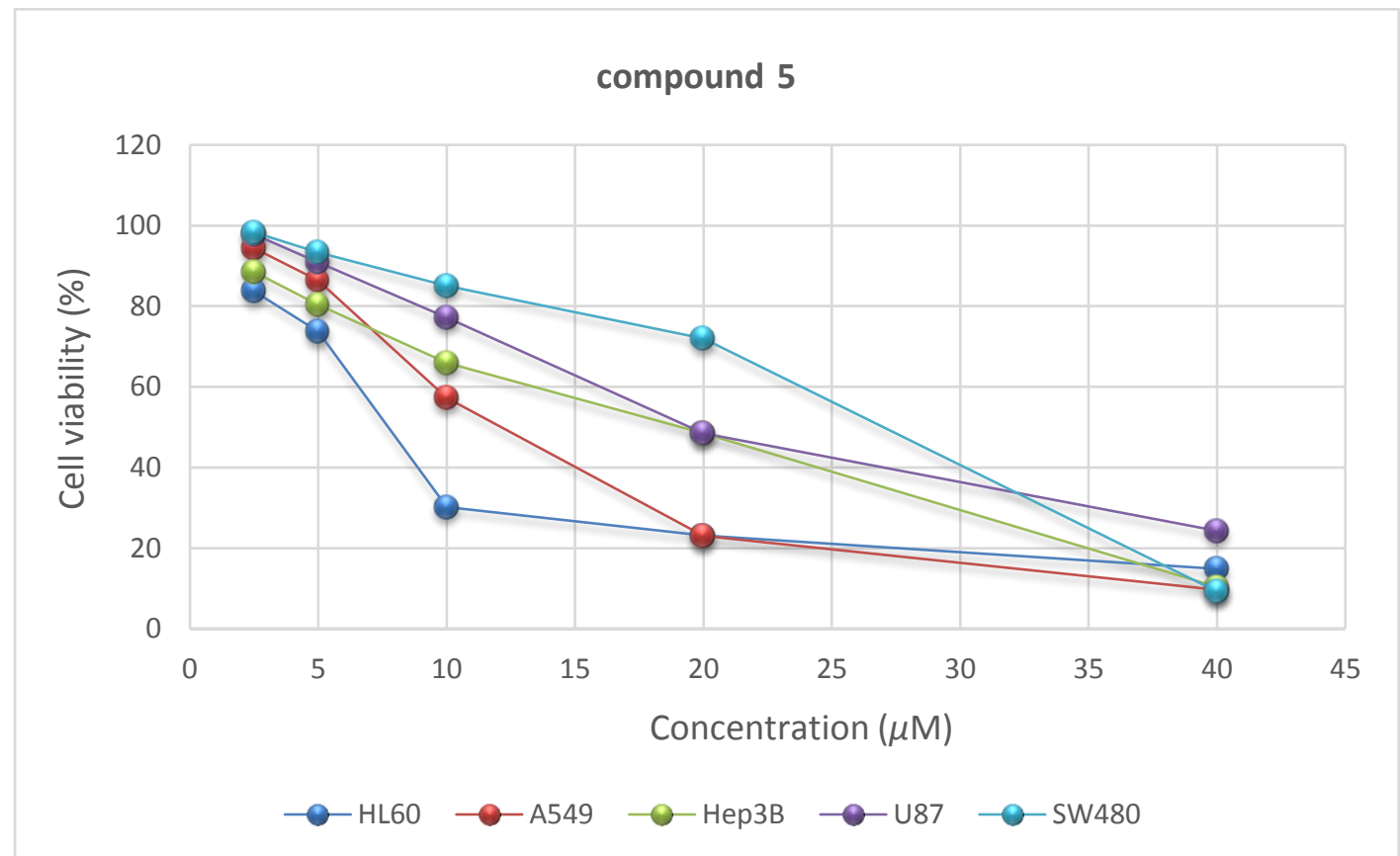

Figure S9 Dose-response viability curves of five cancer cell lines after treated with compound $\mathbf{5}$ for 48 h. Data represent mean \pm SD of three independent experiments. 

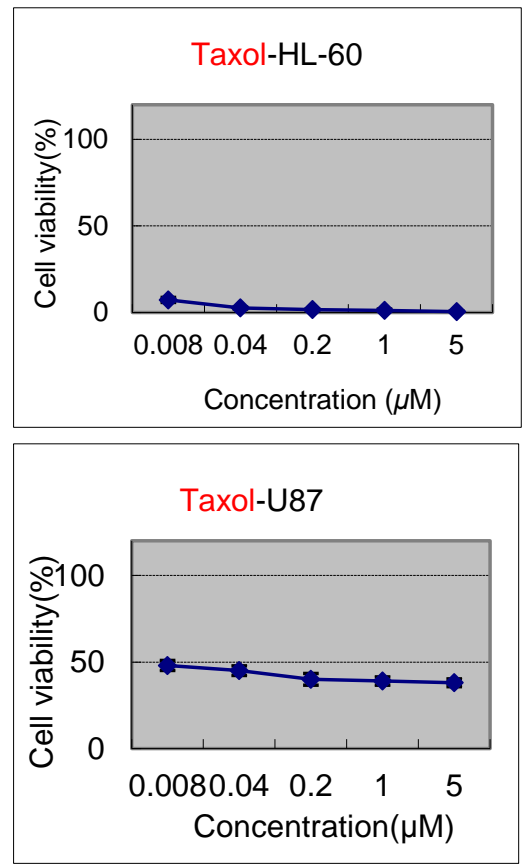
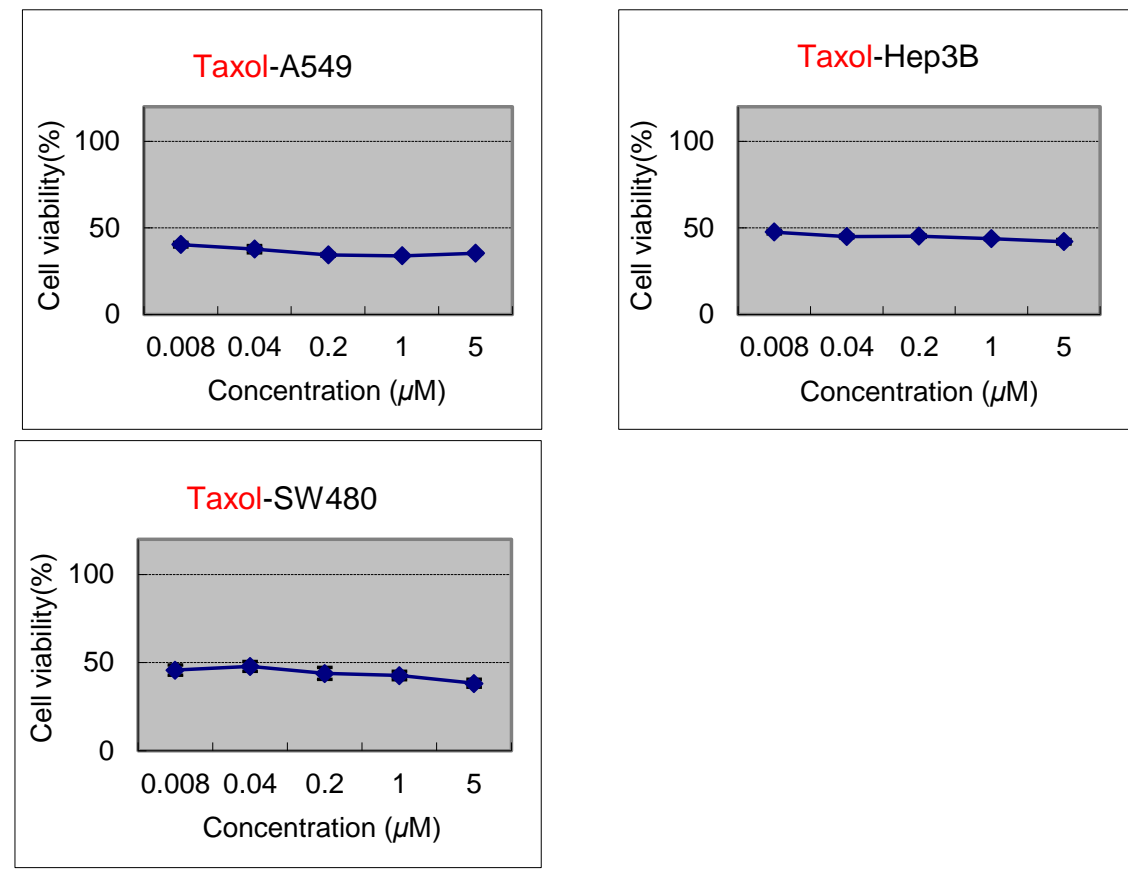

Figure S10 Dose-response viability curves of five cancer cell lines after treated with Taxol for $48 \mathrm{~h}$.

Data represent mean $\pm \mathrm{SD}$ of three independent experiments.

ECD calculations: The conformations generated by BALLOON ${ }^{1,2}$ were subjected to semiempirical PM3 quantum mechanical geometry optimizations using the Gaussian 09 program. ${ }^{3}$ Duplicate conformations were identified and removed when the root-mean-square (RMS) distance was less than $0.5 \AA$ for any two geometry-optimized conformations. The remaining conformations were further optimized at the B3LYP/6-31G(d) level in $\mathrm{MeOH}$ with the IEFPCM solvation model using Gaussian 09, and the duplicate conformations emerging after these calculations were removed according to the same RMS criteria above. The harmonic vibrational frequencies were calculated to confirm the stability of the final conformers. The electronic circular dichroism (ECD) spectrum were calculated for each conformer using the TDDFT methodology at the B3LYP/6-311++G(d,p)//B3LYP/6-31G(d) level with $\mathrm{MeOH}$ as solvent by the IEFPCM solvation model implemented in Gaussian 09 program. The ECD spectra for each conformer were simulated using a Gaussian function with a bandwidth $\sigma$ of $0.4 \mathrm{eV}$. The spectra were combined after Boltzmann weighting according to their population contributions and UV correction was applied. ${ }^{4}$

(1) Vainio, M. J.; Johnson, M. S. Generating conformer ensembles using a multiobjective genetic algorithm. J. Chem. Inf. Model. 2007, 47, 2462-2474. 
(2) Puranen, J. S.; Vainio, M. J.; Johnson, M. S. Accurate conformation-dependent molecular electrostatic potentials for high-throughput in silico drug discovery. J. Comput. Chem. 2010, 31, 1722-1732.

(3) Frisch, M. J.; Trucks, G. W. S.; Schlegel, H. B.; Scuseria, G. E.; Robb, M. A.; Cheeseman, J. R.; Scalmani, G.; Barone, V.; Mennucci, B.; Petersson, G. A.; Nakatsuji, H.; Caricato, M.; Li, X.; Hratchian, H. P.; Izmaylov, A. F.; Bloino, J.; Zheng, G.; Sonnenberg, J. L.; Hada, M.; Ehara, M.; Toyota, K.; Fukuda, R.; Hasegawa, J.; Ishida, M.; Nakajima, T.; Honda, Y.; Kitao, O.; Nakai, H.; Vreven, T.; Montgomery, J. A., Jr.; Peralta, J. E.; Ogliaro, F.; Bearpark, M.; Heyd, J. J.; Brothers, E.; Kudin, K. N.; Staroverov, V. N.; Kobayashi, R.; Normand, J.; Raghavachari, K.; Rendell, A.; Burant, J. C.; Iyengar, S. S.; Tomasi, J.; Cossi, M.; Rega, N.; Millam, N. J.; Klene, M.; Knox, J. E.; Cross, J. B.; Bakken, V.; Adamo, C.; Jaramillo, J.; Gomperts, R.; Stratmann, R. E.; Yazyev, O.; Austin, A. J.; Cammi, R.; Pomelli, C.; Ochterski, J. W.; Martin, R. L.; Morokuma, K.; Zakrzewski, V. G.; Voth, G. A.; Salvador, P.; Dannenberg, J. J.; Dapprich, S.; Daniels, A. D.; Farkas, Ö.; Foresman, J. B.; Ortiz, J. V.; Cioslowski, J.; Fox, D. J. Gaussian 09, Revision D 01, Gaussian, Inc.: Wallingford, CT, 2009.

(4) Zhu, H. J. Organic stereochemistry: experimental and computational methods. Wiley-VCH Verlag GmbH \& Co. KGaA, Weinheim, Germany, 2015.

\section{ECD calculations of compound 2}

Important thermodynamic parameters (a.u.) and Boltzmann distributions of the optimized 2 at B3LYP/6-311++G(d,p)//B3LYP/6-31G(d) level with MeOH as solvent by the IEFPCM solvation model.

\begin{tabular}{lll}
\hline Conformations & Gibbers & Ratio (\%) \\
\hline $\mathbf{2 - 1}$ & -1291.654832 & 34.75 \\
$\mathbf{2 - 2}$ & -1291.654613 & 33.66 \\
$\mathbf{2 - 3}$ & -1291.654050 & 31.59 \\
\hline
\end{tabular}

Optimized coordinates $(\AA)$ of compound 2 in MeOH at B3LYP/6-31G(d) level.

\begin{tabular}{|c|c|c|c|c|c|c|c|}
\hline Atom & $\mathbf{X}$ & $\mathbf{Y}$ & $\mathbf{Z}$ & Atom & $\mathbf{X}$ & $\mathbf{Y}$ & $\mathbf{Z}$ \\
\hline $\mathrm{C}$ & -4.133 & 1.517 & 0.228 & $\mathrm{H}$ & -5.067 & 1.087 & 2.094 \\
\hline $\mathrm{C}$ & -0.179 & 2.256 & 0.196 & $\mathrm{H}$ & -5.216 & -1.263 & 2.026 \\
\hline $\mathrm{C}$ & -3.078 & 1.503 & -0.602 & $\mathrm{H}$ & -5.796 & -0.681 & 0.471 \\
\hline $\mathrm{C}$ & 1.09 & 2.692 & 0.157 & $\mathrm{H}$ & -4.312 & -0.888 & -1.539 \\
\hline $\mathrm{C}$ & 0.434 & -0.477 & 1.304 & $\mathrm{H}$ & -3.463 & -2.422 & -1.631 \\
\hline $\mathrm{C}$ & -1.009 & -1.761 & -1.234 & $\mathrm{H}$ & -0.388 & 1.196 & -1.655 \\
\hline $\mathrm{C}$ & -4.343 & 0.61 & 1.423 & $\mathrm{H}$ & -2.034 & 0.182 & 0.666 \\
\hline $\mathrm{C}$ & -4.893 & -0.796 & 1.086 & $\mathrm{H}$ & 1.652 & 1.998 & -1.762 \\
\hline $\mathrm{C}$ & -3.53 & -1.49 & -1.064 & $\mathrm{H}$ & -2.163 & -0.433 & -2.304 \\
\hline $\mathrm{C}$ & -0.543 & 1.012 & -0.578 & $\mathrm{H}$ & 2.31 & -0.164 & -1.329 \\
\hline $\mathrm{C}$ & -1.972 & 0.489 & -0.374 & $\mathrm{H}$ & -4.639 & -2.711 & 0.269 \\
\hline $\mathrm{C}$ & 2.043 & 1.896 & -0.738 & $\mathrm{H}$ & 3.387 & 0.654 & 1.203 \\
\hline $\mathrm{C}$ & -2.178 & -0.769 & -1.254 & $\mathrm{H}$ & -2.116 & 3.074 & -1.748 \\
\hline $\mathrm{C}$ & 1.945 & 0.362 & -0.442 & $\mathrm{H}$ & -3.883 & 3.046 & -1.88 \\
\hline
\end{tabular}




\begin{tabular}{cccccccc}
$\mathrm{C}$ & -3.988 & -1.835 & 0.379 & $\mathrm{H}$ & -2.9 & 1.848 & -2.739 \\
$\mathrm{C}$ & 2.741 & -0.133 & 0.806 & $\mathrm{H}$ & 2.366 & 3.671 & 1.606 \\
$\mathrm{C}$ & 0.475 & -0.079 & -0.196 & $\mathrm{H}$ & 0.735 & 4.355 & 1.475 \\
$\mathrm{C}$ & -2.992 & 2.415 & -1.802 & $\mathrm{H}$ & 1.95 & 4.678 & 0.225 \\
$\mathrm{C}$ & 1.557 & 3.911 & 0.905 & $\mathrm{H}$ & 3.975 & 2.432 & 0.184 \\
$\mathrm{C}$ & 3.487 & 2.412 & -0.795 & $\mathrm{H}$ & 3.512 & 3.431 & -1.194 \\
$\mathrm{C}$ & 5.94 & -0.466 & 0.507 & $\mathrm{H}$ & 4.09 & 1.784 & -1.46 \\
$\mathrm{C}$ & 5.386 & -2.595 & -0.73 & $\mathrm{H}$ & 6.231 & -1.022 & 1.408 \\
$\mathrm{C}$ & 3.565 & -1.412 & 0.553 & $\mathrm{H}$ & 5.609 & 0.529 & 0.822 \\
$\mathrm{C}$ & 4.856 & -1.228 & -0.271 & $\mathrm{H}$ & 6.838 & -0.334 & -0.107 \\
$\mathrm{~N}$ & 1.683 & -0.397 & 1.784 & $\mathrm{H}$ & 5.628 & -3.23 & 0.132 \\
$\mathrm{O}$ & -0.559 & -0.847 & 1.941 & $\mathrm{H}$ & 6.298 & -2.482 & -1.328 \\
$\mathrm{O}$ & -1.102 & -2.907 & -1.619 & $\mathrm{H}$ & 4.645 & -3.126 & -1.34 \\
$\mathrm{O}$ & 0.242 & -1.316 & -0.922 & $\mathrm{H}$ & 3.832 & -1.852 & 1.524 \\
$\mathrm{O}$ & -2.929 & -2.321 & 1.206 & $\mathrm{H}$ & 2.907 & -2.137 & 0.054 \\
$\mathrm{H}$ & -4.944 & 2.214 & 0.015 & $\mathrm{H}$ & 4.613 & -0.649 & -1.175 \\
$\mathrm{H}$ & -0.943 & 2.755 & 0.786 & $\mathrm{H}$ & 1.889 & -0.716 & 2.724 \\
$\mathrm{H}$ & -3.423 & 0.505 & 2.013 & $\mathrm{H}$ & -2.26 & -1.632 & 1.382 \\
\hline & & & & & & & \\
\hline
\end{tabular}

\begin{tabular}{|c|c|c|c|c|c|c|c|}
\hline Atom & $\mathbf{X}$ & $\mathbf{Y}$ & $\mathbf{Z}$ & Atom & $\mathbf{X}$ & $\mathbf{Y}$ & $\mathbf{Z}$ \\
\hline $\mathrm{C}$ & 3.981 & 1.309 & -1.183 & $\mathrm{H}$ & 4.596 & 0.274 & -2.94 \\
\hline $\mathrm{C}$ & 0.045 & 2.143 & -0.572 & $\mathrm{H}$ & 4.92 & -1.909 & -2.116 \\
\hline $\mathrm{C}$ & 3.084 & 1.583 & -0.222 & $\mathrm{H}$ & 5.704 & -0.829 & -0.971 \\
\hline $\mathrm{C}$ & -1.184 & 2.631 & -0.338 & $\mathrm{H}$ & 4.579 & -0.373 & 1.232 \\
\hline $\mathrm{C}$ & -0.575 & -0.923 & -0.649 & $\mathrm{H}$ & 3.829 & -1.783 & 1.96 \\
\hline $\mathrm{C}$ & 1.315 & -1.252 & 1.822 & $\mathrm{H}$ & 0.667 & 1.622 & 1.395 \\
\hline $\mathrm{C}$ & 4.033 & 0.052 & -2.026 & $\mathrm{H}$ & 1.893 & -0.067 & -0.786 \\
\hline $\mathrm{C}$ & 4.722 & -1.152 & -1.344 & $\mathrm{H}$ & -1.291 & 2.389 & 1.776 \\
\hline $\mathrm{C}$ & 3.762 & -1.093 & 1.115 & $\mathrm{H}$ & 2.577 & 0.336 & 2.144 \\
\hline $\mathrm{C}$ & 0.616 & 1.142 & 0.402 & $\mathrm{H}$ & -2.128 & 0.146 & 1.862 \\
\hline $\mathrm{C}$ & 2.004 & 0.564 & 0.092 & $\mathrm{H}$ & 4.741 & -2.673 & 0.1 \\
\hline $\mathrm{C}$ & -1.892 & 2.084 & 0.904 & $\mathrm{H}$ & -3.158 & 0.71 & -0.857 \\
\hline $\mathrm{C}$ & 2.425 & -0.337 & 1.283 & $\mathrm{H}$ & 2.263 & 3.454 & 0.513 \\
\hline $\mathrm{C}$ & -1.833 & 0.527 & 0.88 & $\mathrm{H}$ & 4.026 & 3.448 & 0.325 \\
\hline $\mathrm{C}$ & 4.015 & -1.901 & -0.186 & $\mathrm{H}$ & 3.265 & 2.605 & 1.684 \\
\hline $\mathrm{C}$ & -2.774 & -0.087 & -0.209 & $\mathrm{H}$ & -2.79 & 3.311 & -1.628 \\
\hline $\mathrm{C}$ & -0.402 & -0.001 & 0.583 & $\mathrm{H}$ & -1.183 & 3.924 & -2.059 \\
\hline $\mathrm{C}$ & 3.165 & 2.837 & 0.615 & $\mathrm{H}$ & -2.053 & 4.584 & -0.663 \\
\hline $\mathrm{C}$ & -1.834 & 3.663 & -1.219 & $\mathrm{H}$ & -4.007 & 2.382 & 0.349 \\
\hline $\mathrm{C}$ & -3.308 & 2.618 & 1.159 & $\mathrm{H}$ & -3.295 & 3.706 & 1.276 \\
\hline $\mathrm{C}$ & -4.817 & -1.95 & -1.809 & $\mathrm{H}$ & -3.713 & 2.192 & 2.084 \\
\hline $\mathrm{C}$ & -6.293 & -1.806 & 0.231 & $\mathrm{H}$ & -4.338 & -2.901 & -1.543 \\
\hline $\mathrm{C}$ & -3.963 & -0.869 & 0.381 & $\mathrm{H}$ & -4.156 & -1.407 & -2.496 \\
\hline $\mathrm{C}$ & -5.161 & -1.127 & -0.557 & $\mathrm{H}$ & -5.726 & -2.186 & -2.374 \\
\hline
\end{tabular}




\begin{tabular}{cccccccc}
$\mathrm{N}$ & -1.868 & -0.922 & -0.998 & $\mathrm{H}$ & -5.984 & -2.798 & 0.583 \\
$\mathrm{O}$ & 0.31 & -1.599 & -1.184 & $\mathrm{H}$ & -7.183 & -1.936 & -0.394 \\
$\mathrm{O}$ & 1.532 & -2.214 & 2.527 & $\mathrm{H}$ & -6.58 & -1.214 & 1.109 \\
$\mathrm{O}$ & 0.01 & -0.887 & 1.658 & $\mathrm{H}$ & -3.587 & -1.819 & 0.787 \\
$\mathrm{O}$ & 2.883 & -2.658 & -0.614 & $\mathrm{H}$ & -4.334 & -0.294 & 1.238 \\
$\mathrm{H}$ & 4.784 & 2.026 & -1.354 & $\mathrm{H}$ & -5.529 & -0.146 & -0.894 \\
$\mathrm{H}$ & 0.64 & 2.457 & -1.426 & $\mathrm{H}$ & -2.185 & -1.498 & -1.768 \\
$\mathrm{H}$ & 3.032 & -0.248 & -2.364 & $\mathrm{H}$ & 2.115 & -2.084 & -0.801 \\
\hline
\end{tabular}

\begin{tabular}{|c|c|c|c|c|c|c|c|}
\hline Atom & $\mathbf{X}$ & $\mathbf{Y}$ & $\mathbf{Z}$ & Atom & $\mathbf{X}$ & $\mathbf{Y}$ & $\mathbf{Z}$ \\
\hline $\mathrm{C}$ & -3.979 & 1.784 & 0.211 & $\mathrm{H}$ & -4.967 & 1.623 & 2.108 \\
\hline $\mathrm{C}$ & 0.081 & 2.204 & 0.205 & $\mathrm{H}$ & -5.319 & -0.892 & 1.963 \\
\hline $\mathrm{C}$ & -2.866 & 1.592 & -0.516 & $\mathrm{H}$ & -6.258 & 0.07 & 0.823 \\
\hline $\mathrm{C}$ & 1.356 & 2.587 & 0.04 & $\mathrm{H}$ & -3.289 & -2.647 & -0.384 \\
\hline $\mathrm{C}$ & 0.607 & -0.609 & 1.351 & $\mathrm{H}$ & -2.975 & -1.719 & 1.08 \\
\hline $\mathrm{C}$ & -1.017 & -1.796 & -1.024 & $\mathrm{H}$ & -0.32 & 1.06 & -1.561 \\
\hline $\mathrm{C}$ & -4.386 & 0.99 & 1.426 & $\mathrm{H}$ & -1.868 & 0.402 & 0.961 \\
\hline $\mathrm{C}$ & -5.237 & -0.252 & 1.075 & $\mathrm{H}$ & 1.729 & 1.746 & -1.868 \\
\hline $\mathrm{C}$ & -3.279 & -1.636 & 0.029 & $\mathrm{H}$ & -2.584 & -0.669 & -1.763 \\
\hline $\mathrm{C}$ & -0.396 & 0.939 & -0.468 & $\mathrm{H}$ & 2.406 & -0.406 & -1.302 \\
\hline $\mathrm{C}$ & -1.837 & 0.533 & -0.121 & $\mathrm{H}$ & -4.825 & -0.553 & -1.026 \\
\hline $\mathrm{C}$ & 2.202 & 1.7 & -0.874 & $\mathrm{H}$ & 3.517 & 0.625 & 1.162 \\
\hline $\mathrm{C}$ & -2.194 & -0.845 & -0.748 & $\mathrm{H}$ & -1.739 & 2.994 & -1.741 \\
\hline $\mathrm{C}$ & 2.075 & 0.2 & -0.454 & $\mathrm{H}$ & -3.489 & 3.018 & -2.014 \\
\hline $\mathrm{C}$ & -4.727 & -1.12 & -0.089 & $\mathrm{H}$ & -2.5 & 1.696 & -2.653 \\
\hline $\mathrm{C}$ & 2.899 & -0.207 & 0.812 & $\mathrm{H}$ & 2.784 & 3.594 & 1.321 \\
\hline $\mathrm{C}$ & 0.601 & -0.187 & -0.138 & $\mathrm{H}$ & 1.171 & 4.33 & 1.288 \\
\hline $\mathrm{C}$ & -2.638 & 2.367 & -1.794 & $\mathrm{H}$ & 2.284 & 4.54 & -0.076 \\
\hline $\mathrm{C}$ & 1.926 & 3.826 & 0.677 & $\mathrm{H}$ & 4.227 & 2.197 & -0.155 \\
\hline $\mathrm{C}$ & 3.652 & 2.153 & -1.084 & $\mathrm{H}$ & 3.679 & 3.152 & -1.532 \\
\hline $\mathrm{C}$ & 6.12 & -0.468 & 0.539 & $\mathrm{H}$ & 4.169 & 1.473 & -1.769 \\
\hline $\mathrm{C}$ & 5.619 & -2.651 & -0.624 & $\mathrm{H}$ & 6.427 & -0.991 & 1.454 \\
\hline $\mathrm{C}$ & 3.769 & -1.466 & 0.614 & $\mathrm{H}$ & 5.762 & 0.526 & 0.828 \\
\hline $\mathrm{C}$ & 5.056 & -1.281 & -0.215 & $\mathrm{H}$ & 7.013 & -0.328 & -0.081 \\
\hline $\mathrm{N}$ & 1.864 & -0.469 & 1.814 & $\mathrm{H}$ & 5.869 & -3.25 & 0.261 \\
\hline $\mathrm{O}$ & -0.361 & -1.032 & 1.981 & $\mathrm{H}$ & 6.533 & -2.538 & -1.219 \\
\hline $\mathrm{O}$ & -1.19 & -2.914 & -1.466 & $\mathrm{H}$ & 4.895 & -3.219 & -1.219 \\
\hline $\mathrm{O}$ & 0.27 & -1.382 & -0.889 & $\mathrm{H}$ & 4.048 & -1.853 & 1.605 \\
\hline $\mathrm{O}$ & -5.545 & -2.303 & -0.176 & $\mathrm{H}$ & 3.136 & -2.234 & 0.15 \\
\hline $\mathrm{H}$ & -4.703 & 2.518 & -0.144 & $\mathrm{H}$ & 4.801 & -0.74 & -1.139 \\
\hline $\mathrm{H}$ & -0.615 & 2.766 & 0.825 & $\mathrm{H}$ & 2.099 & -0.789 & 2.747 \\
\hline $\mathrm{H}$ & -3.505 & 0.666 & 1.99 & $\mathrm{H}$ & -6.471 & -2.01 & -0.204 \\
\hline
\end{tabular}




\section{HRESIMS spectrum of compound 1}

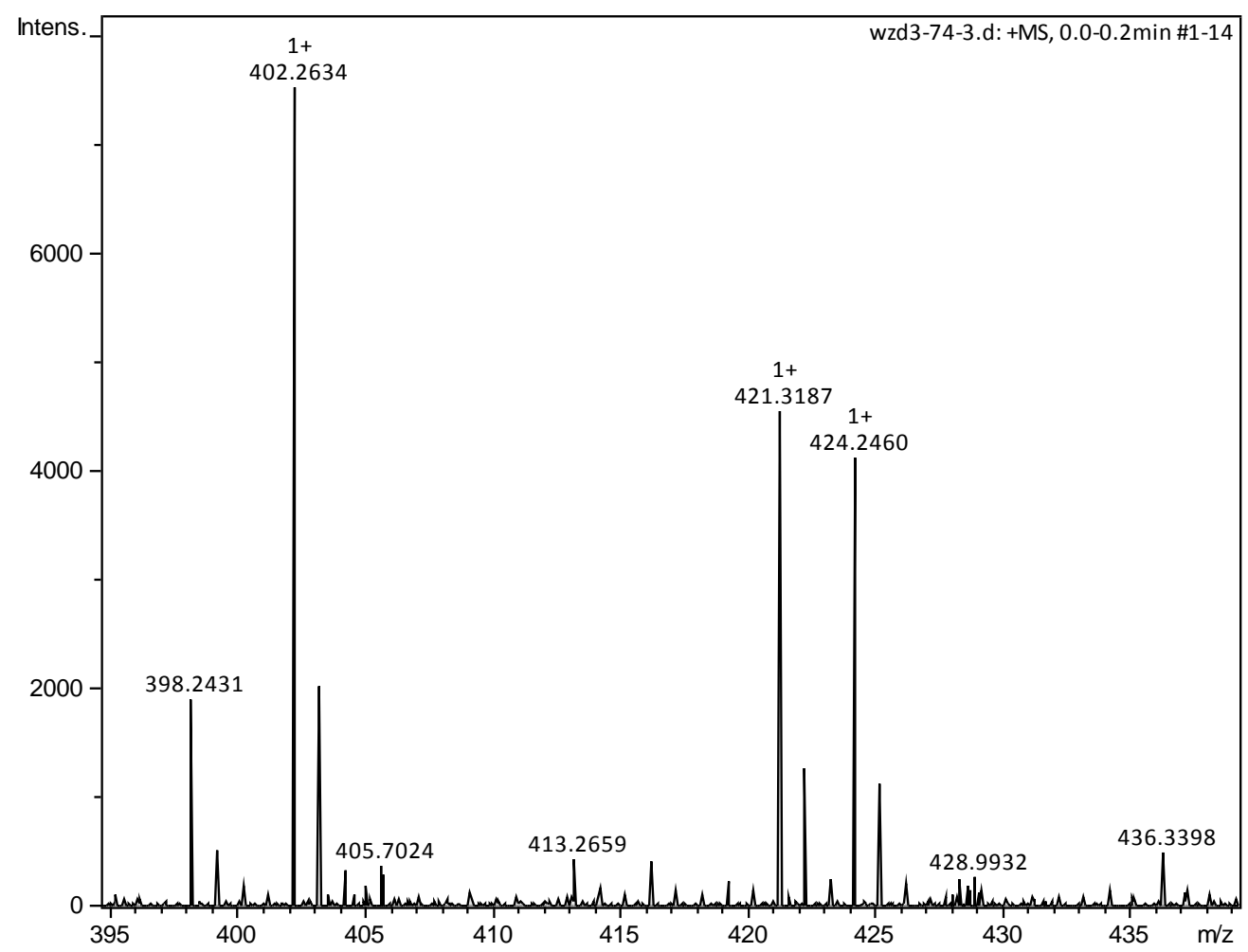

UV spectrum of compound 1

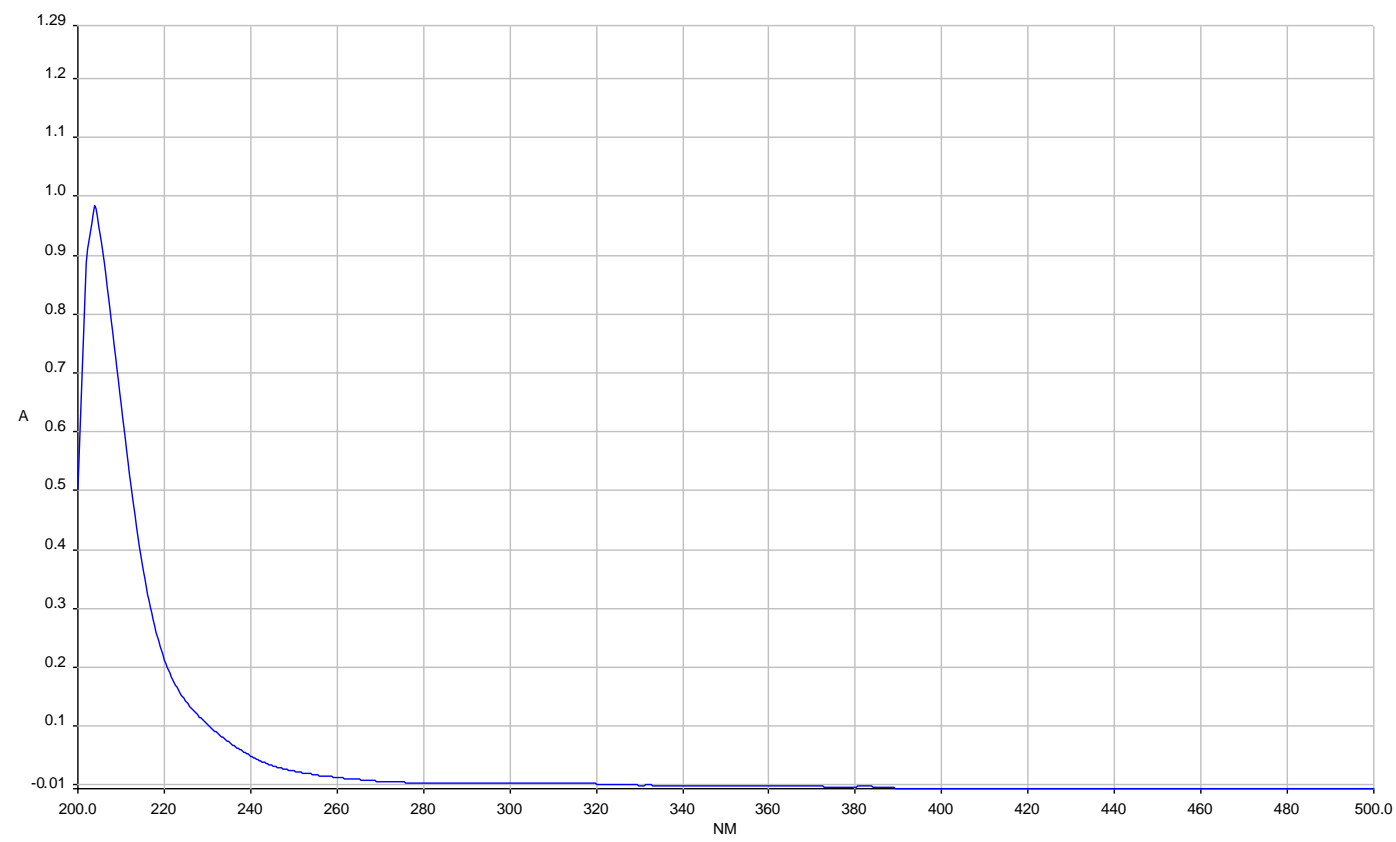




\section{IR spectrum of compound 1}

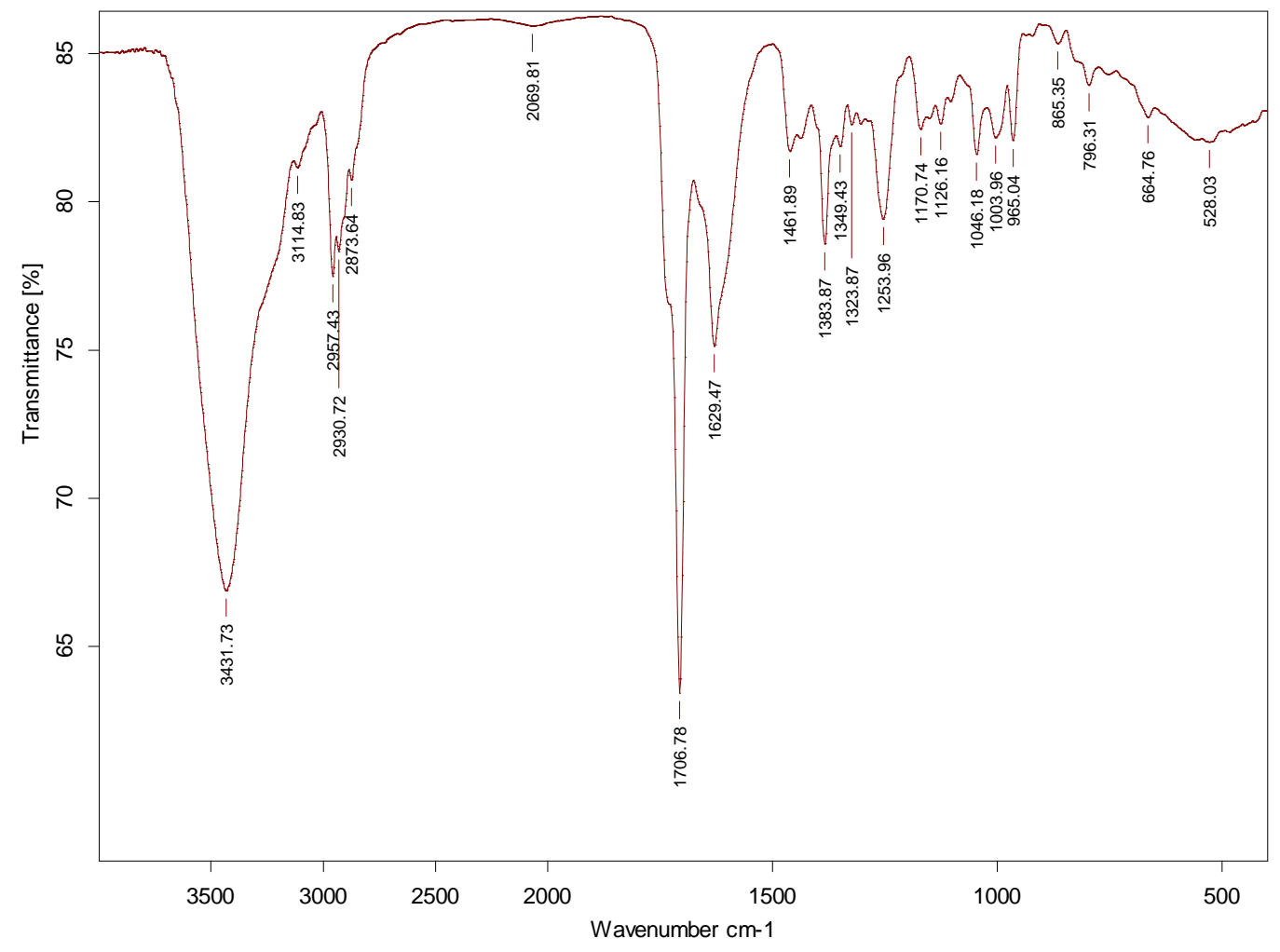

\section{${ }^{1} \mathrm{H}$ NMR spectrum of compound 1}

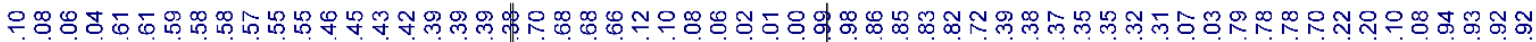
ڤ

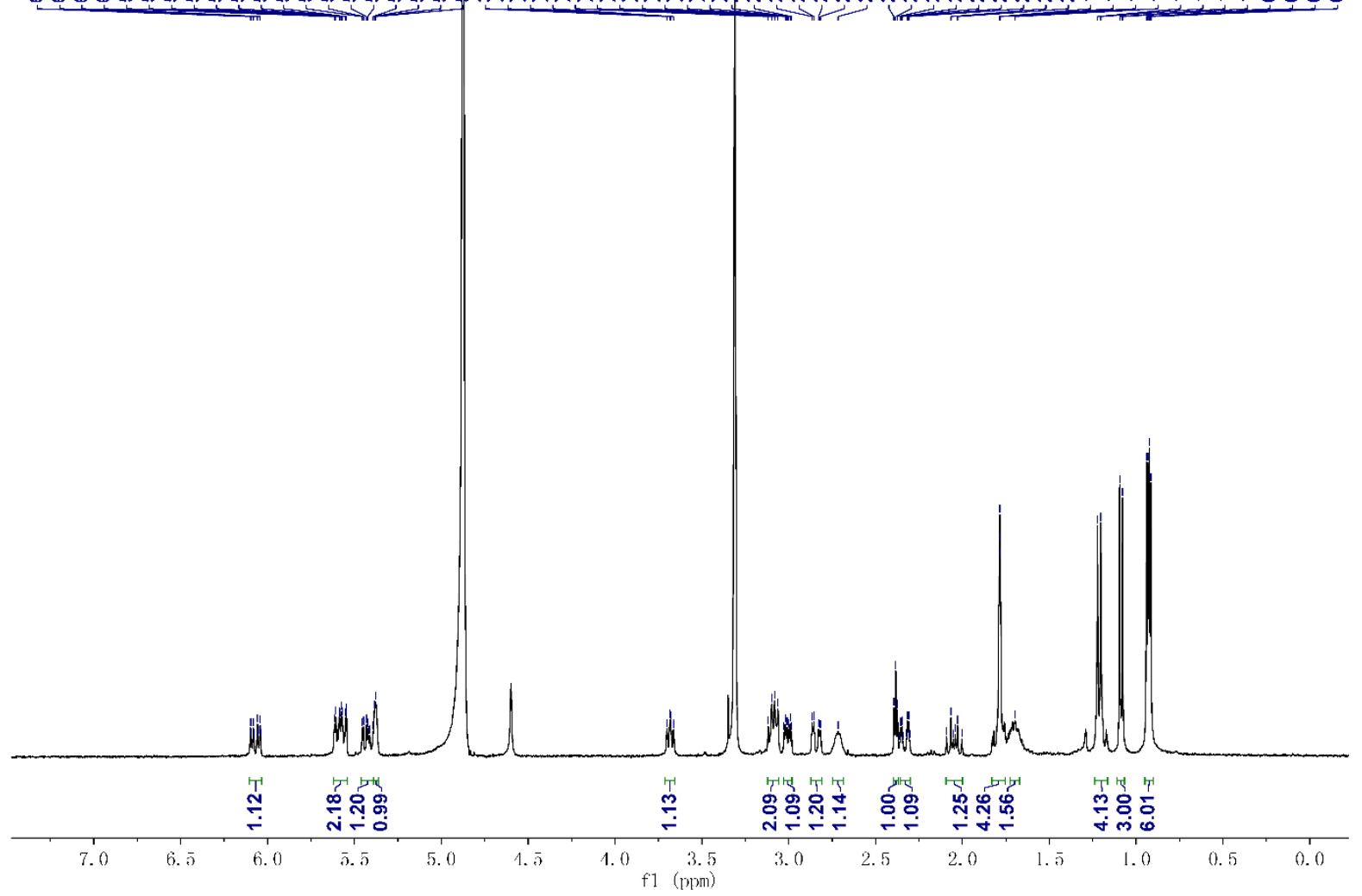


${ }^{13} \mathrm{C}$ NMR and DEPT spectra of compound 1

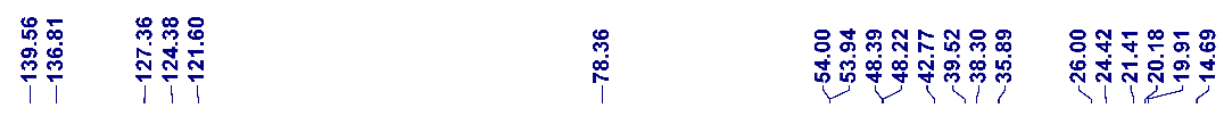
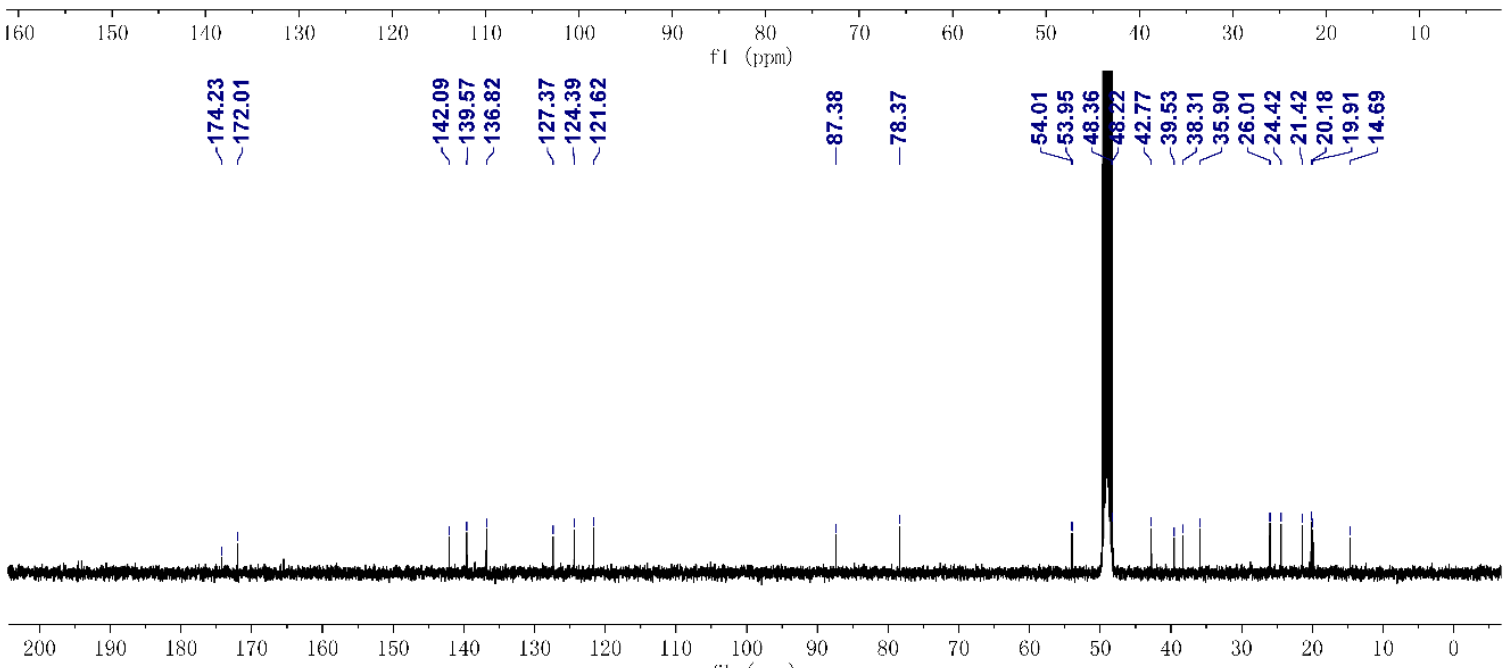

HSQC spectrum of compound 1

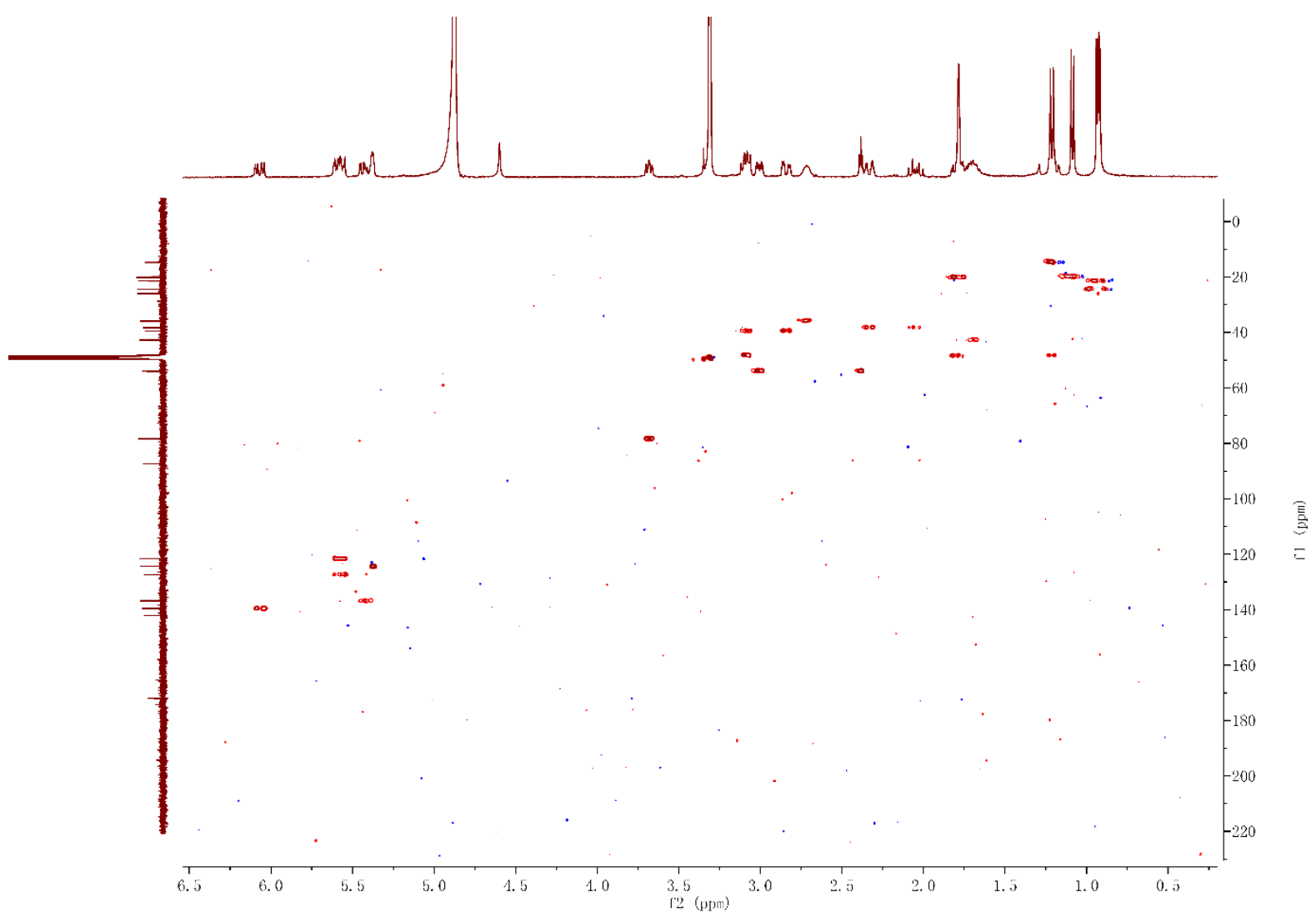


HMBC spectrum of compound 1

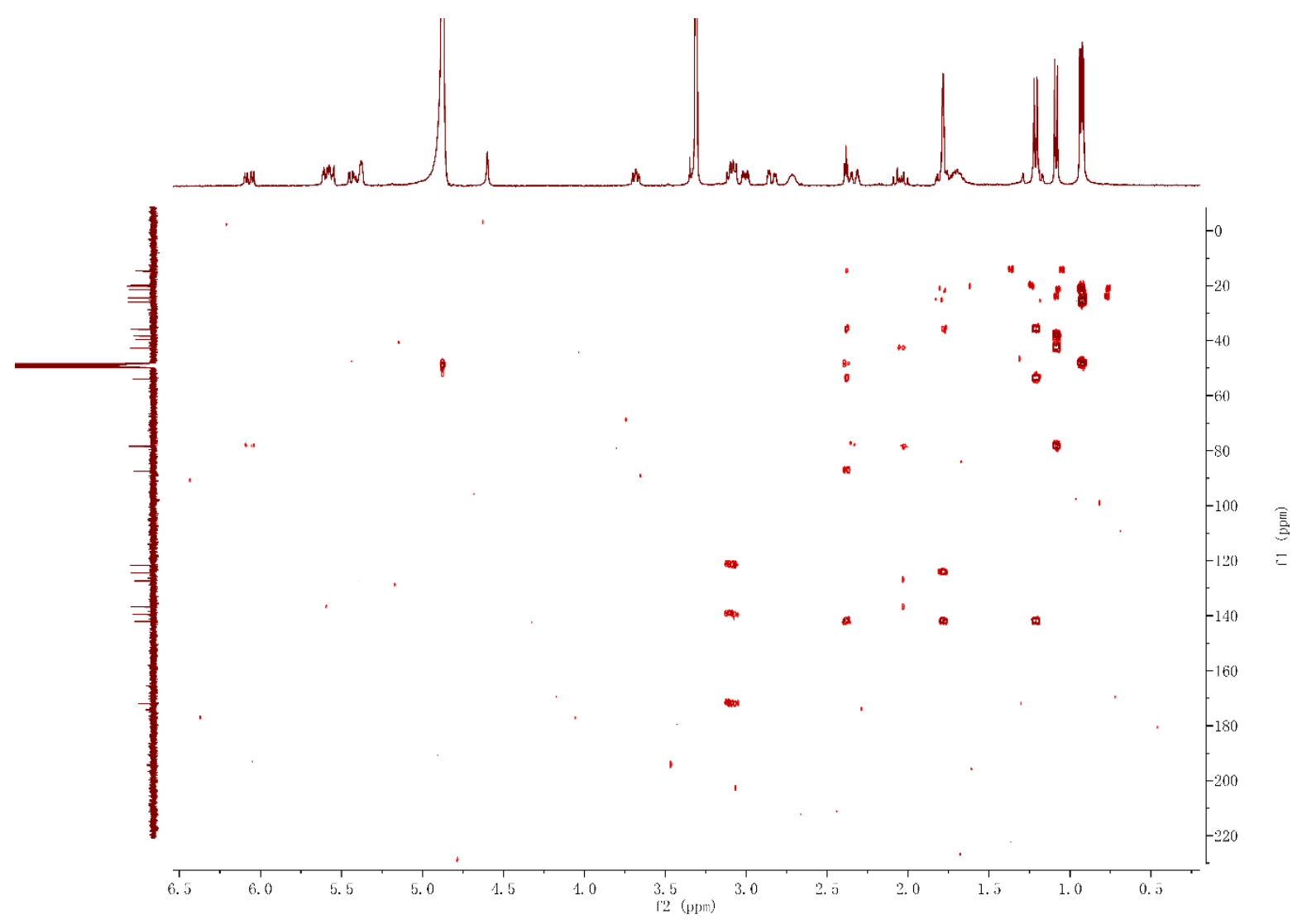

${ }^{1} \mathrm{H}-{ }^{1} \mathrm{H}$ COSY spectrum of compound 1

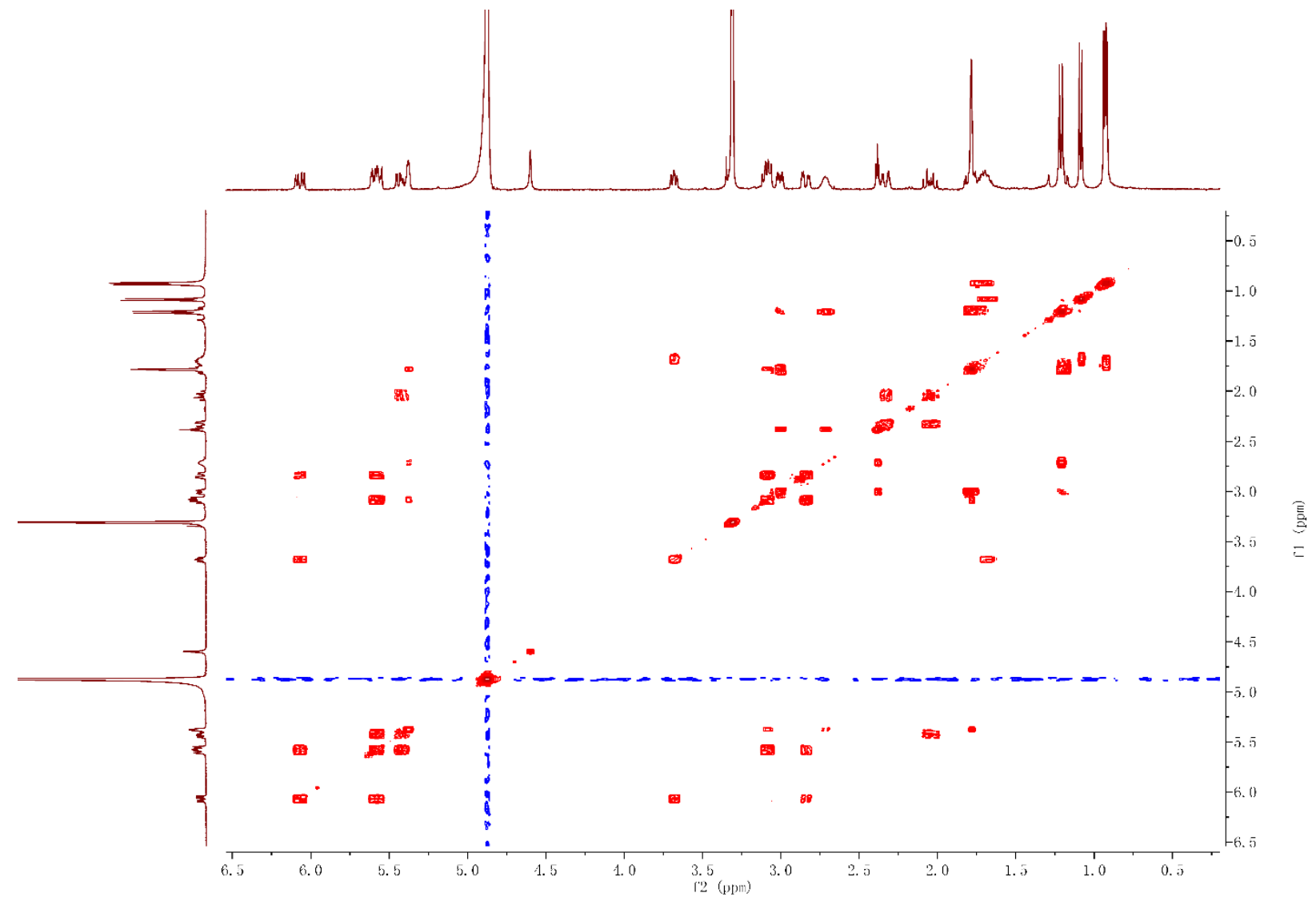

S20 


\section{NOESY spectrum of compound 1}

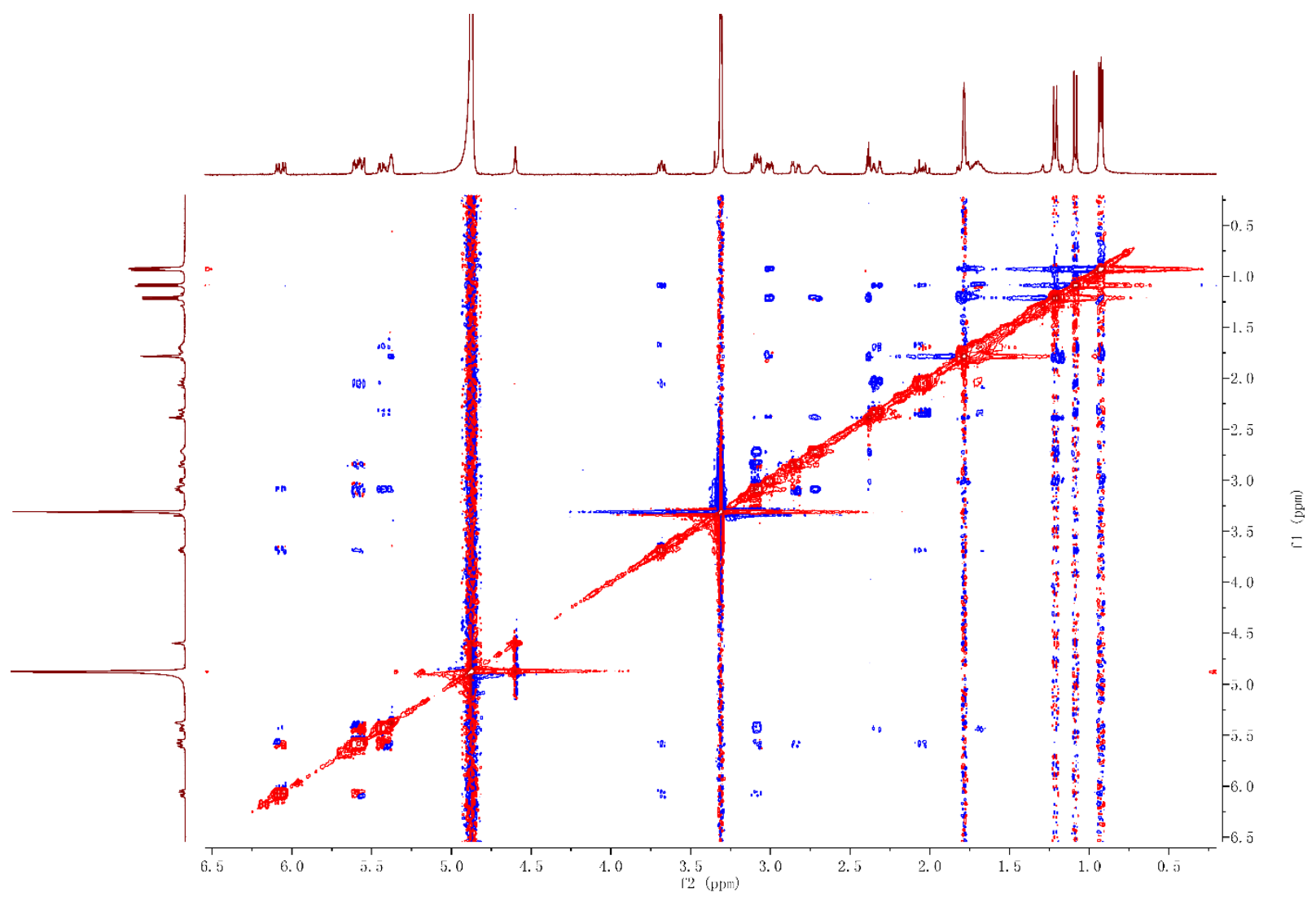

HRESIMS spectrum of compound 2

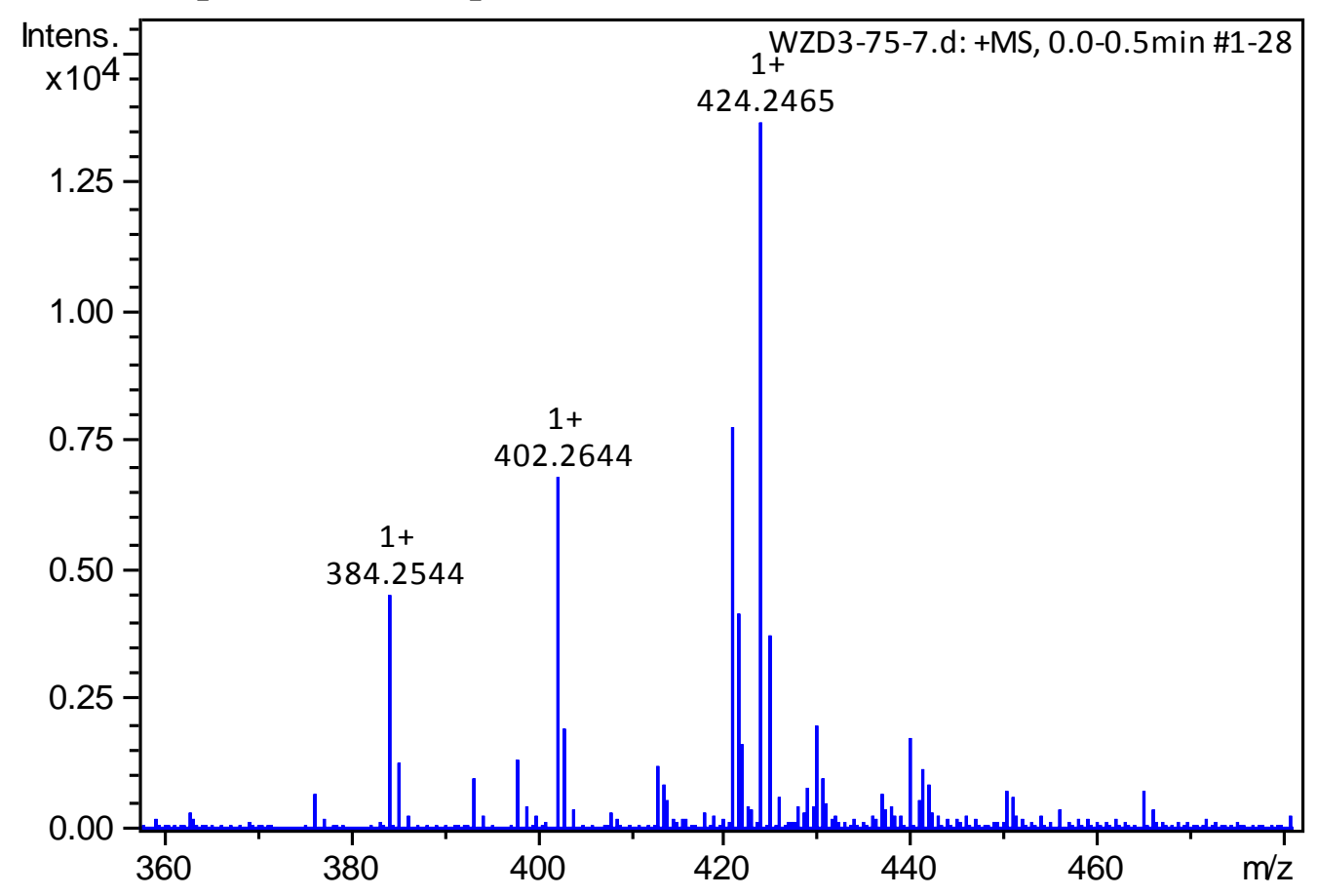


UV spectrum of compound 2

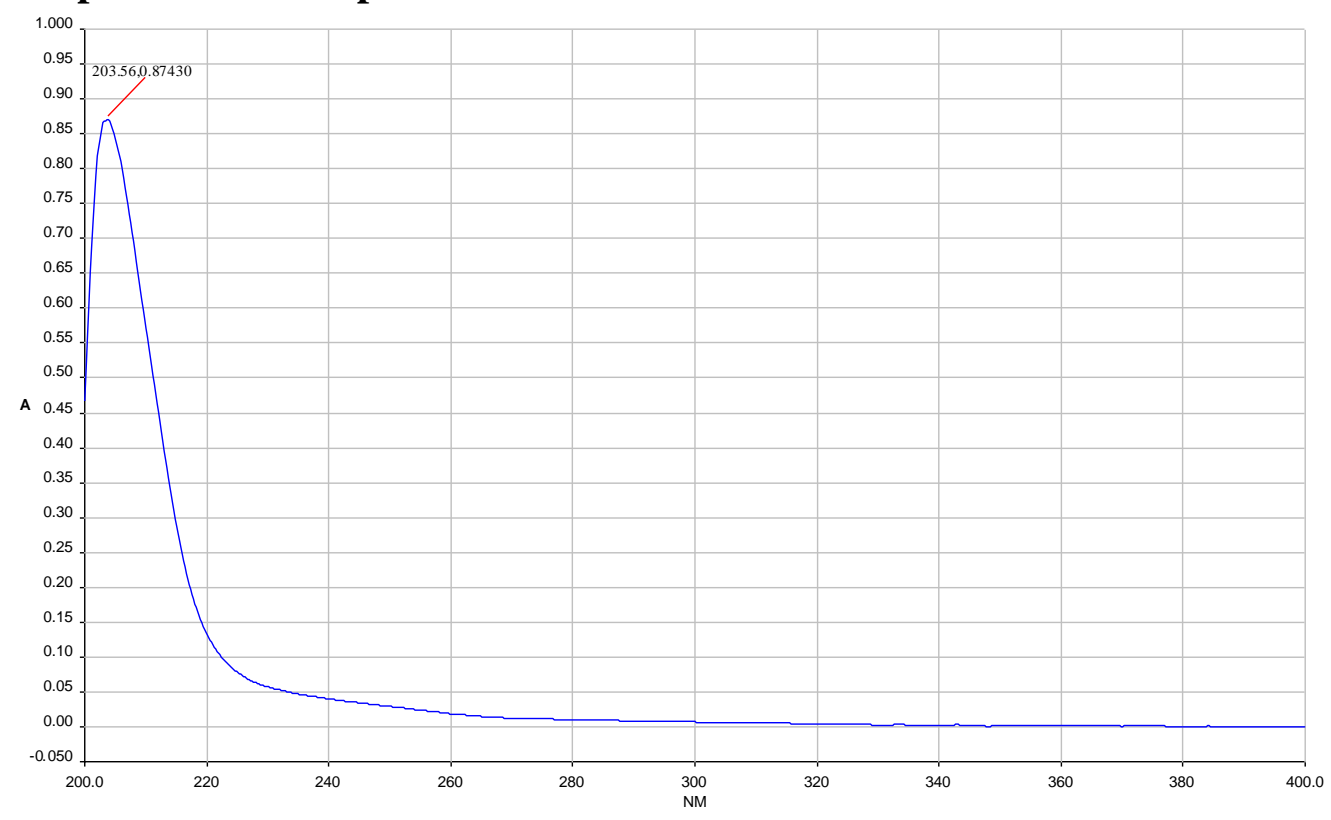

IR spectrum of compound 2

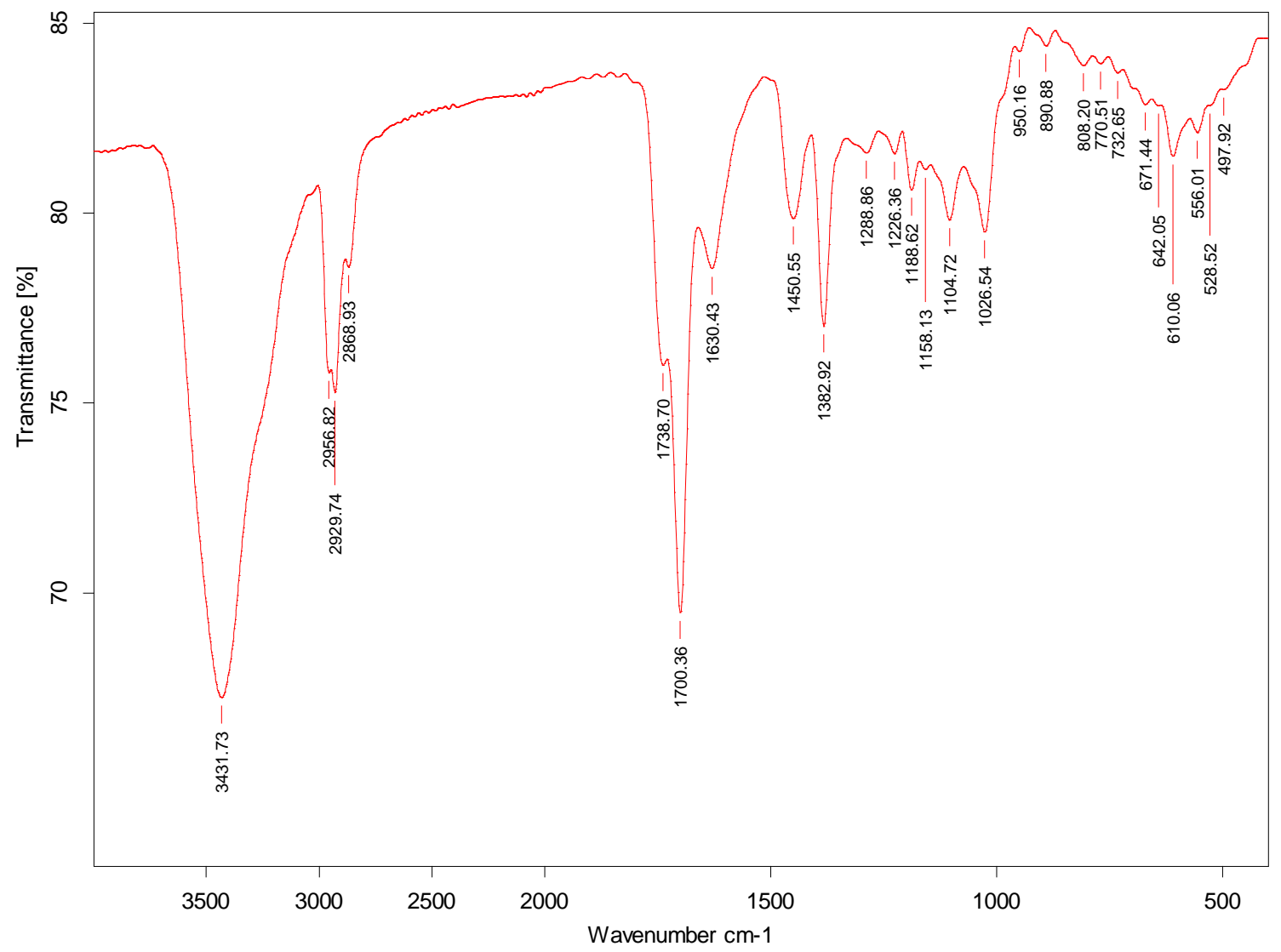




\section{${ }^{1} \mathrm{H}$ NMR spectrum of compound 2}

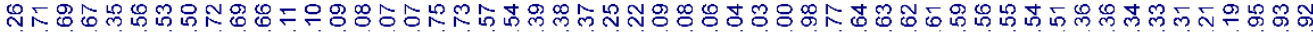

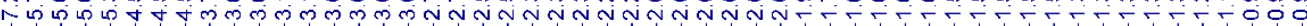

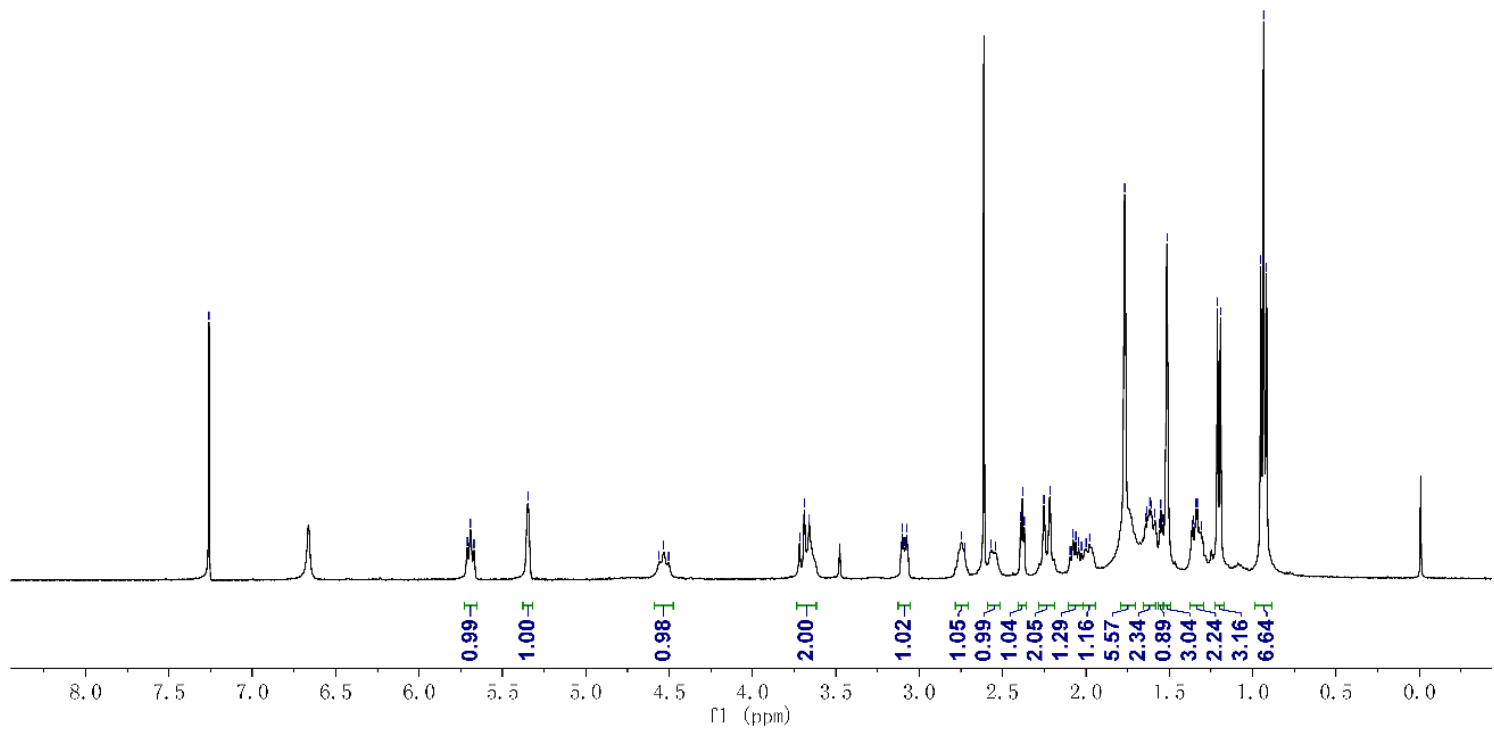

${ }^{13}$ C NMR and DEPT spectra of compound 2
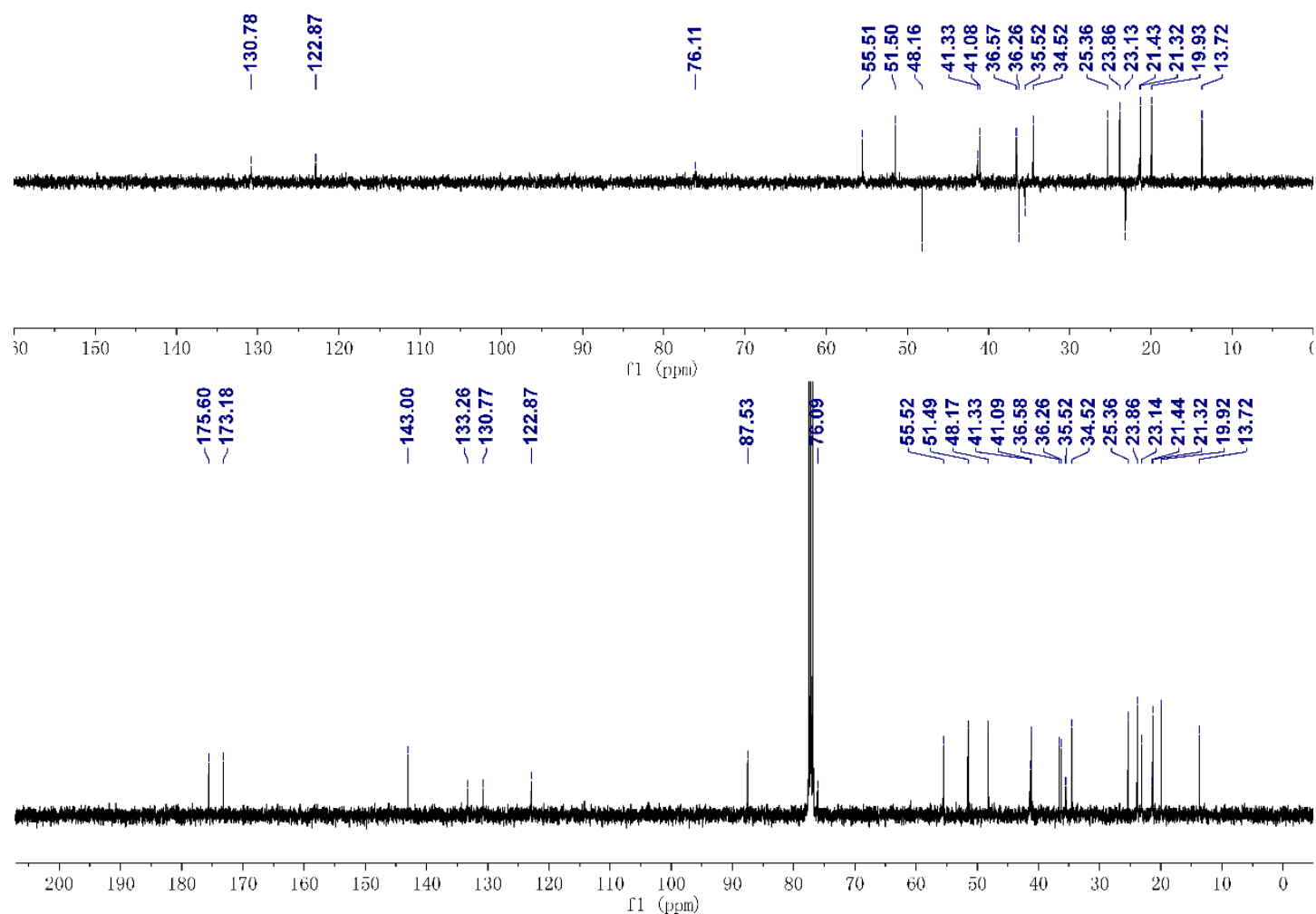
HSQC spectrum of compound 2

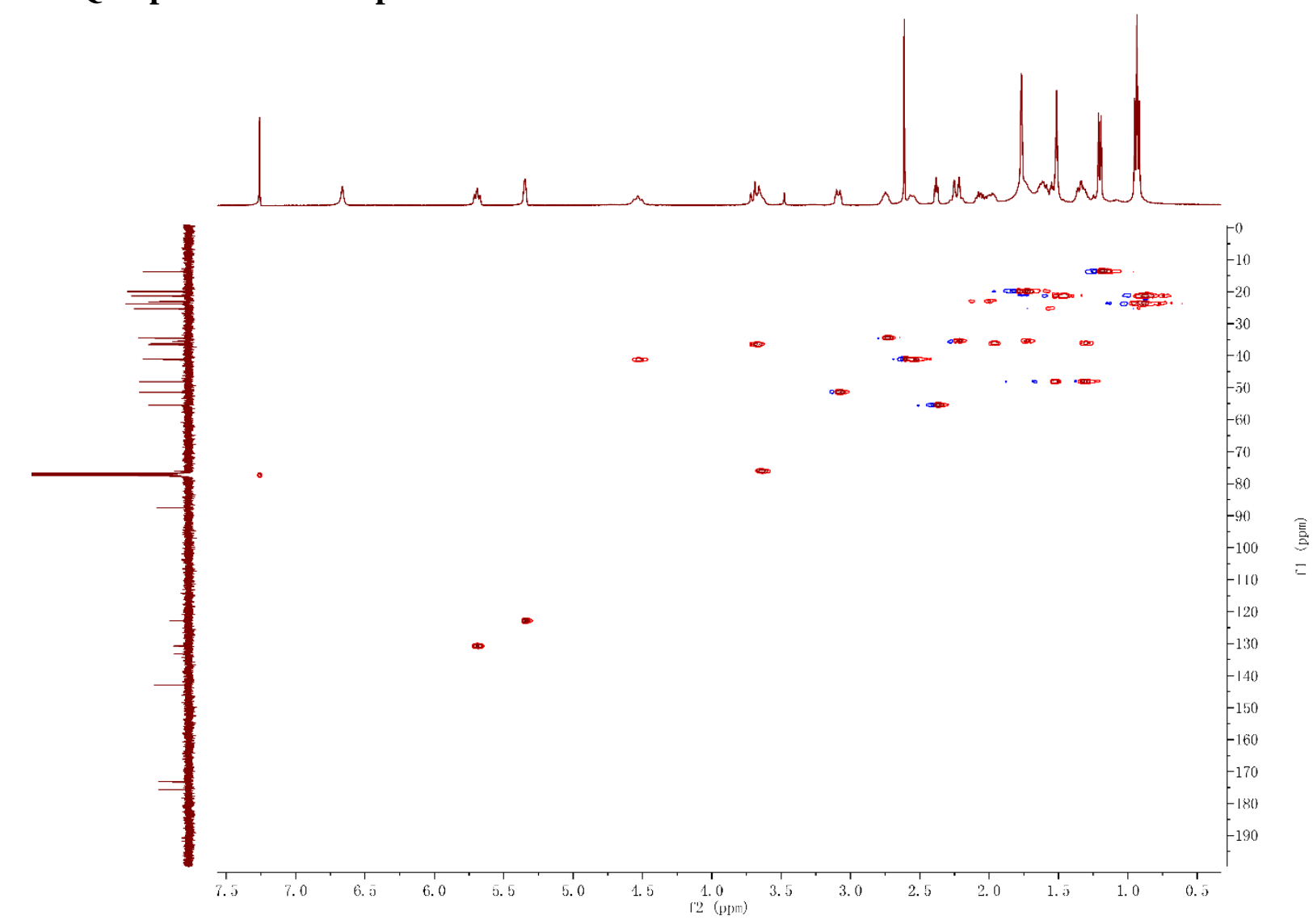

HMBC spectrum of compound 2

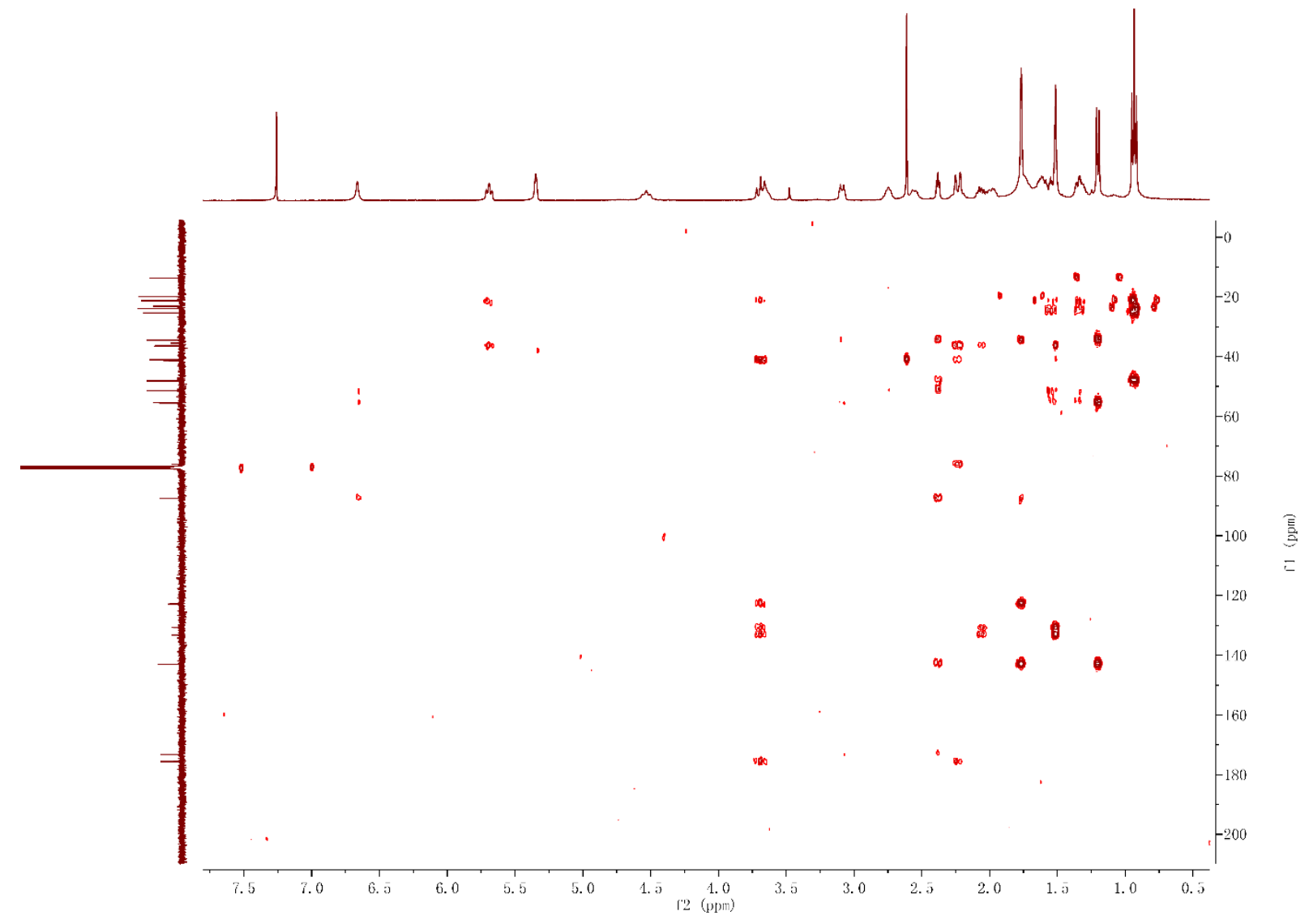

S24 
${ }^{1} \mathrm{H}^{-1} \mathrm{H}$ COSY spectrum of compound 2

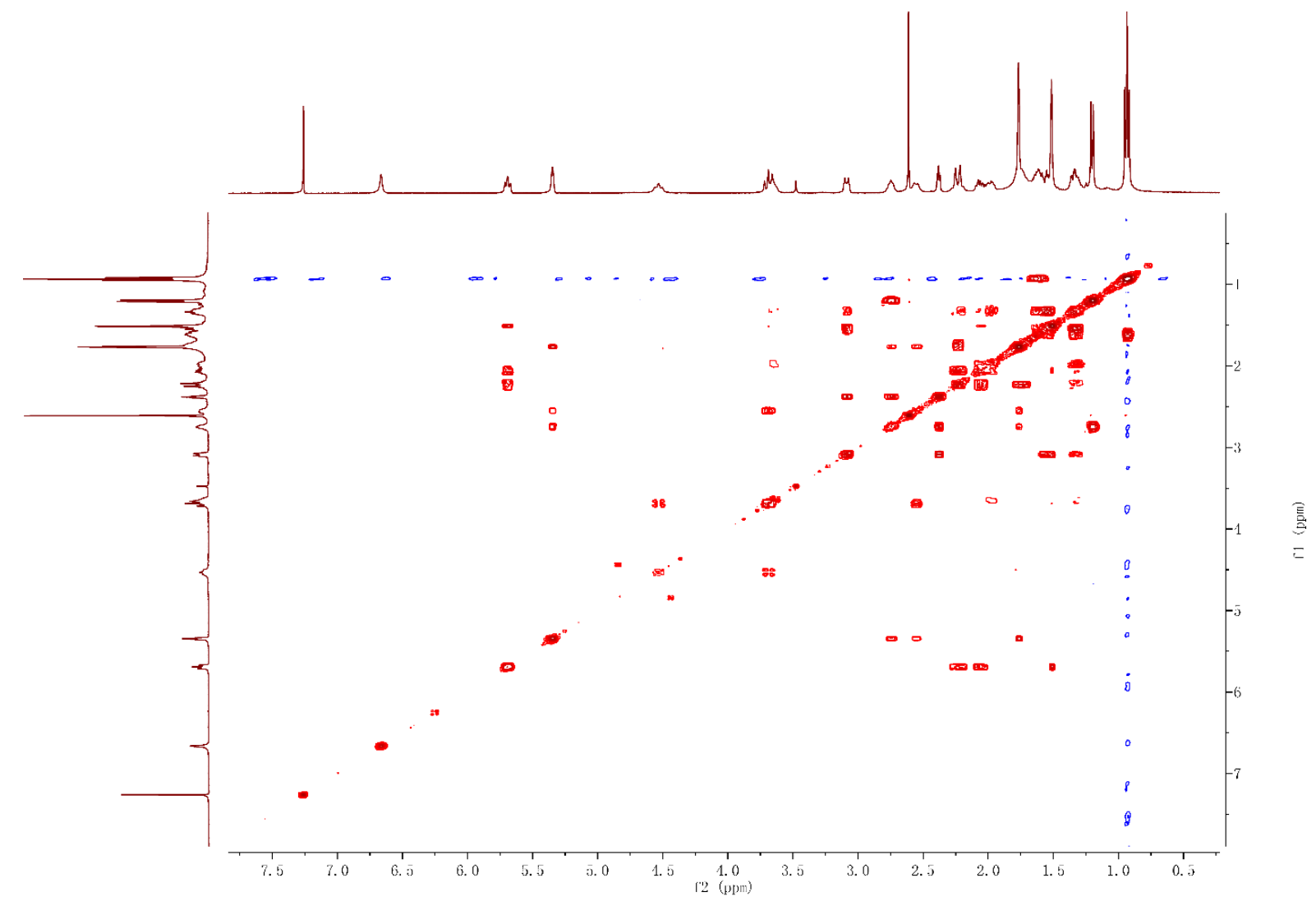

NOESY spectrum of compound 2

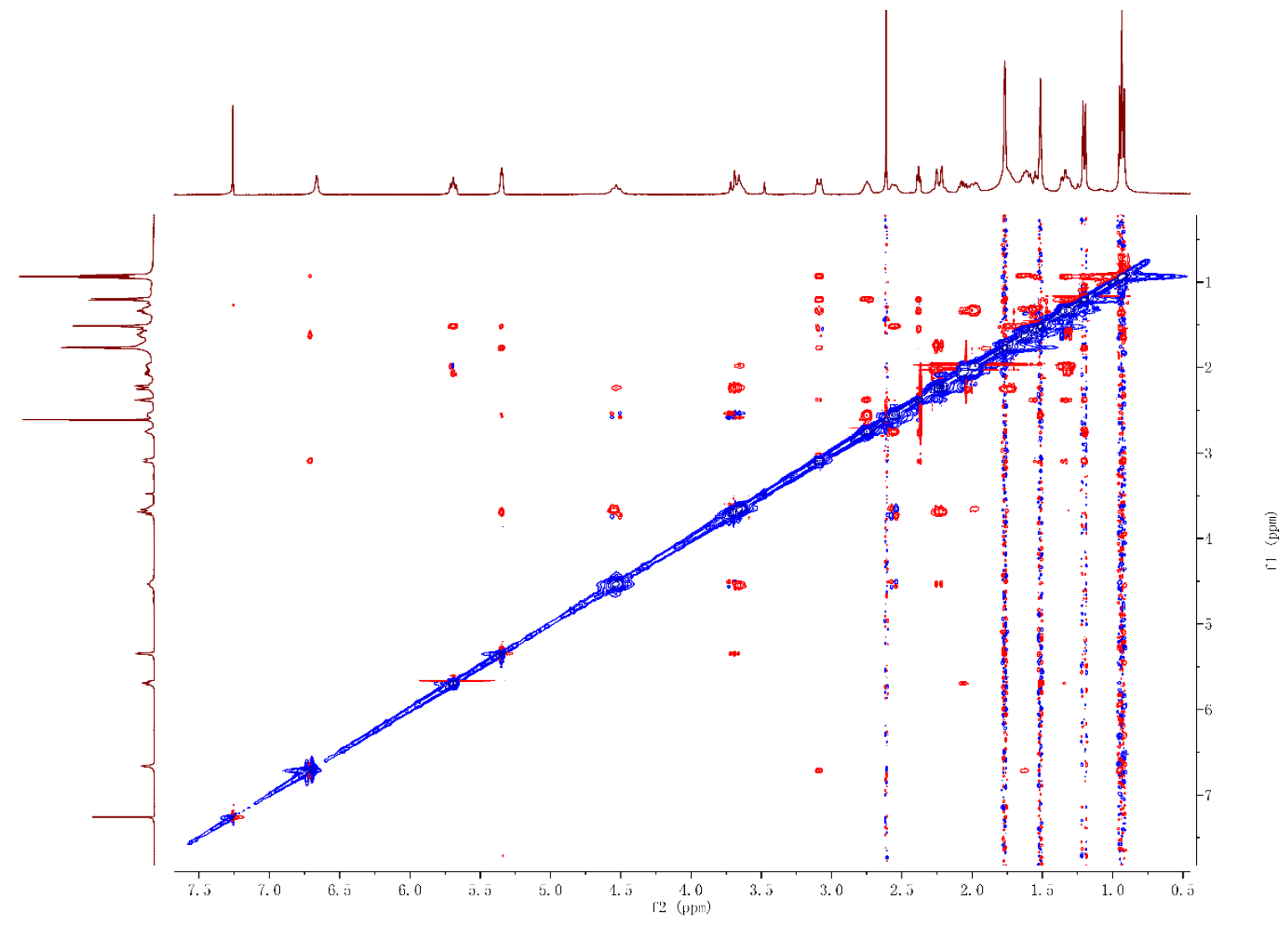


HRESIMS spectrum of compound 3

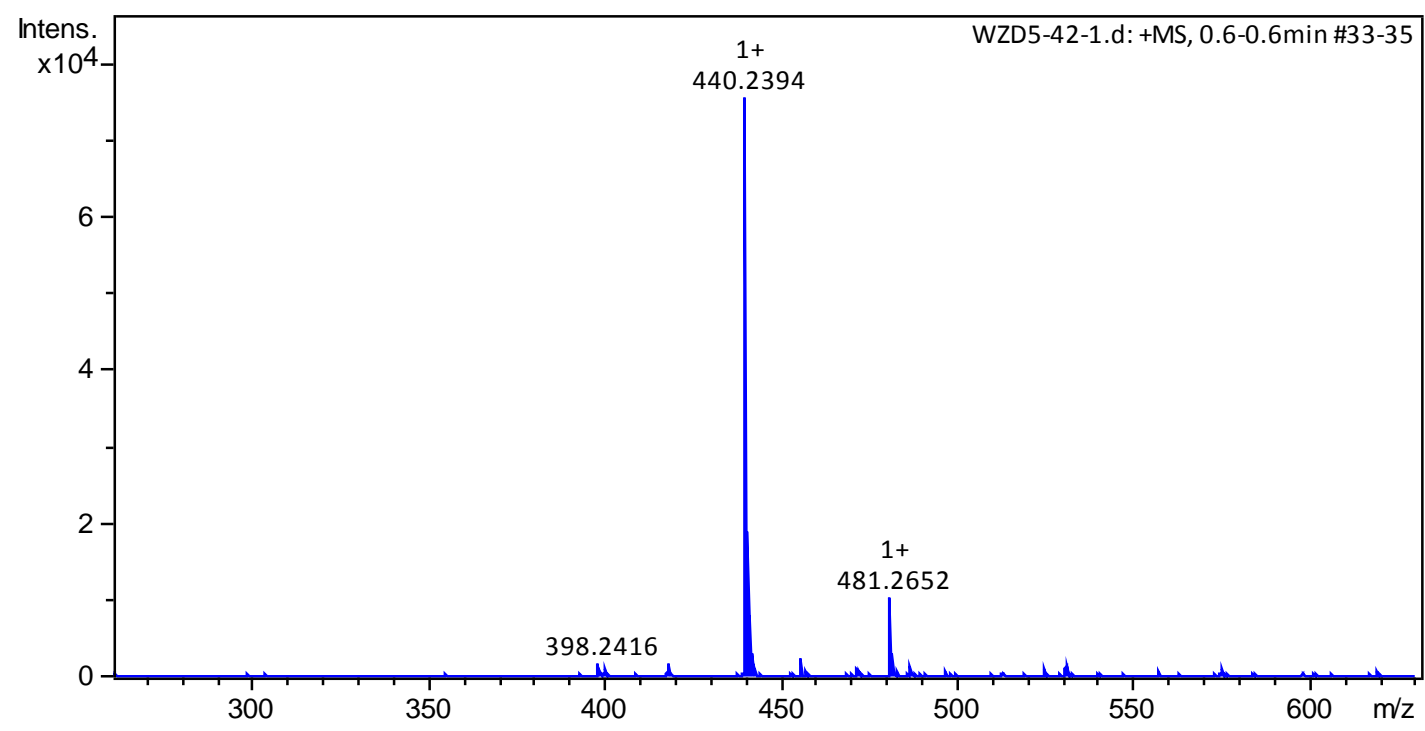

\section{UV spectrum of compound 3}

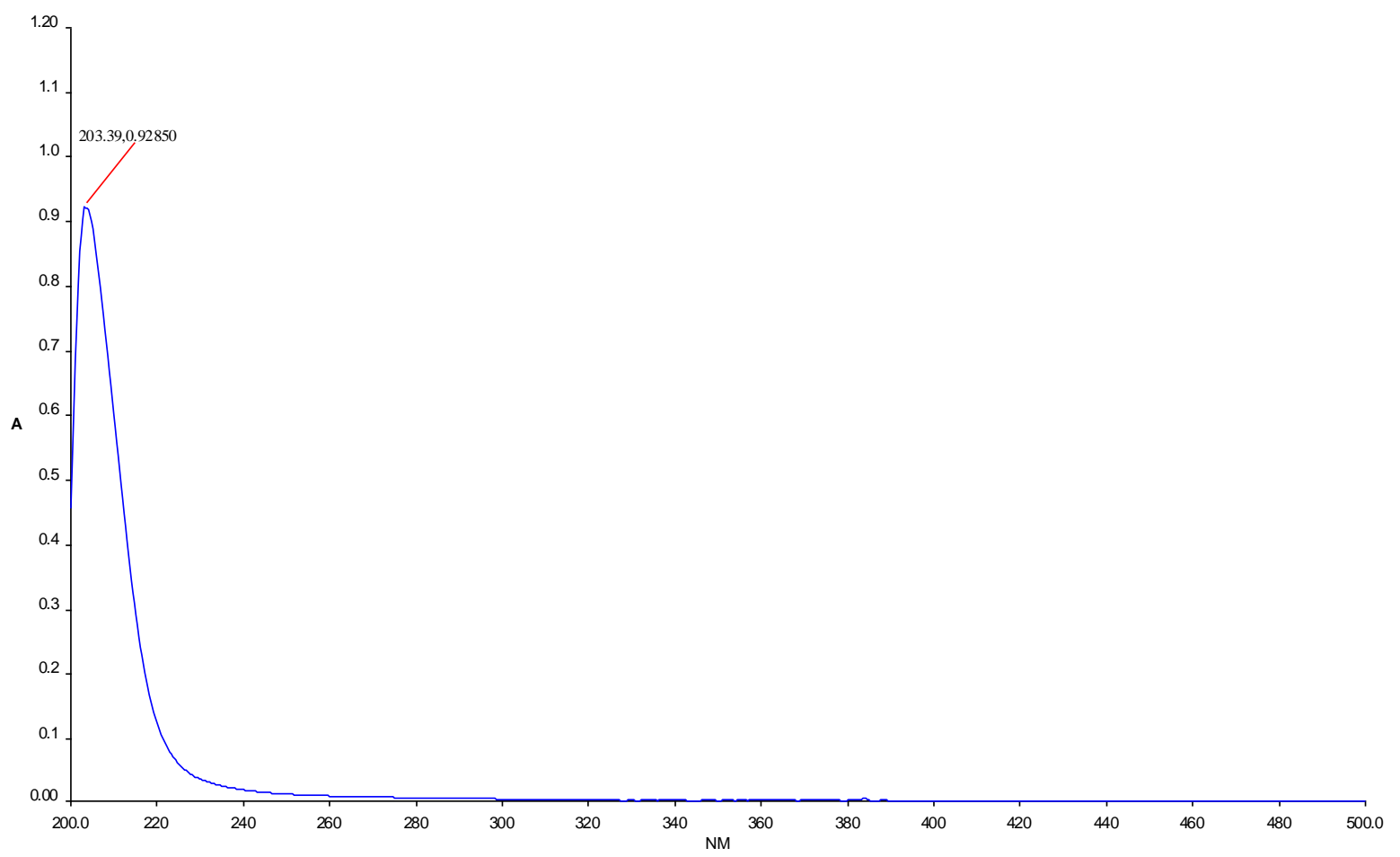


IR spectrum of compound 3

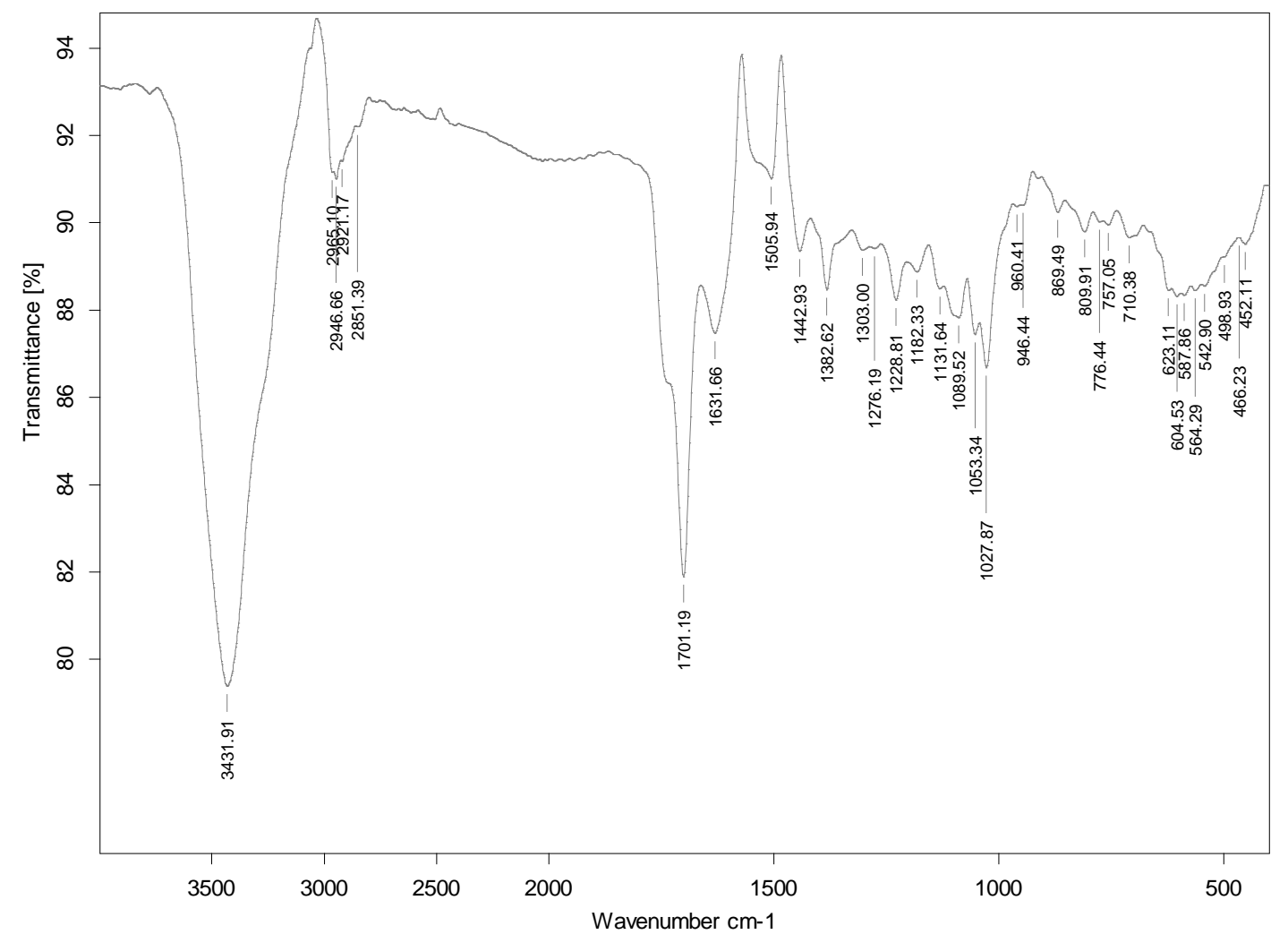

\section{${ }^{1} \mathrm{H}$ NMR spectrum of compound 3}

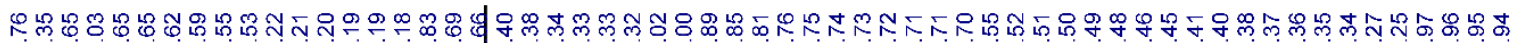

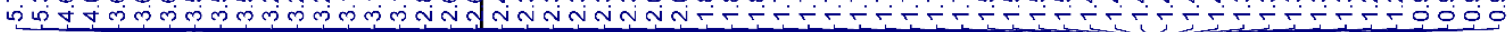

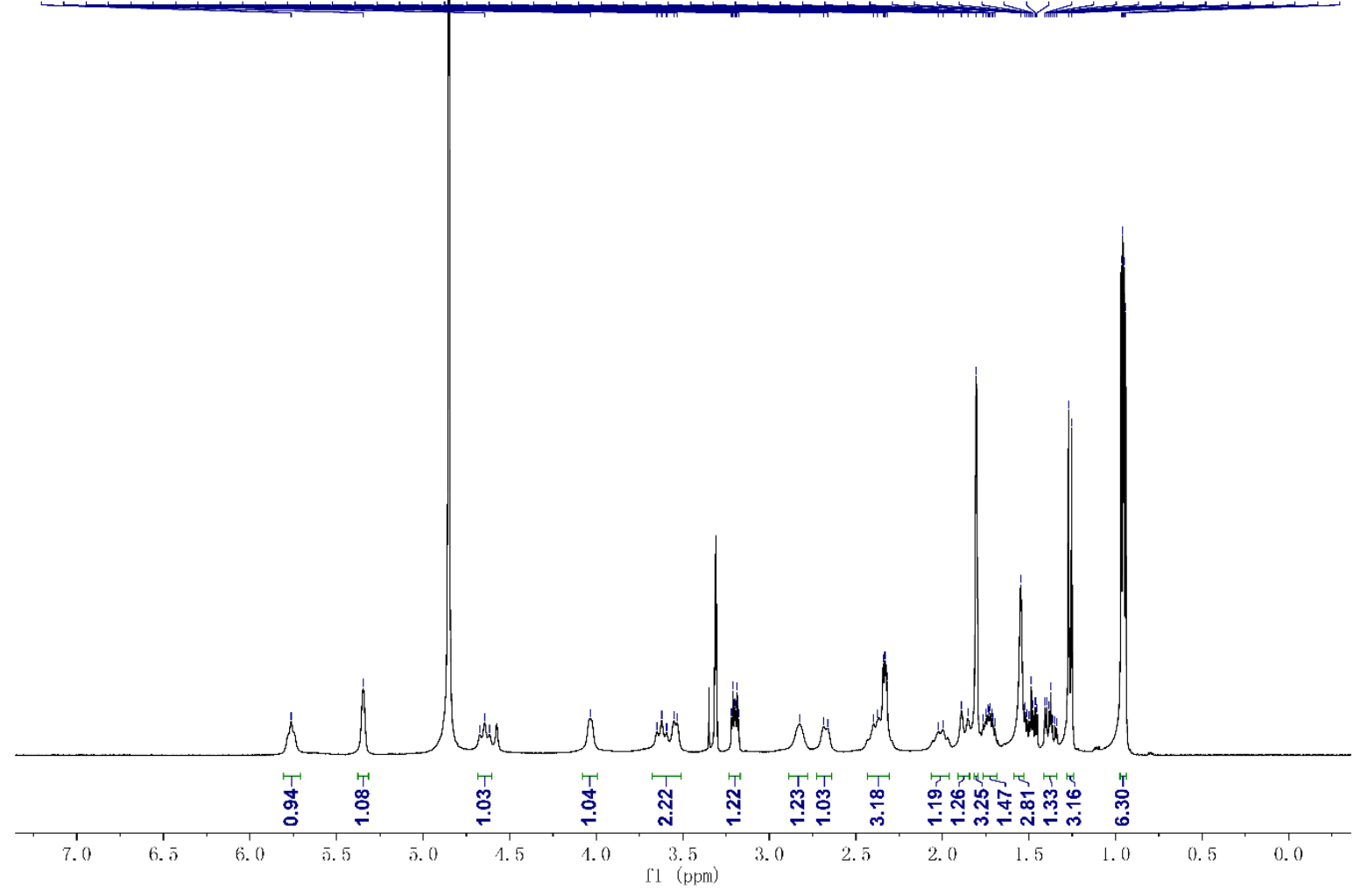


${ }^{13} \mathrm{C}$ NMR and DEPT spectra of compound 3

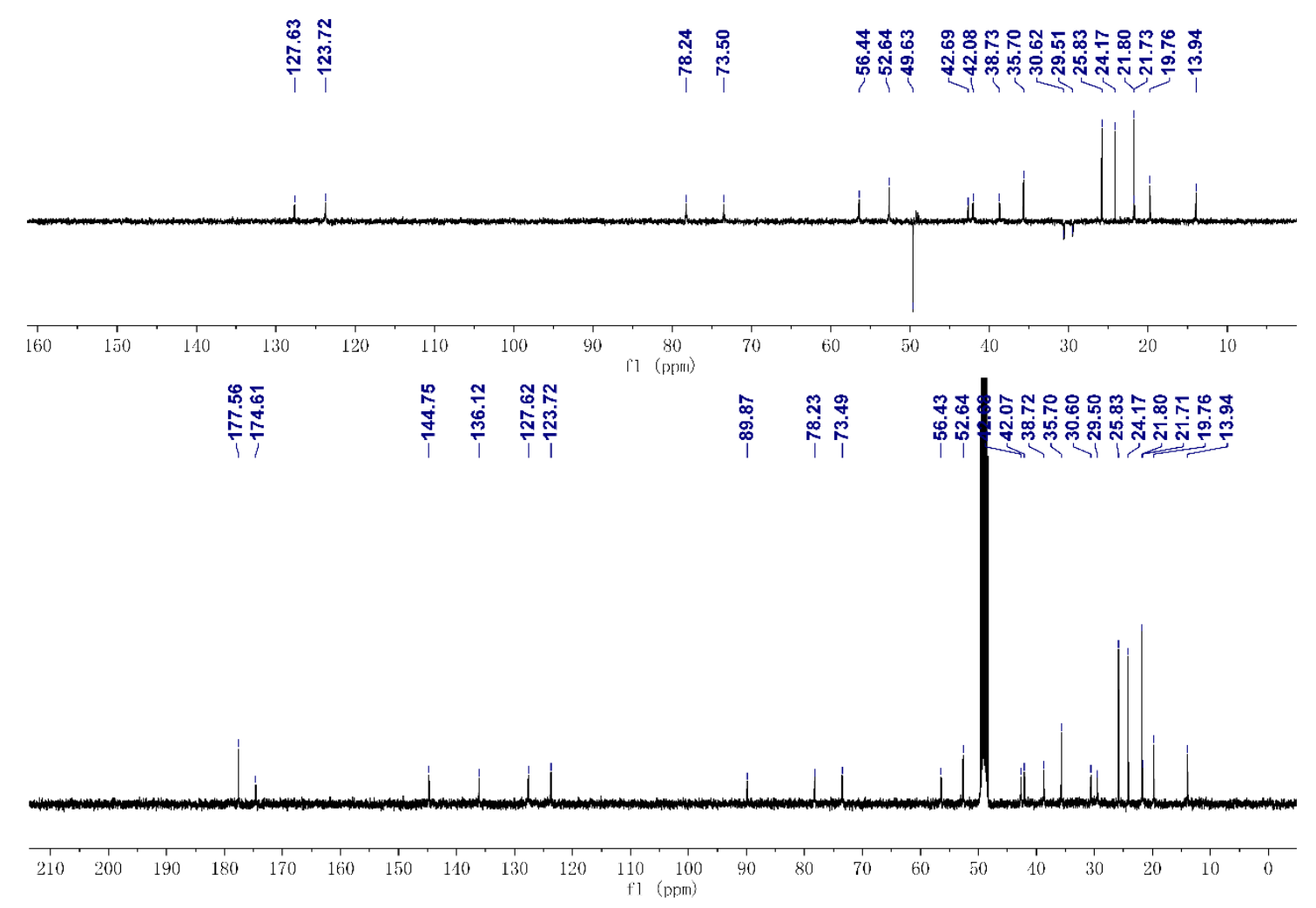

HSQC spectrum of compound 3

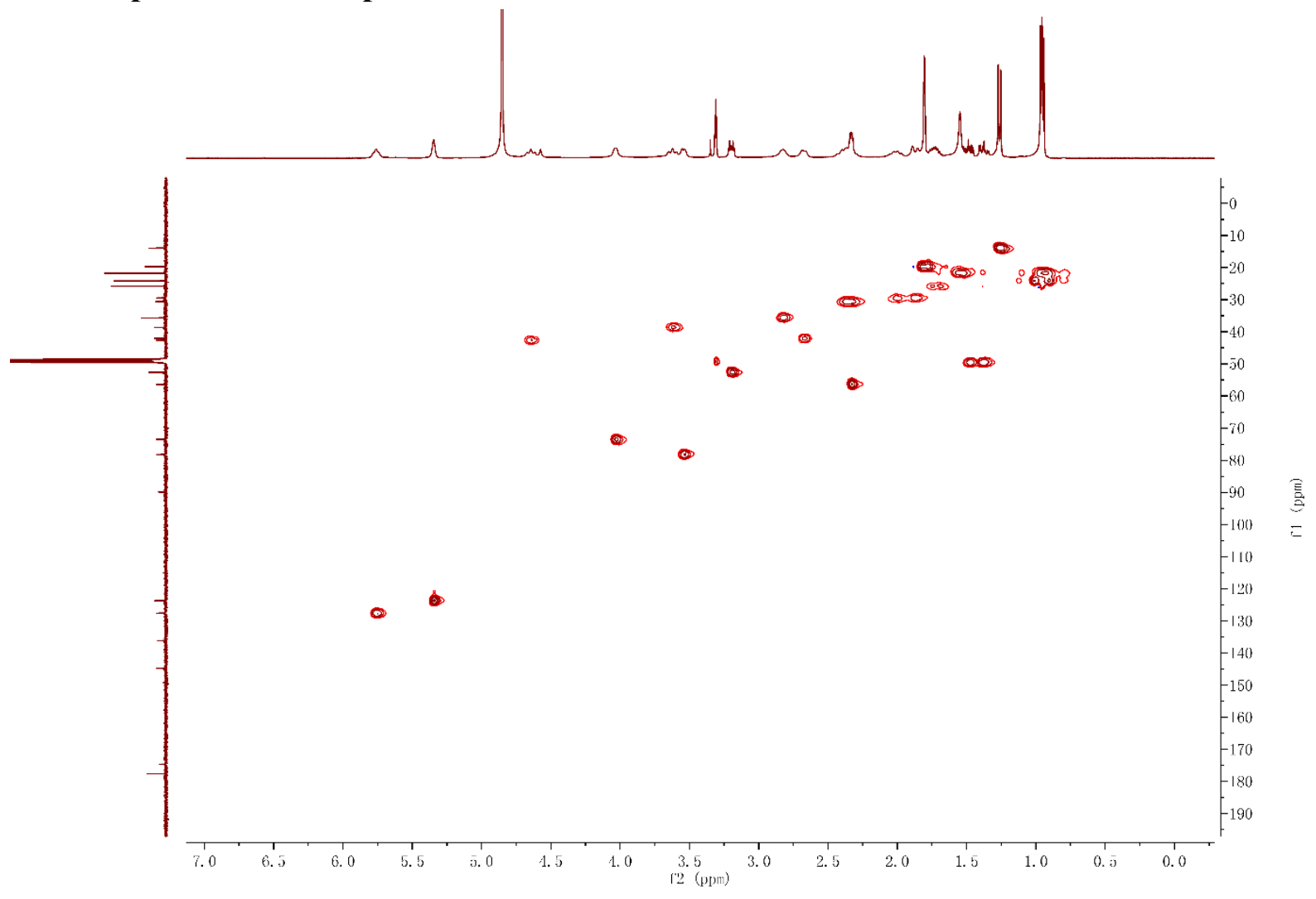




\section{HMBC spectrum of compound 3}

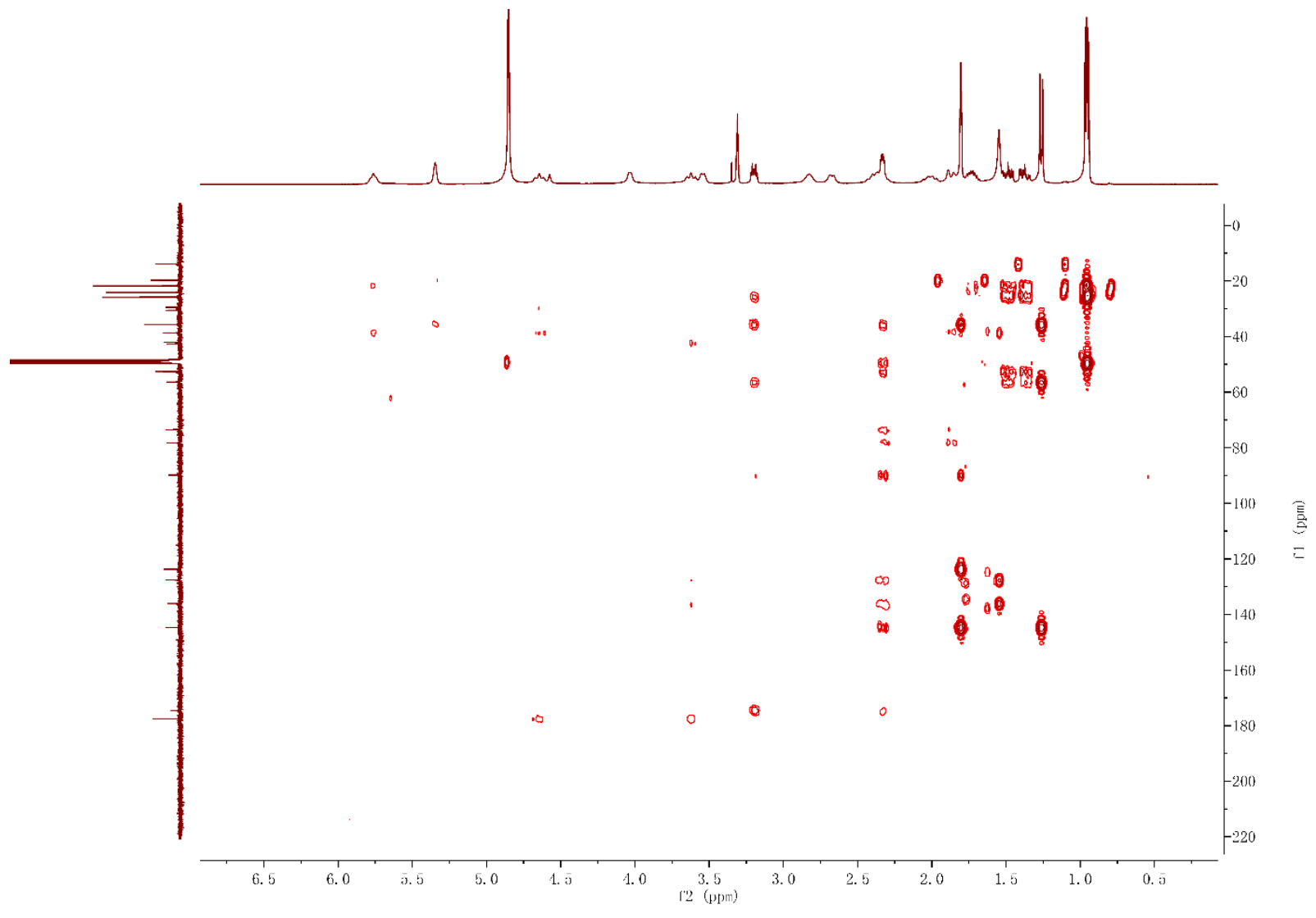

\section{${ }^{1} \mathrm{H}-{ }^{1} \mathrm{H}$ COSY spectrum of compound 3}

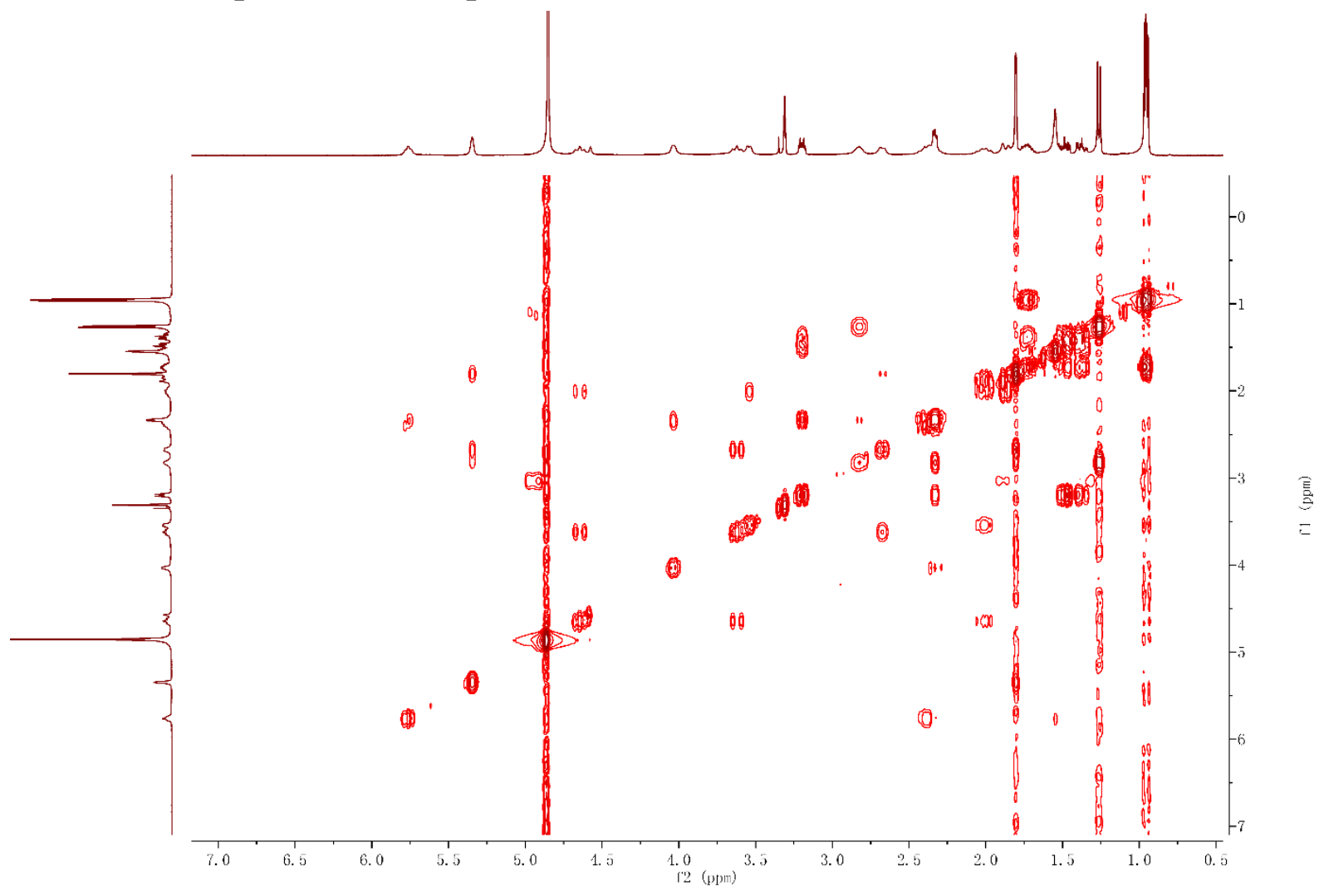




\section{NOESY spectrum of compound 3}

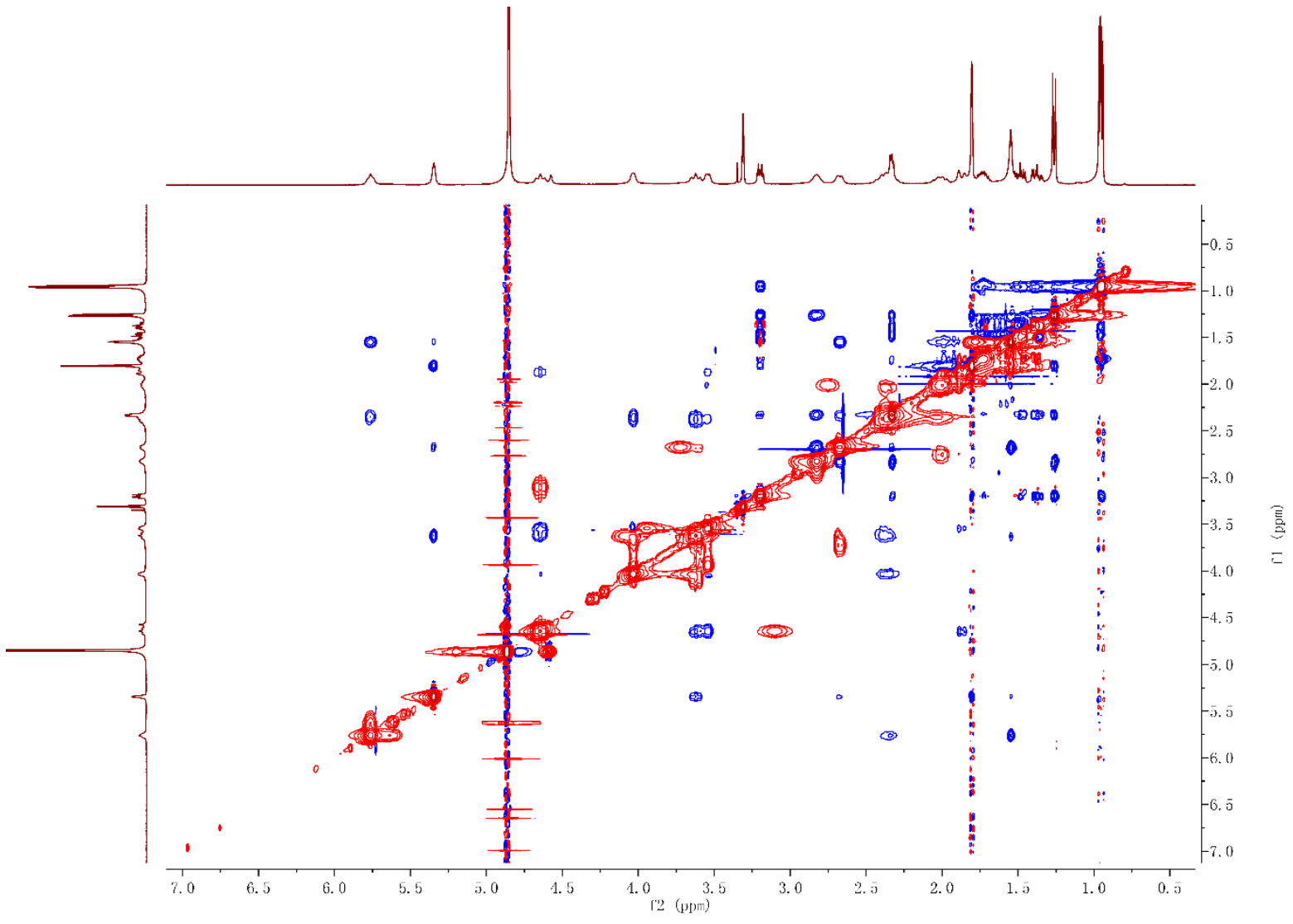

HRESIMS spectrum of compound 4

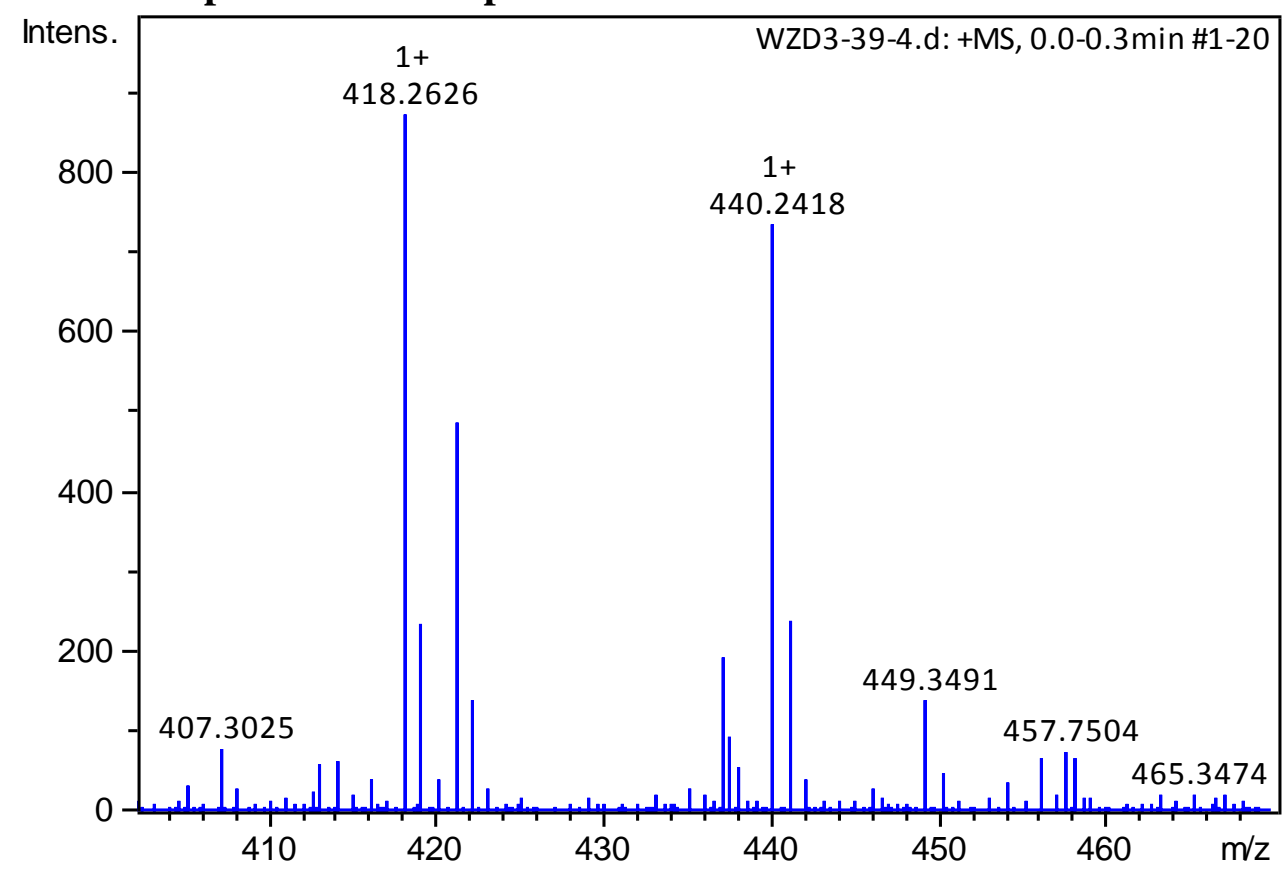




\section{UV spectrum of compound 4}

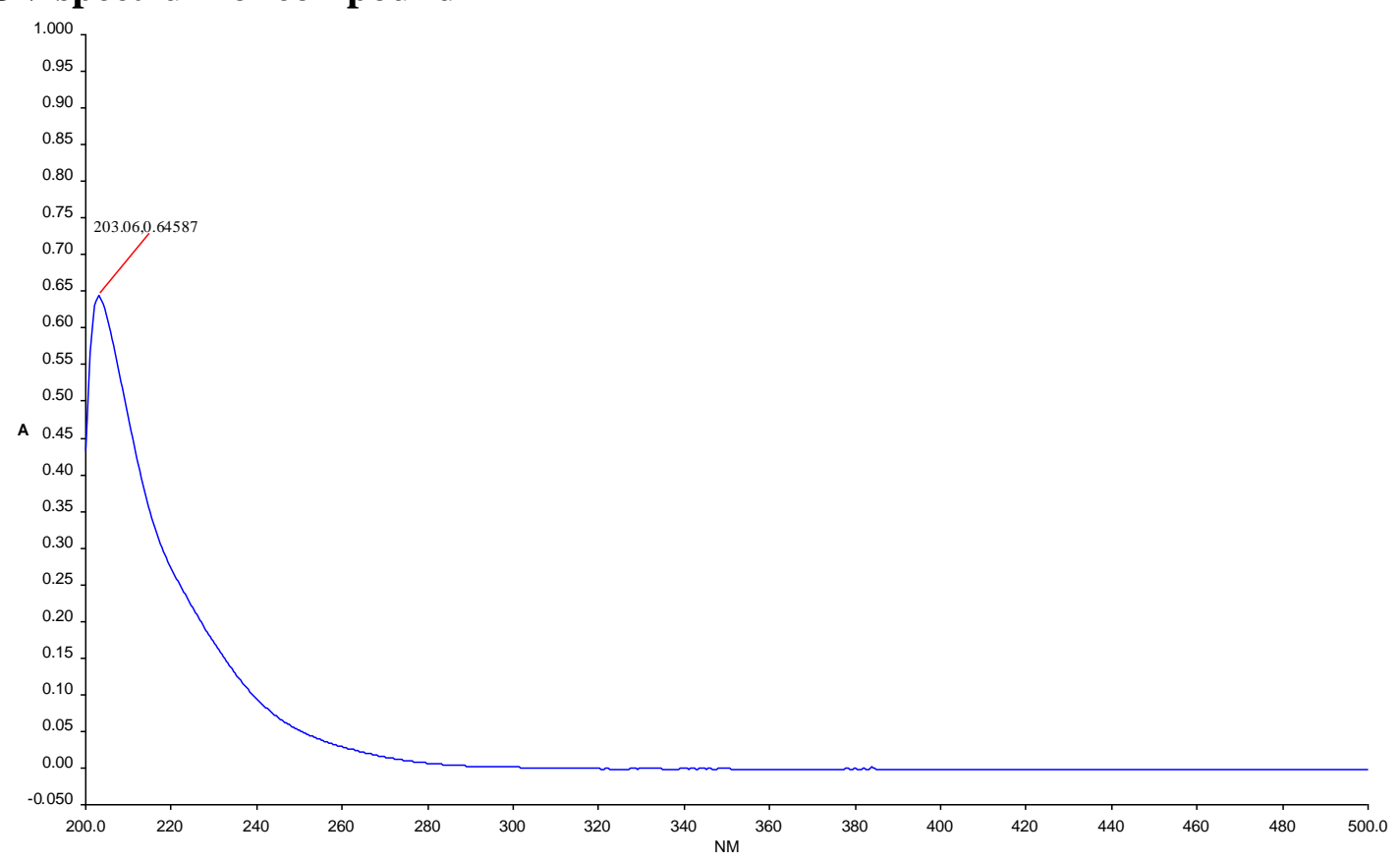

IR spectrum of compound 4

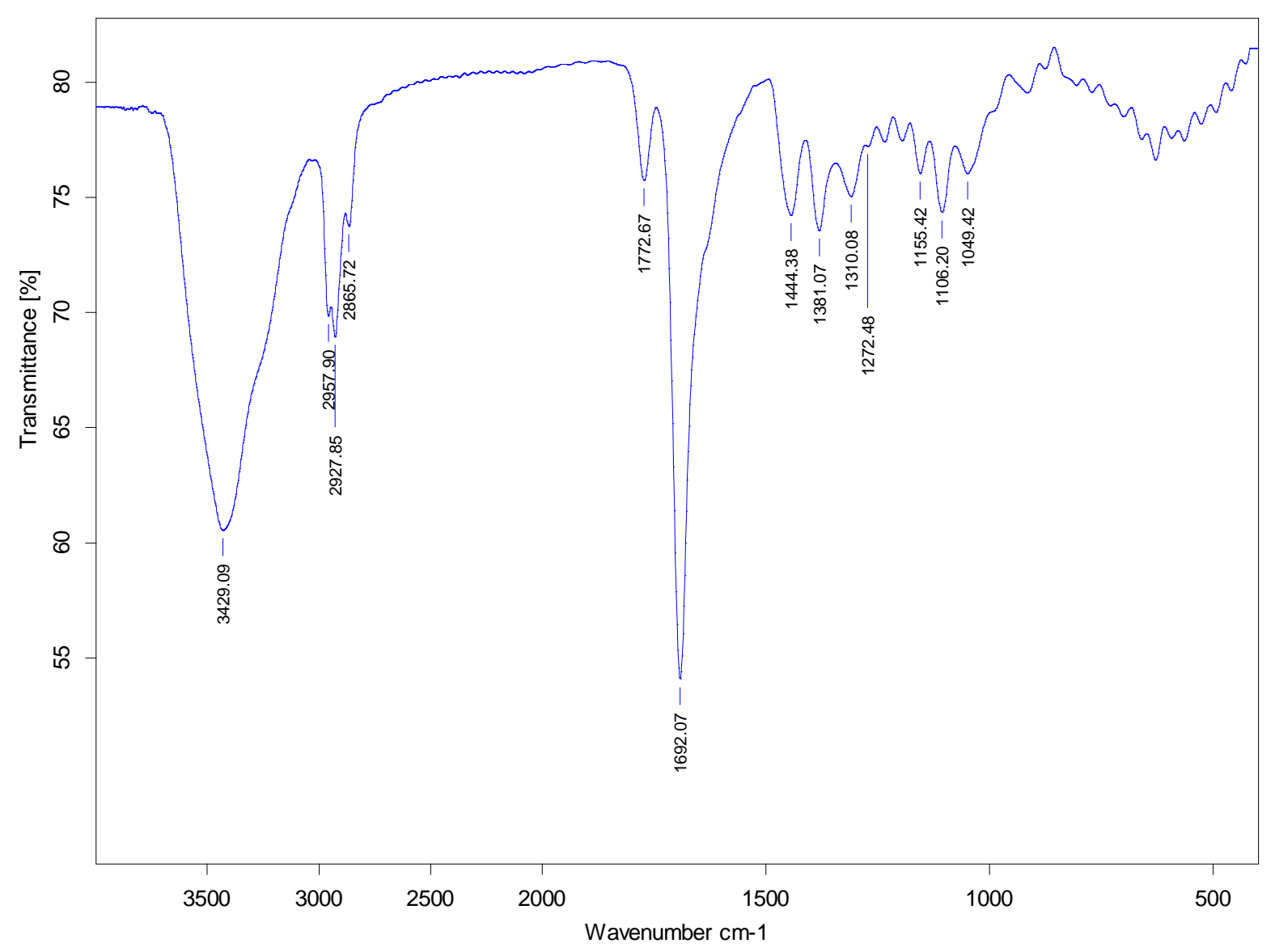


${ }^{1} \mathrm{H}$ NMR spectrum of compound 4

诲

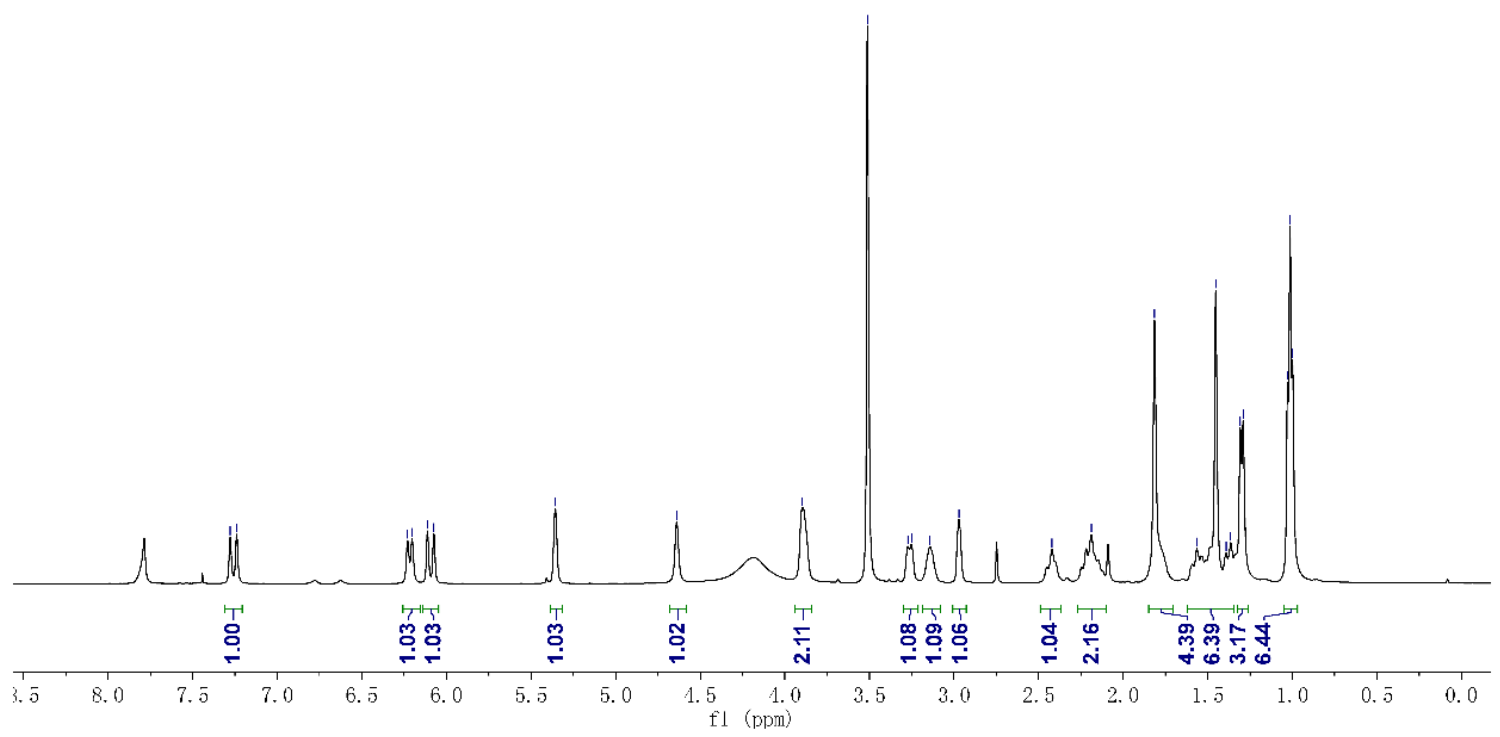

${ }^{13} \mathrm{C}$ NMR and DEPT spectra of compound 4

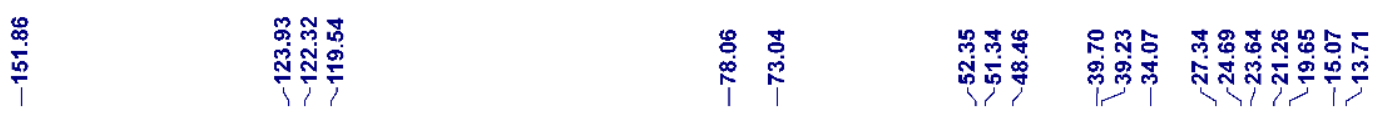
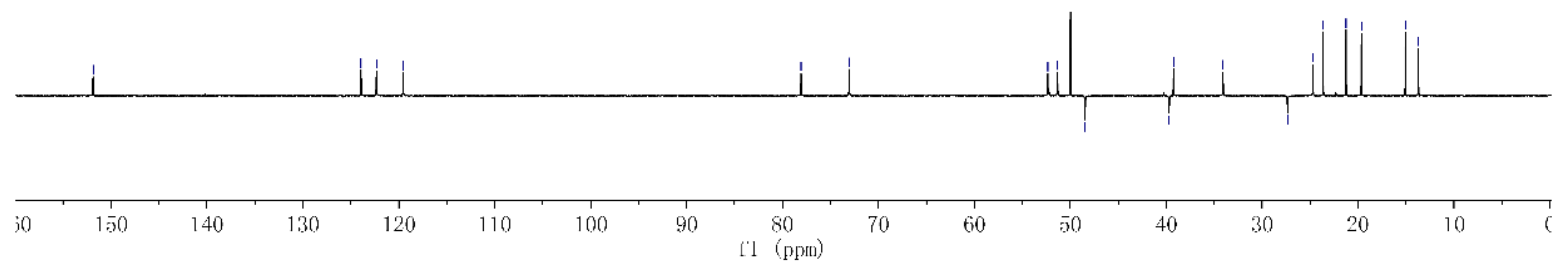

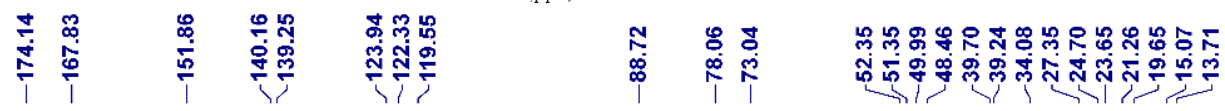

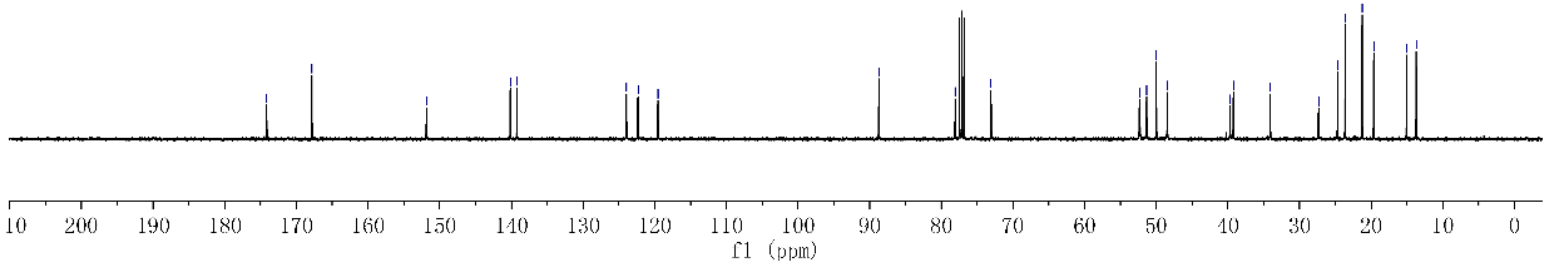




\section{HSQC spectrum of compound 4}

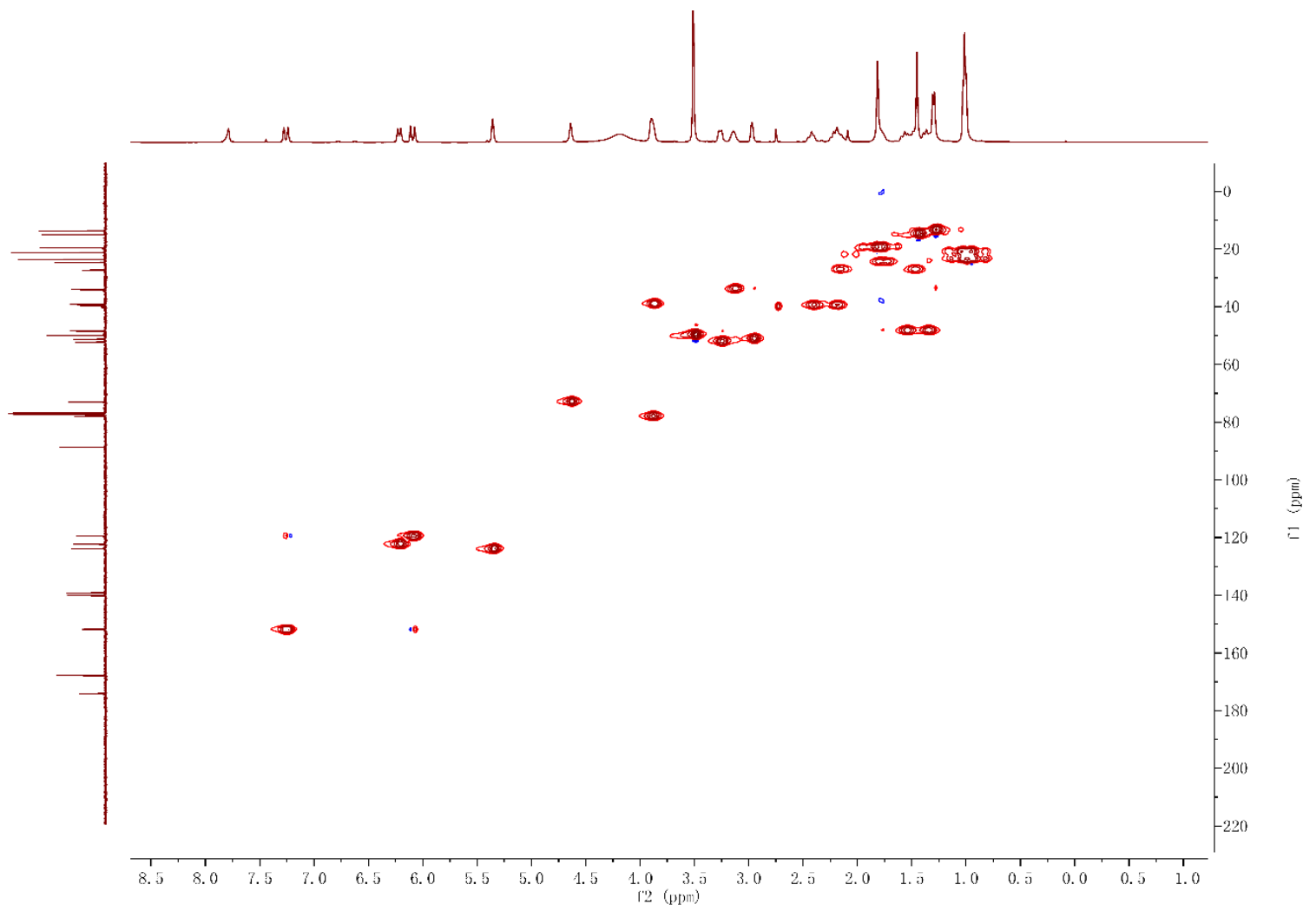

\section{HMBC spectrum of compound 4}

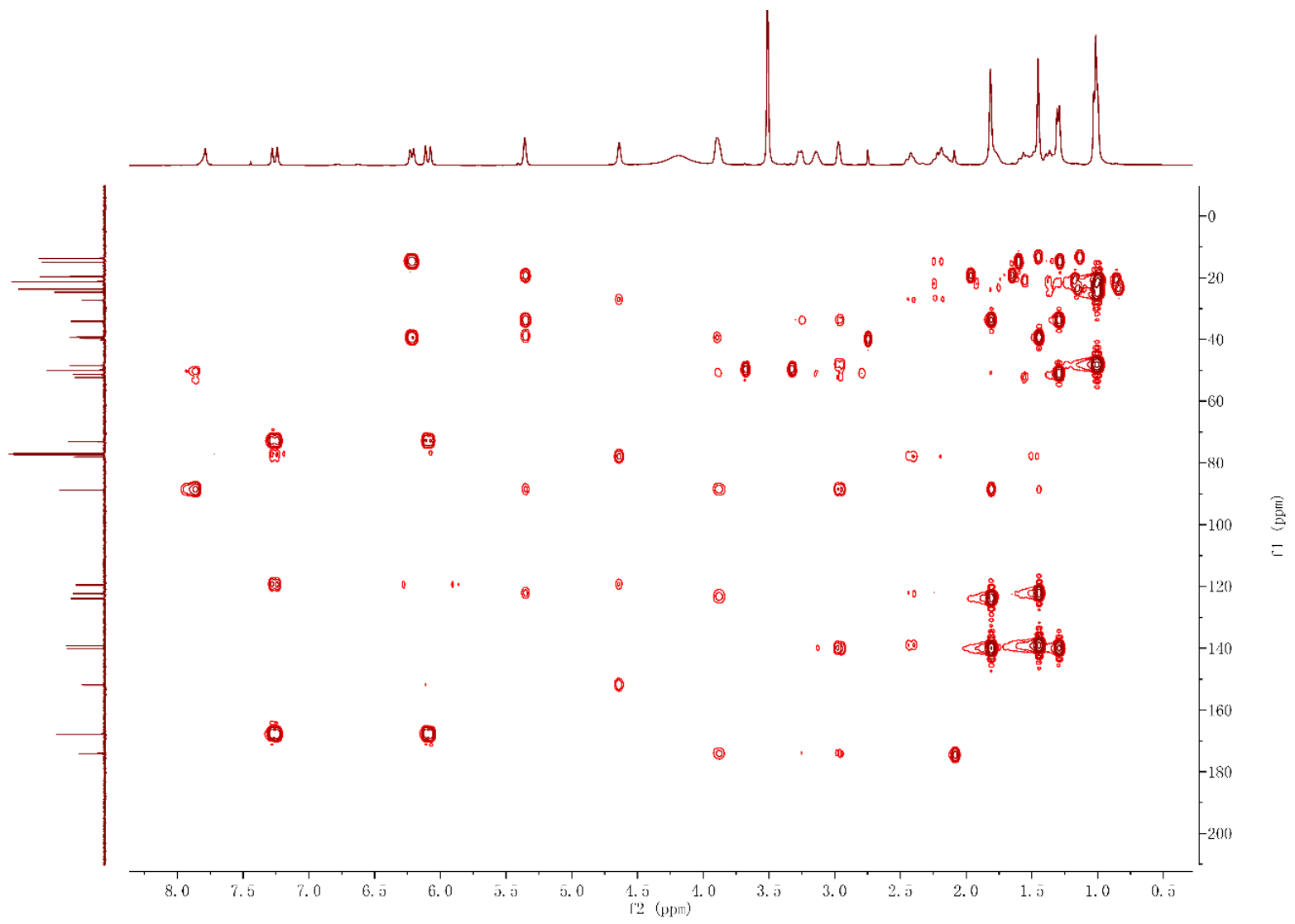


${ }^{1} \mathrm{H}^{-1} \mathrm{H}^{1} \mathrm{COSY}$ spectrum of compound 4

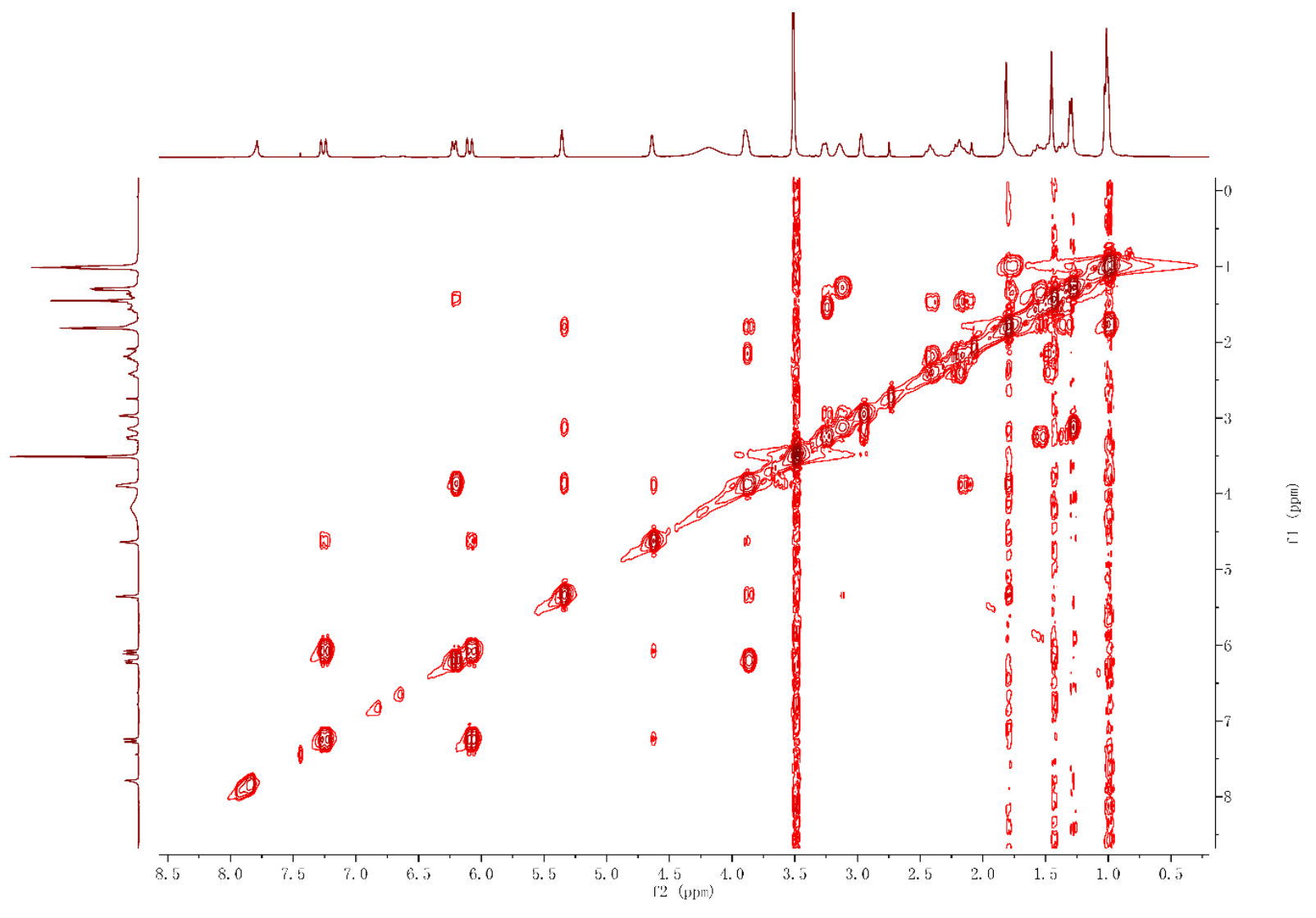

NOESY spectrum of compound 4

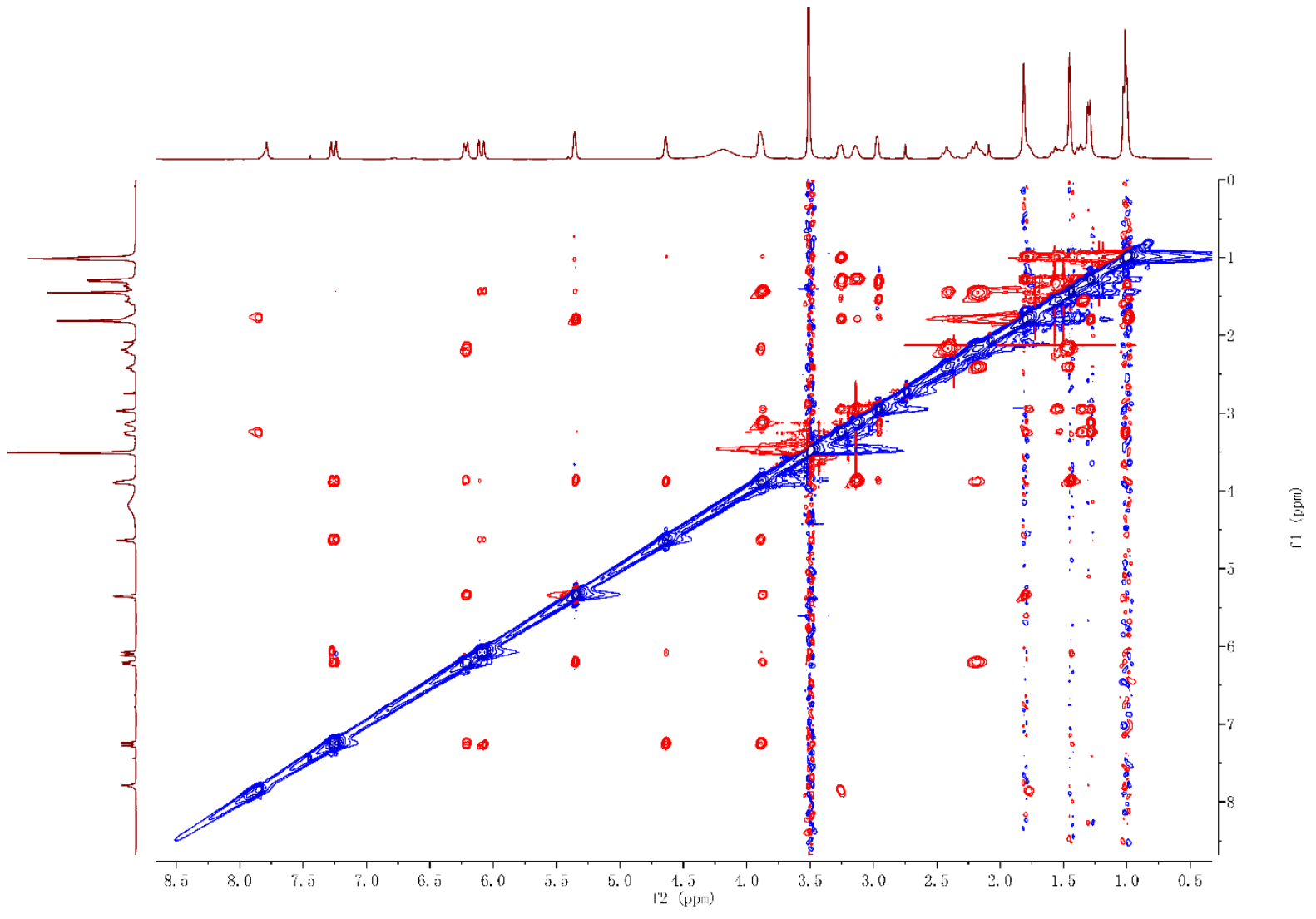


HRESIMS spectrum of compound 5

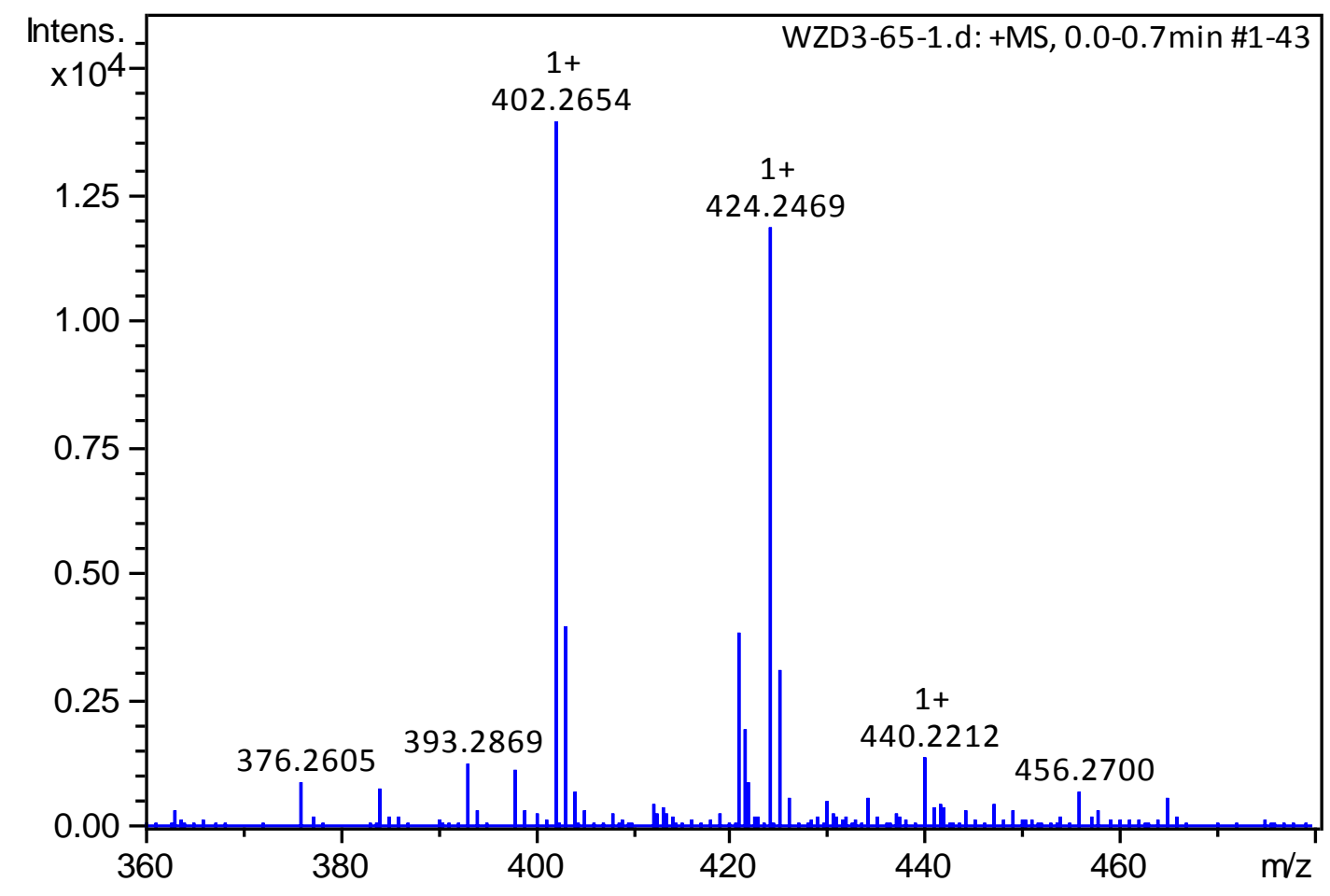

UV spectrum of compound 5

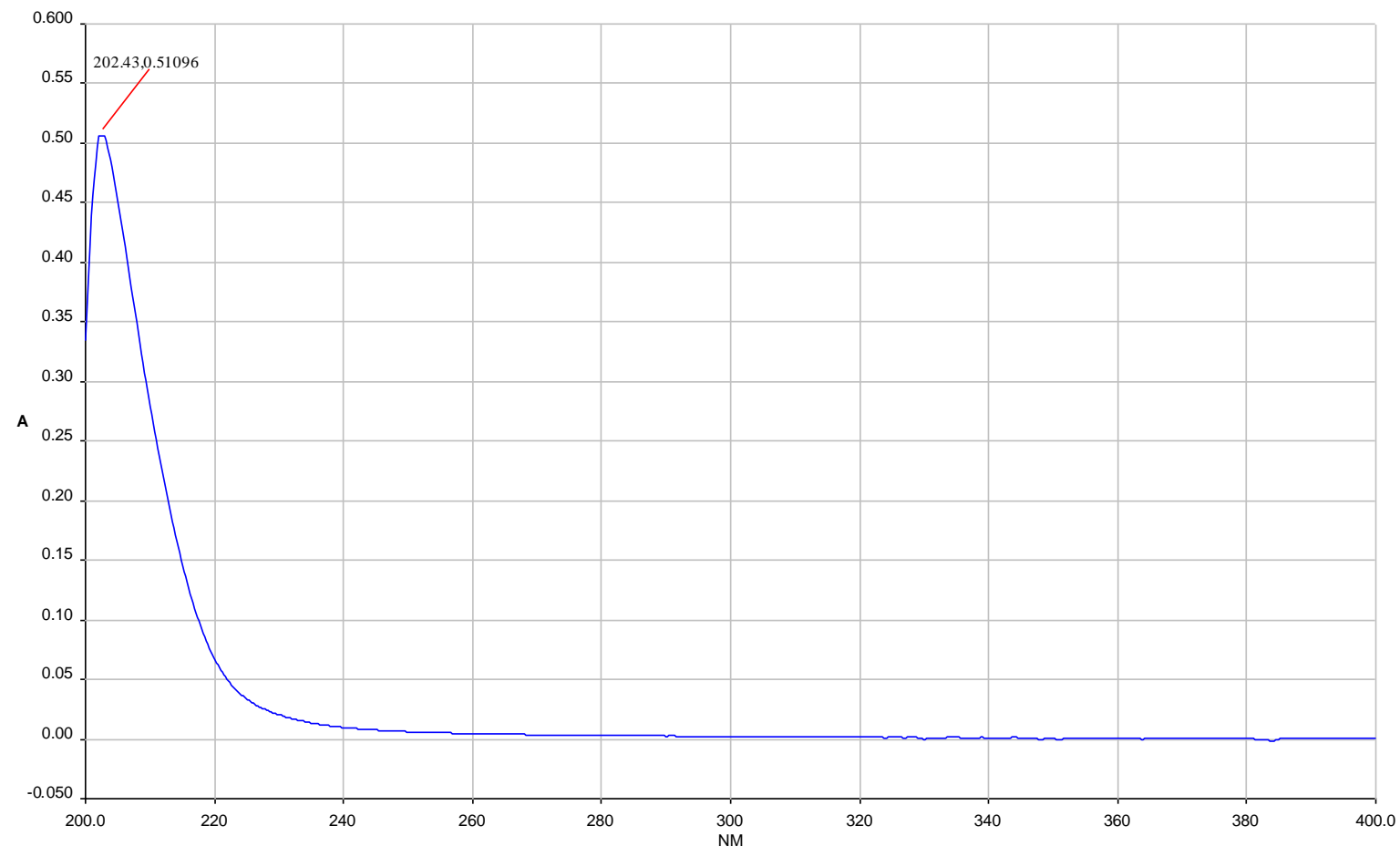


IR spectrum of compound 5

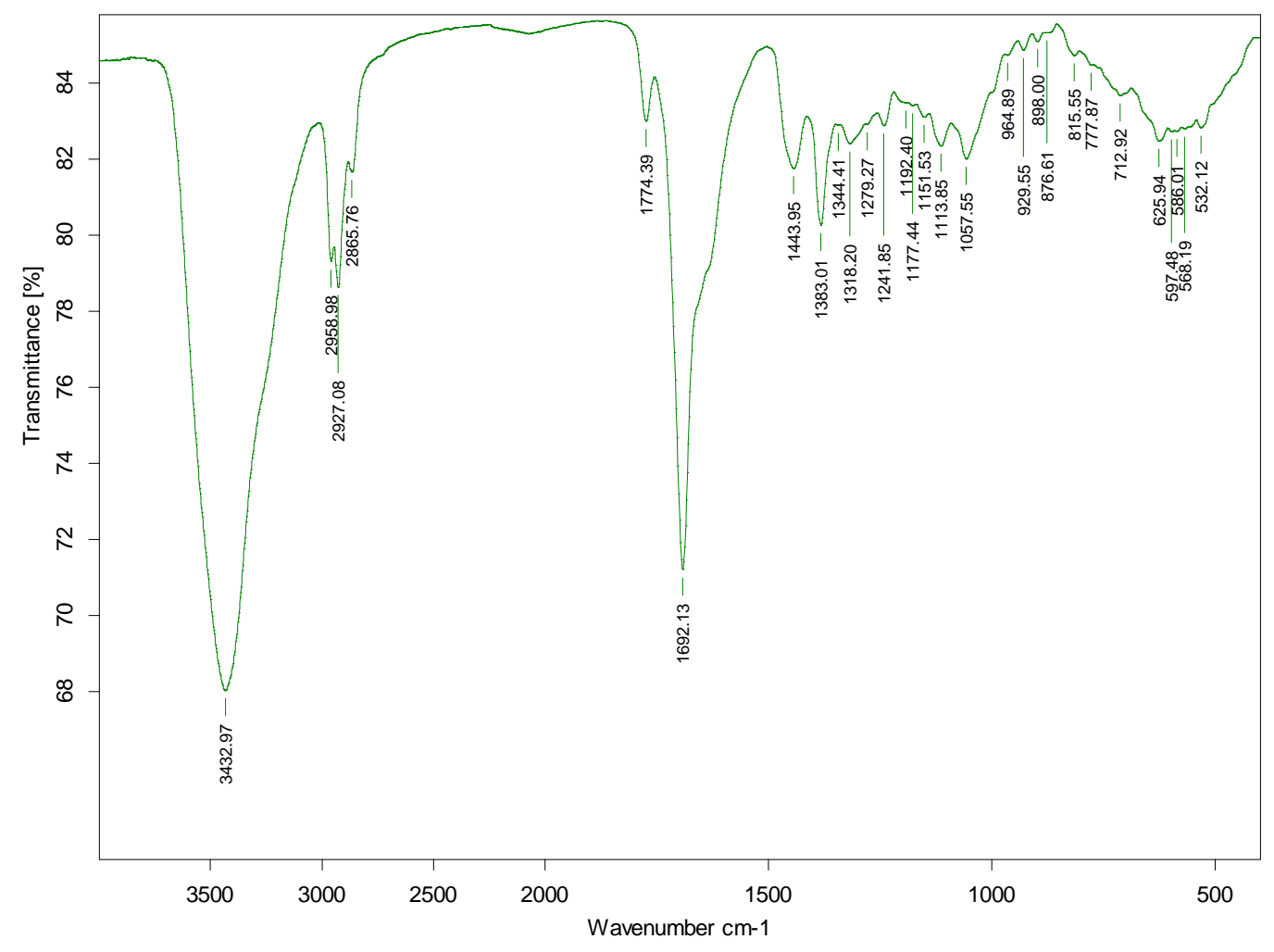

\section{${ }^{1}$ H NMR spectrum of compound 5}

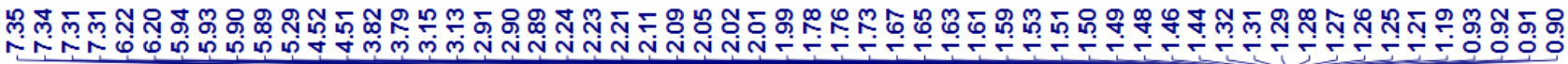

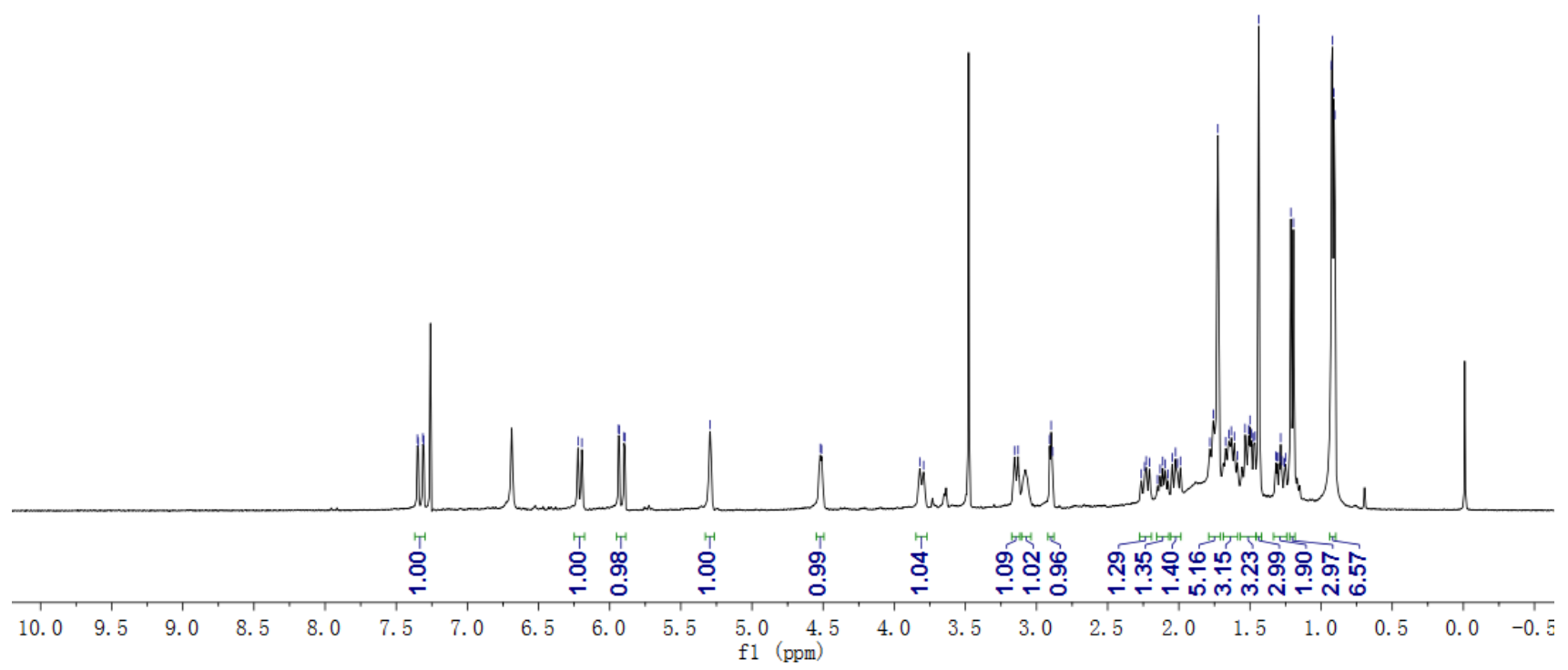


${ }^{13} \mathrm{C}$ NMR and DEPT spectra of compound 5
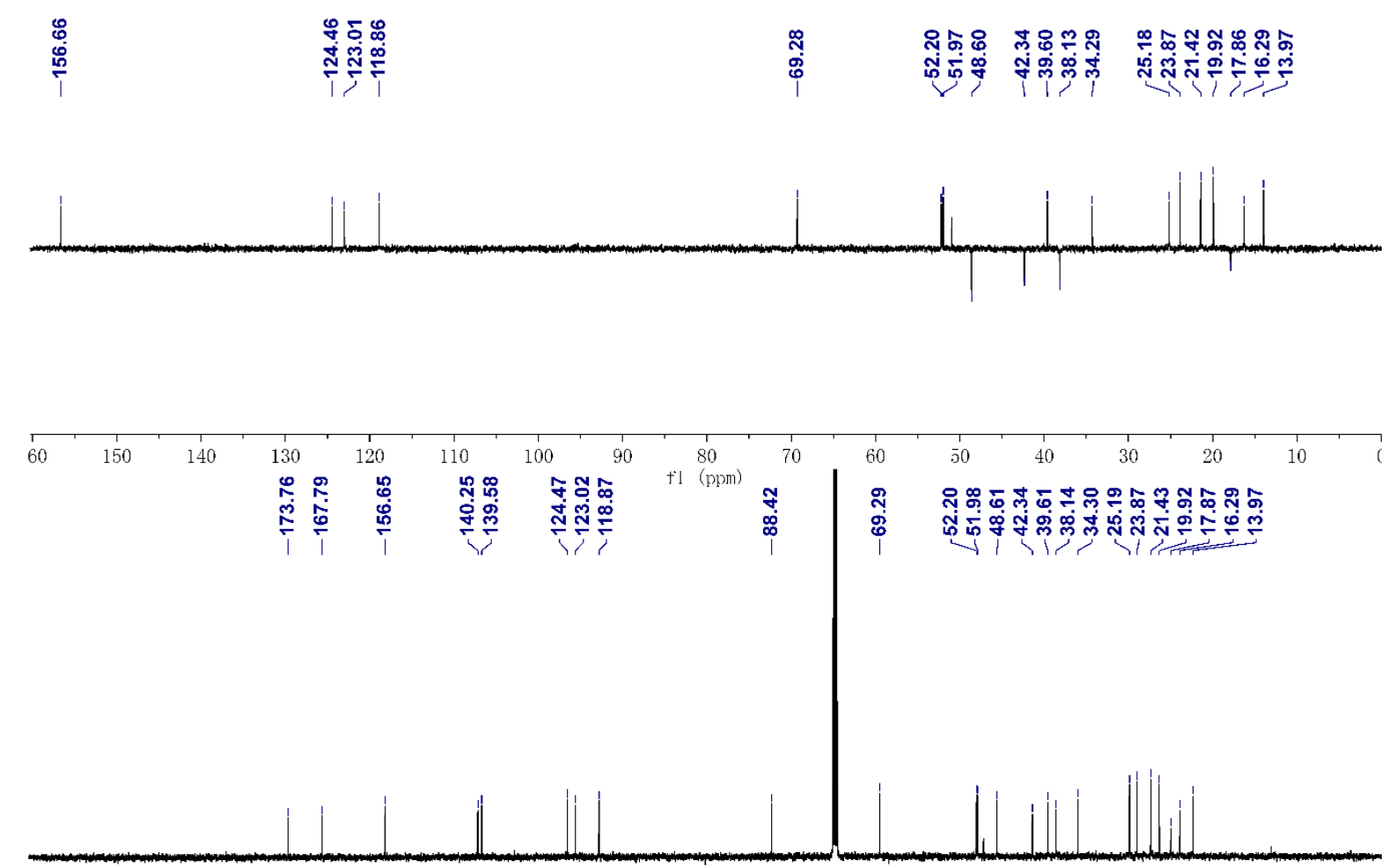

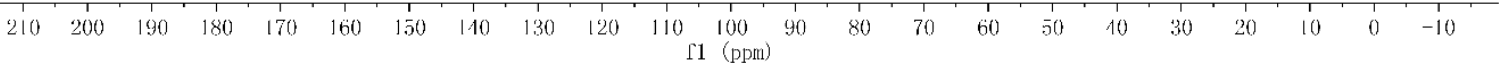

HSQC spectrum of compound 5

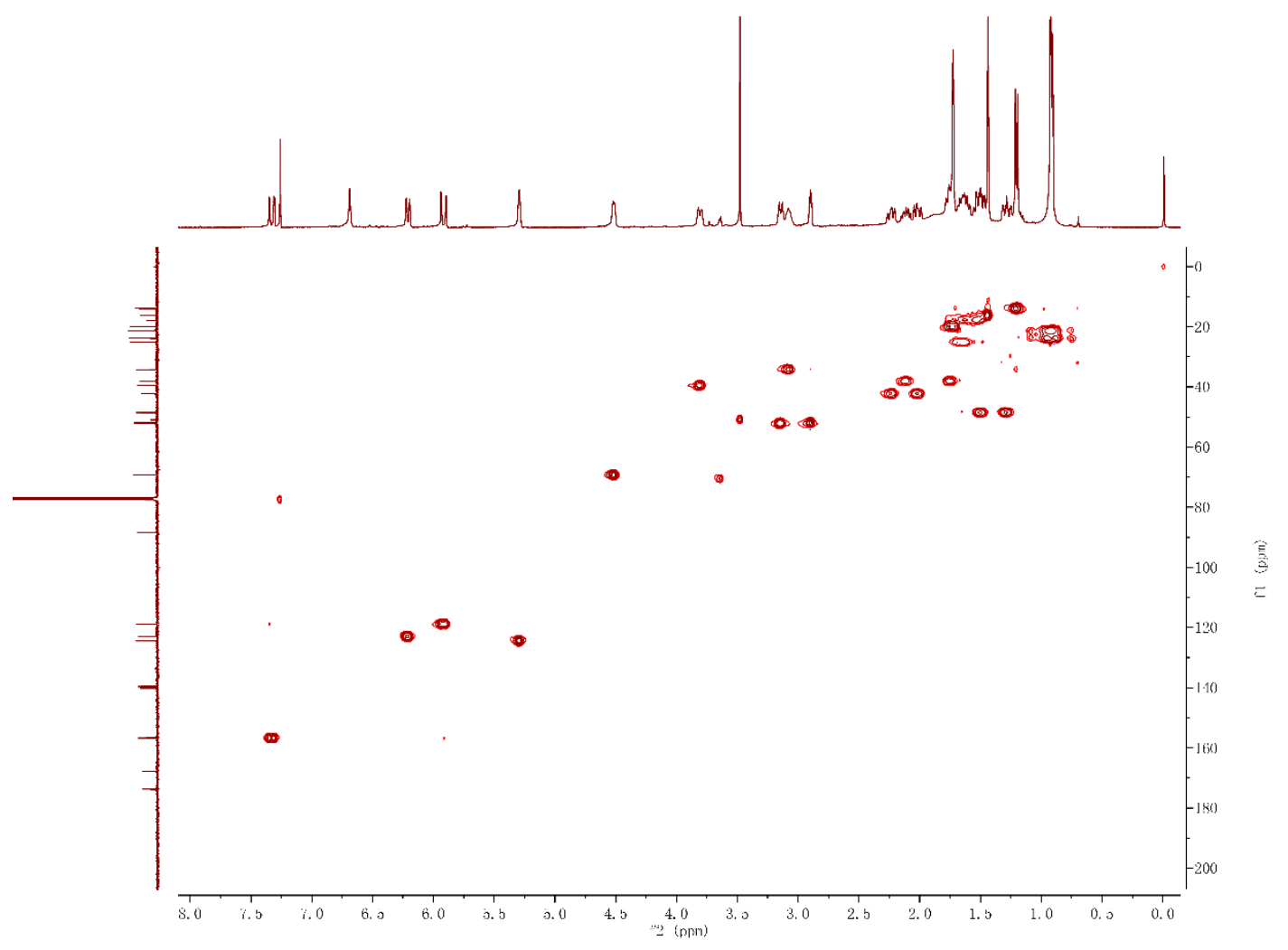




\section{HMBC spectrum of compound 5}

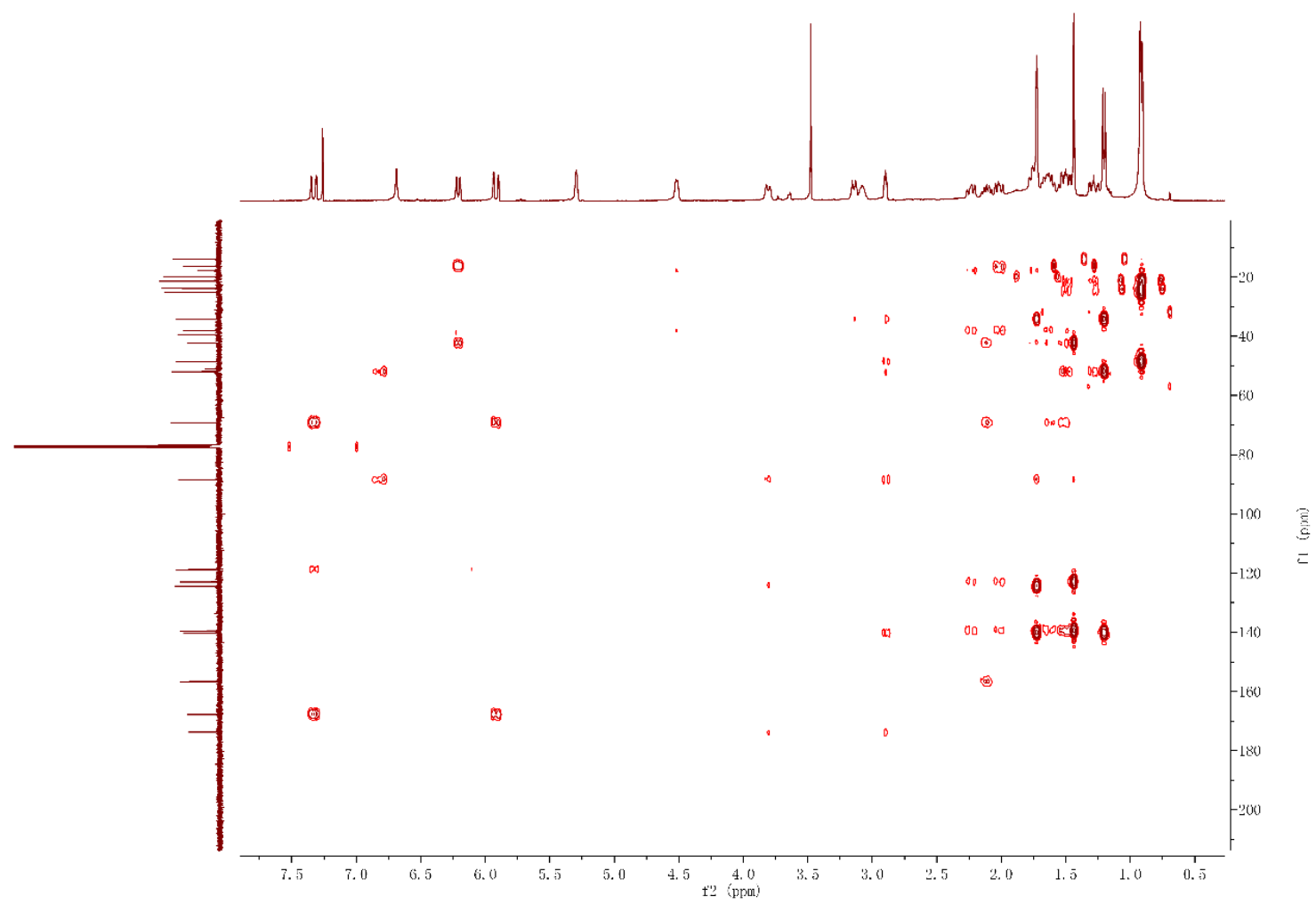

${ }^{1} \mathrm{H}^{-1} \mathrm{H}$ COSY spectrum of compound 5

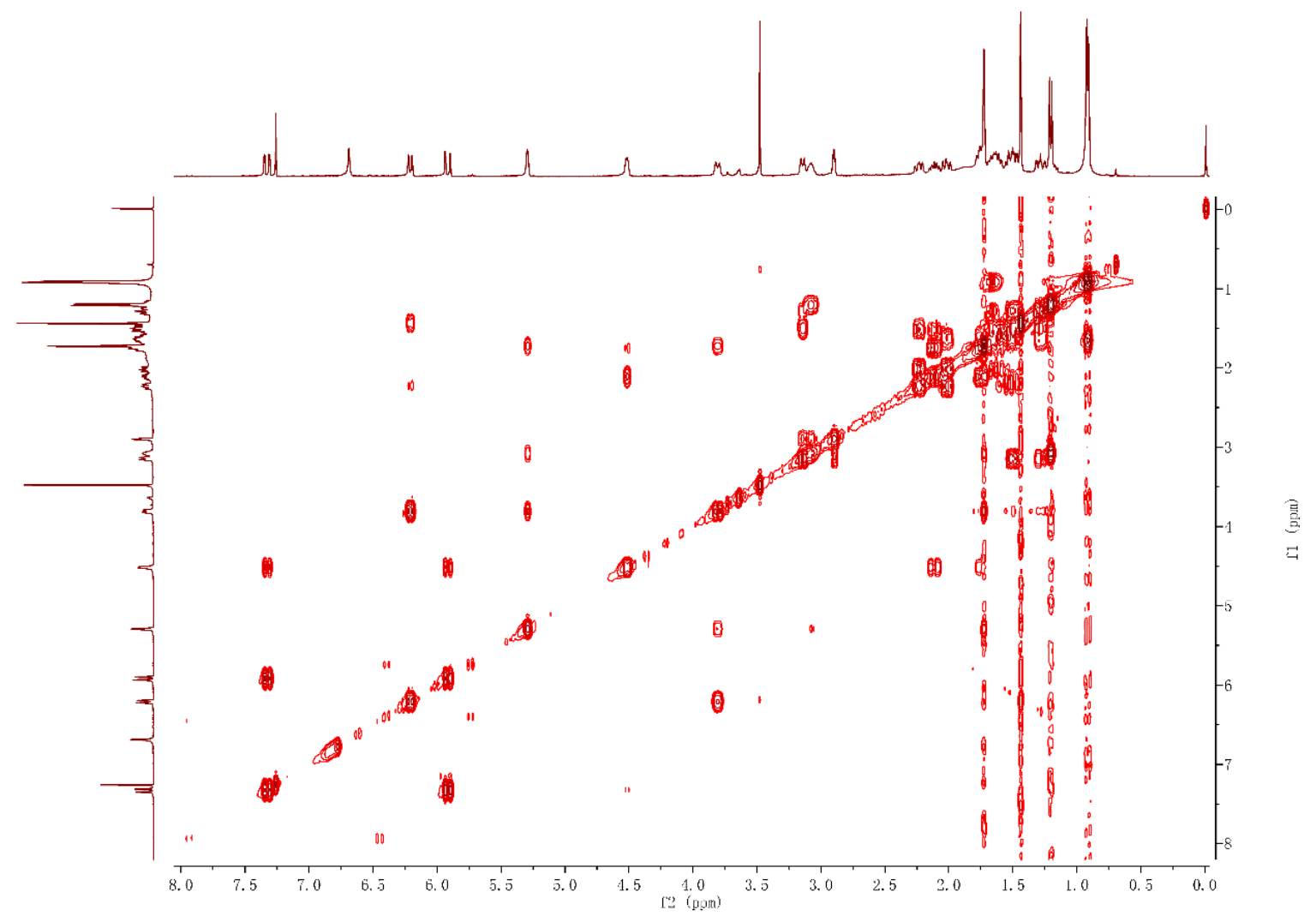




\section{NOESY spectrum of compound 5}

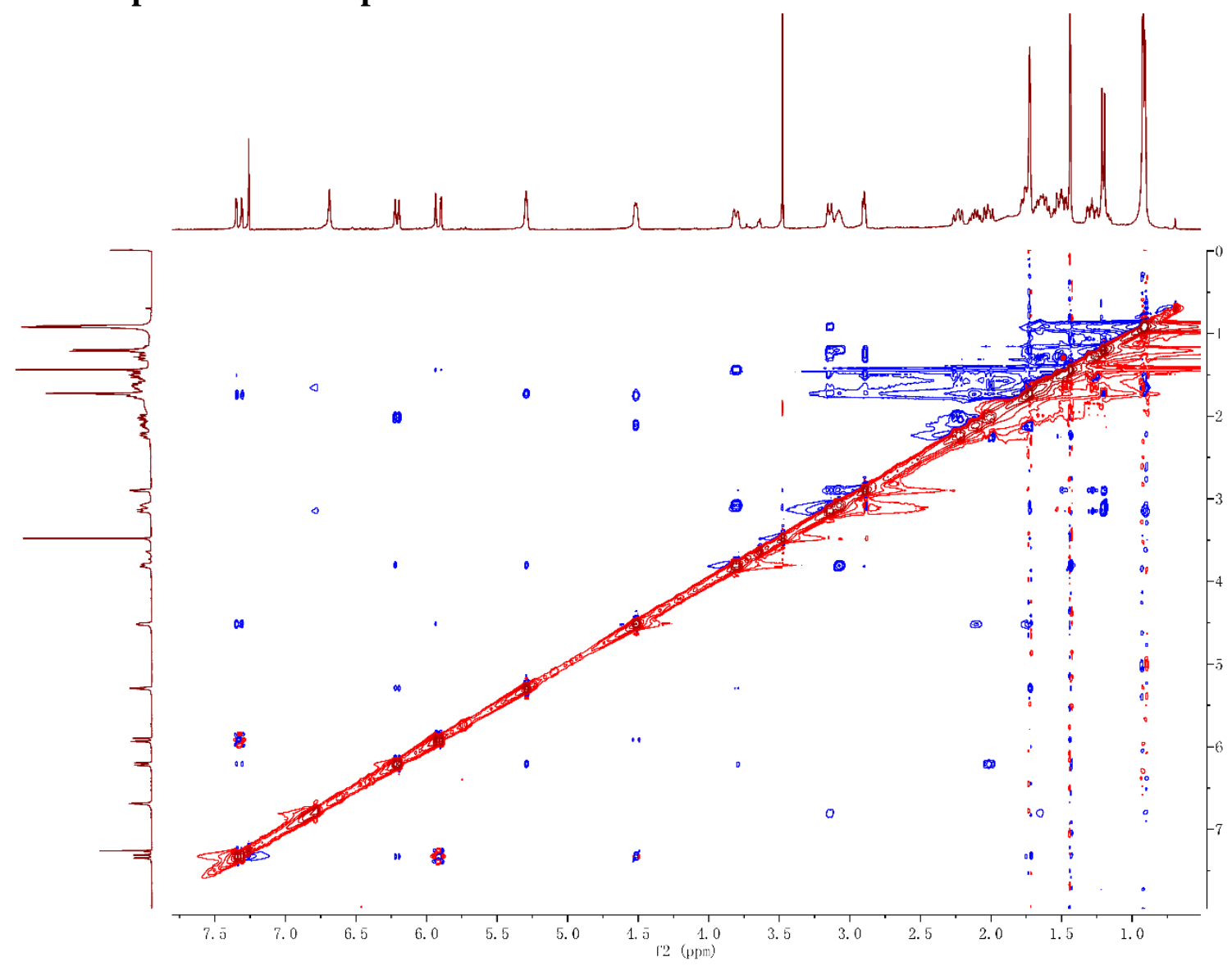

HRESIMS spectrum of compound 6

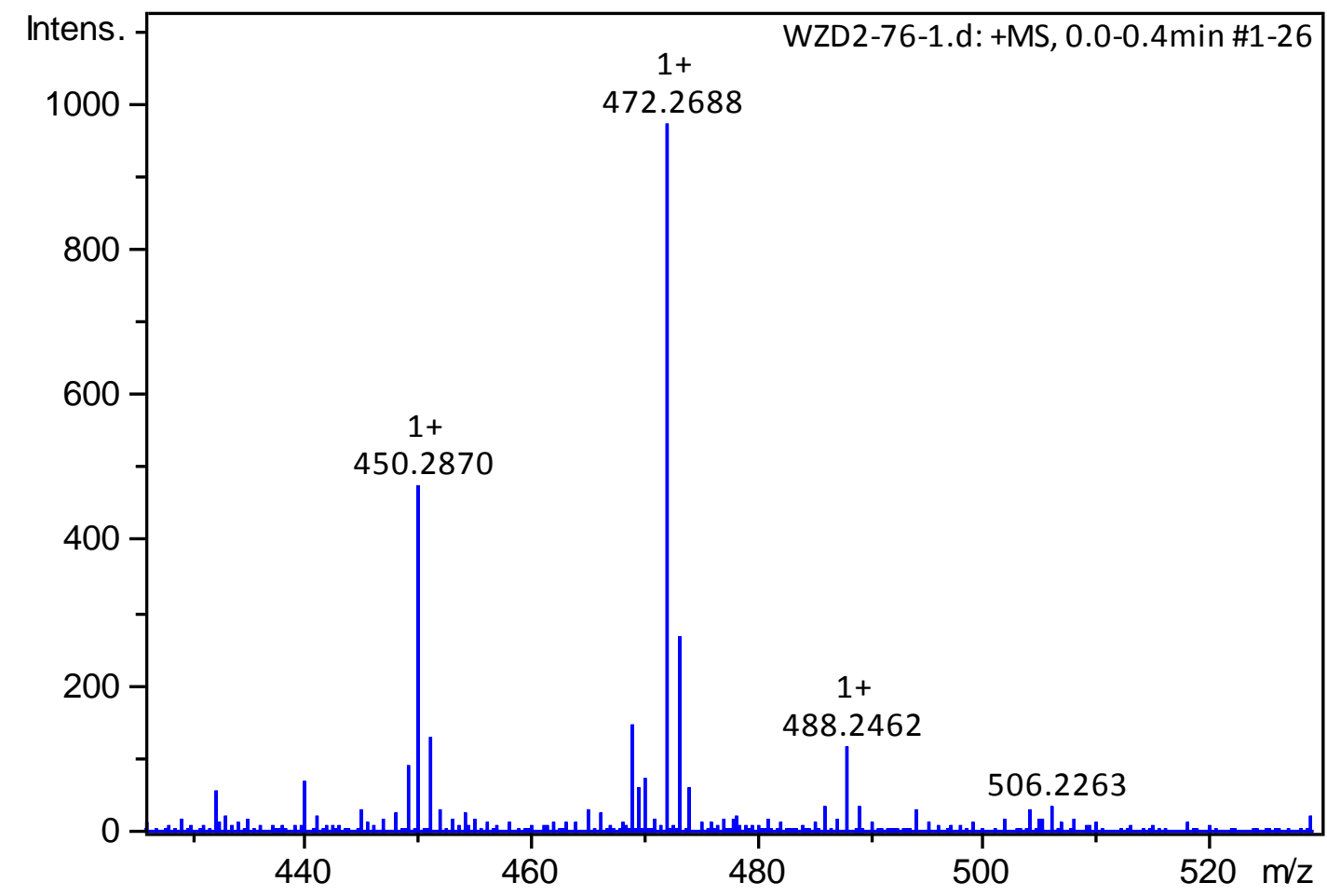


UV spectrum of compound 6

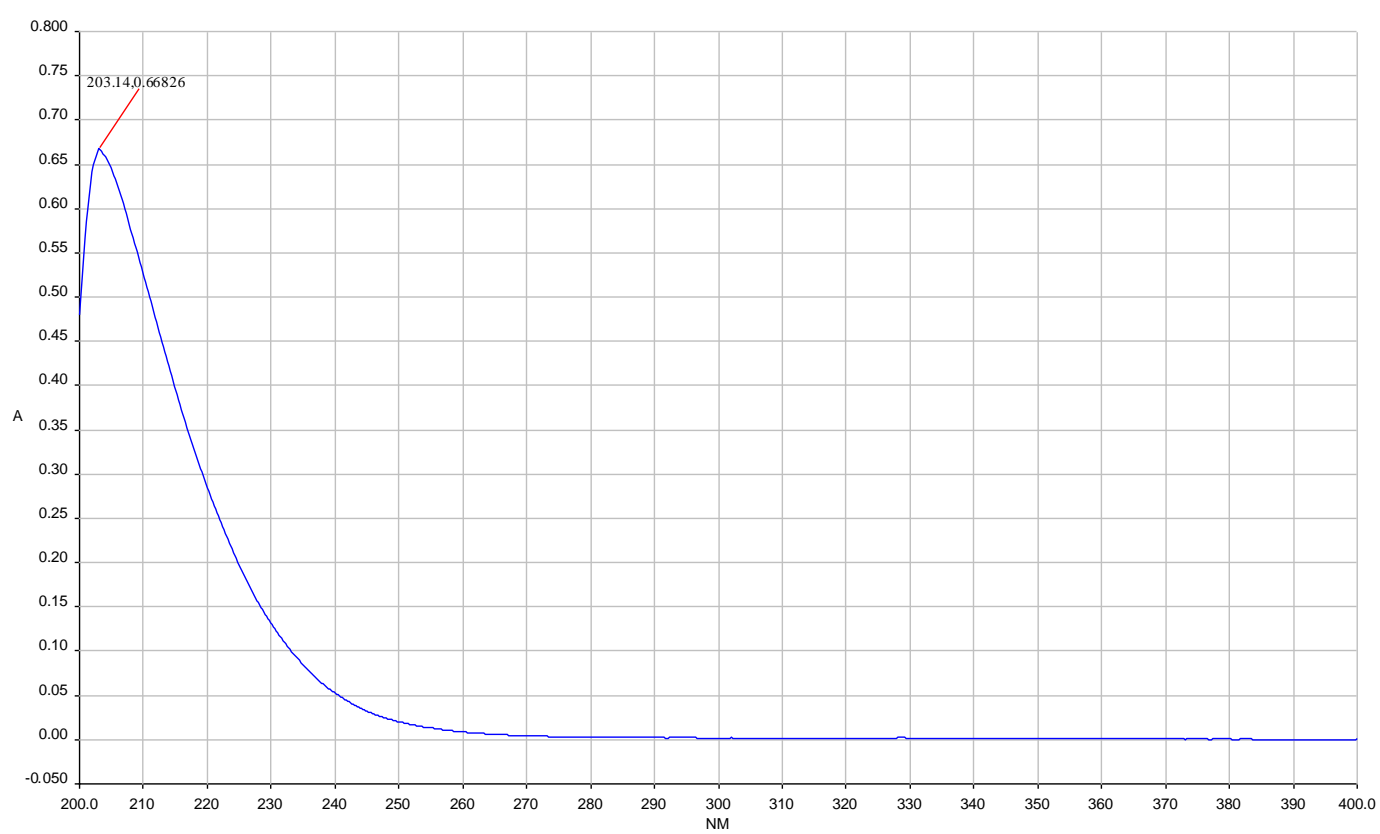

IR spectrum of compound 6

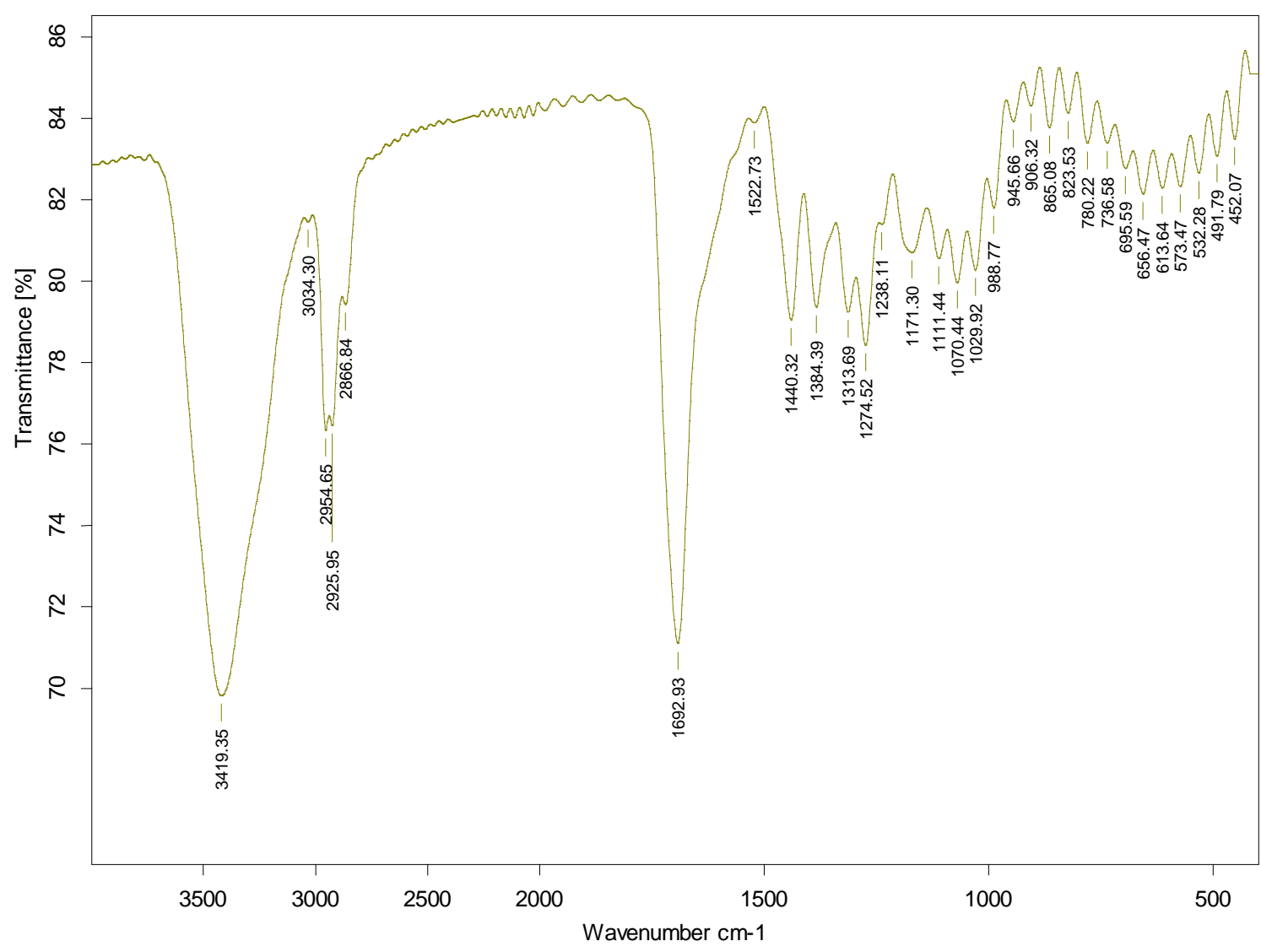




\section{${ }^{1} \mathrm{H}$ NMR spectrum of compound 6}

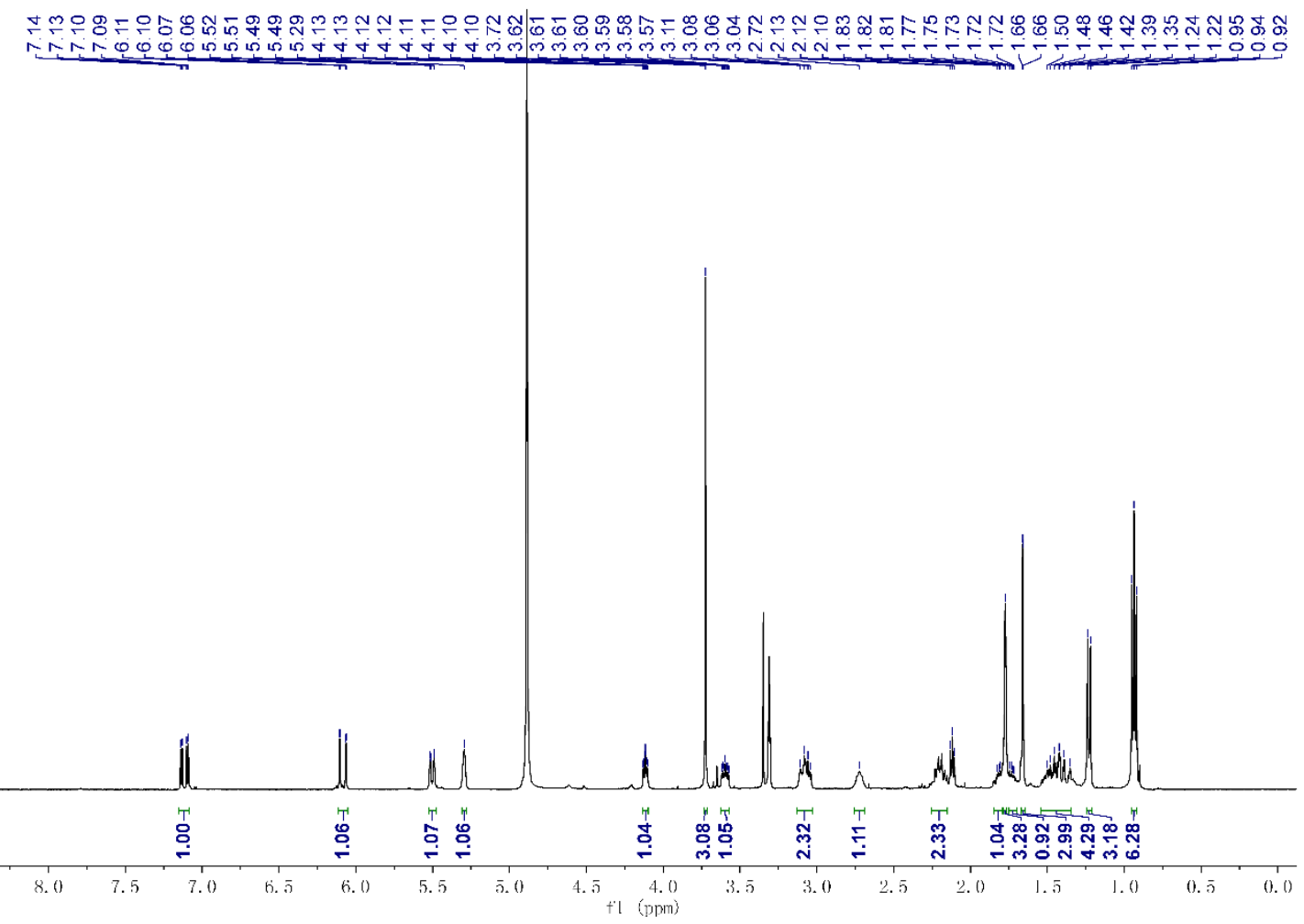

${ }^{13} \mathrm{C}$ NMR and DEPT spectra of compound 6
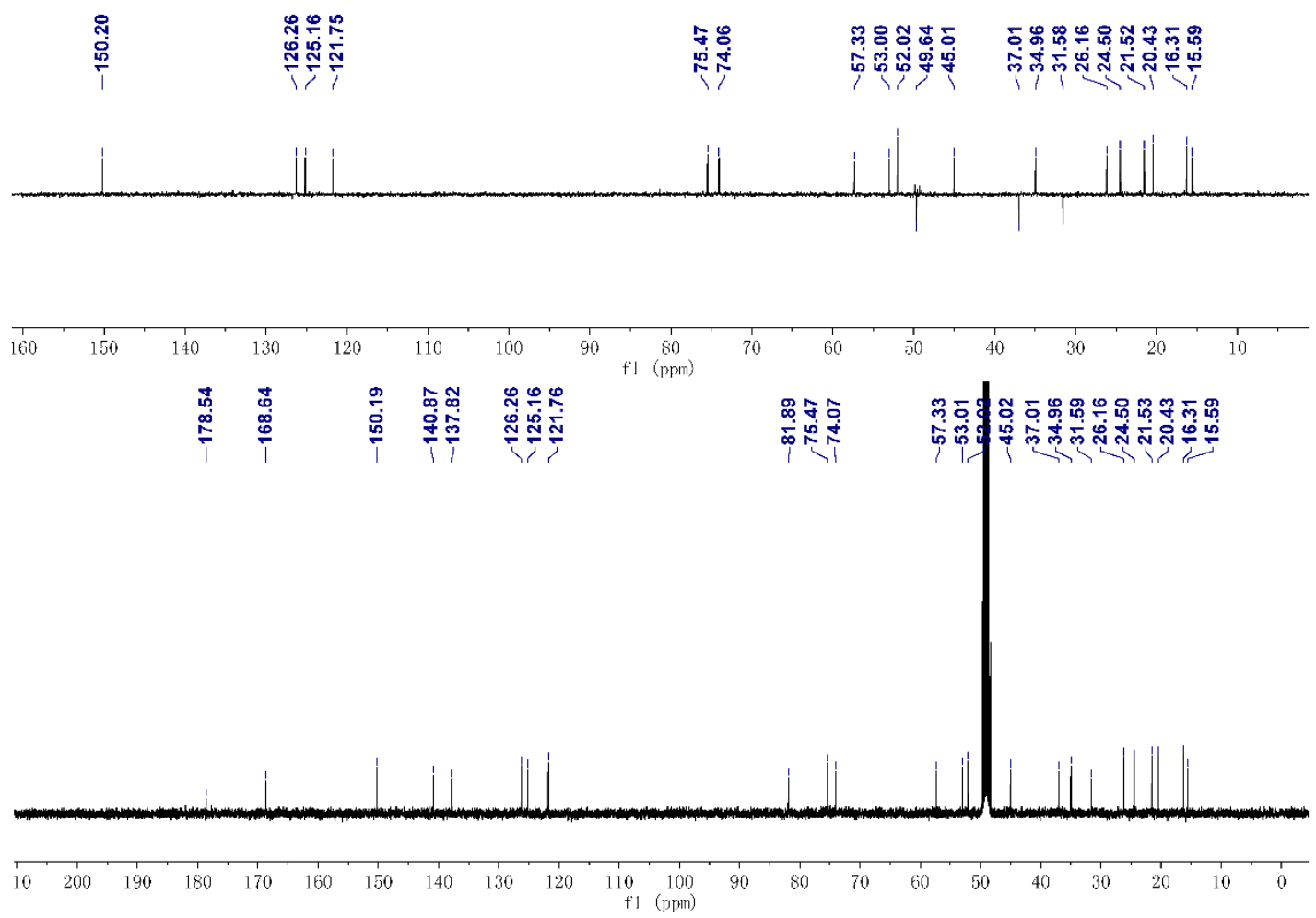
HSQC spectrum of compound 6

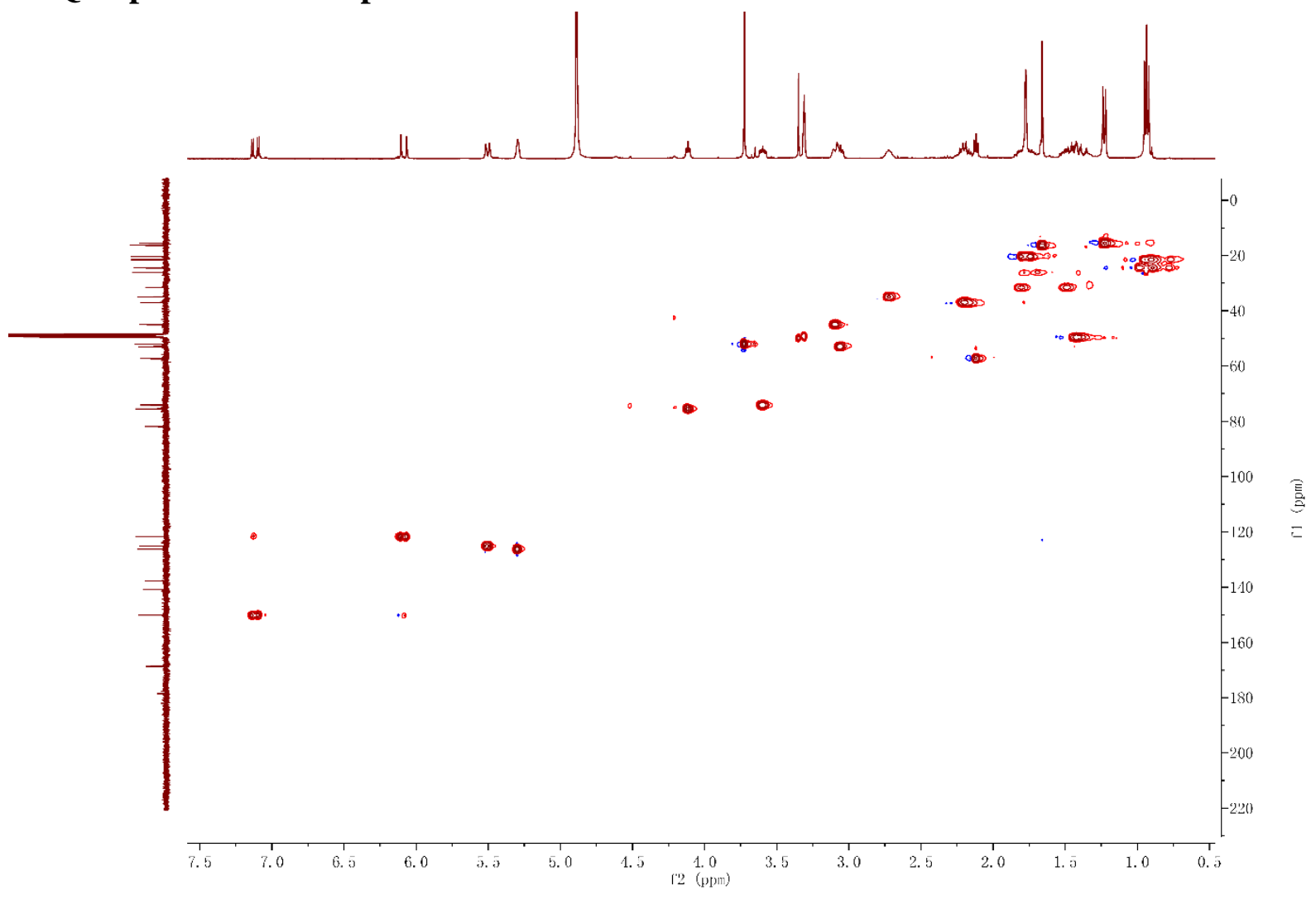

HMBC spectrum of compound 6

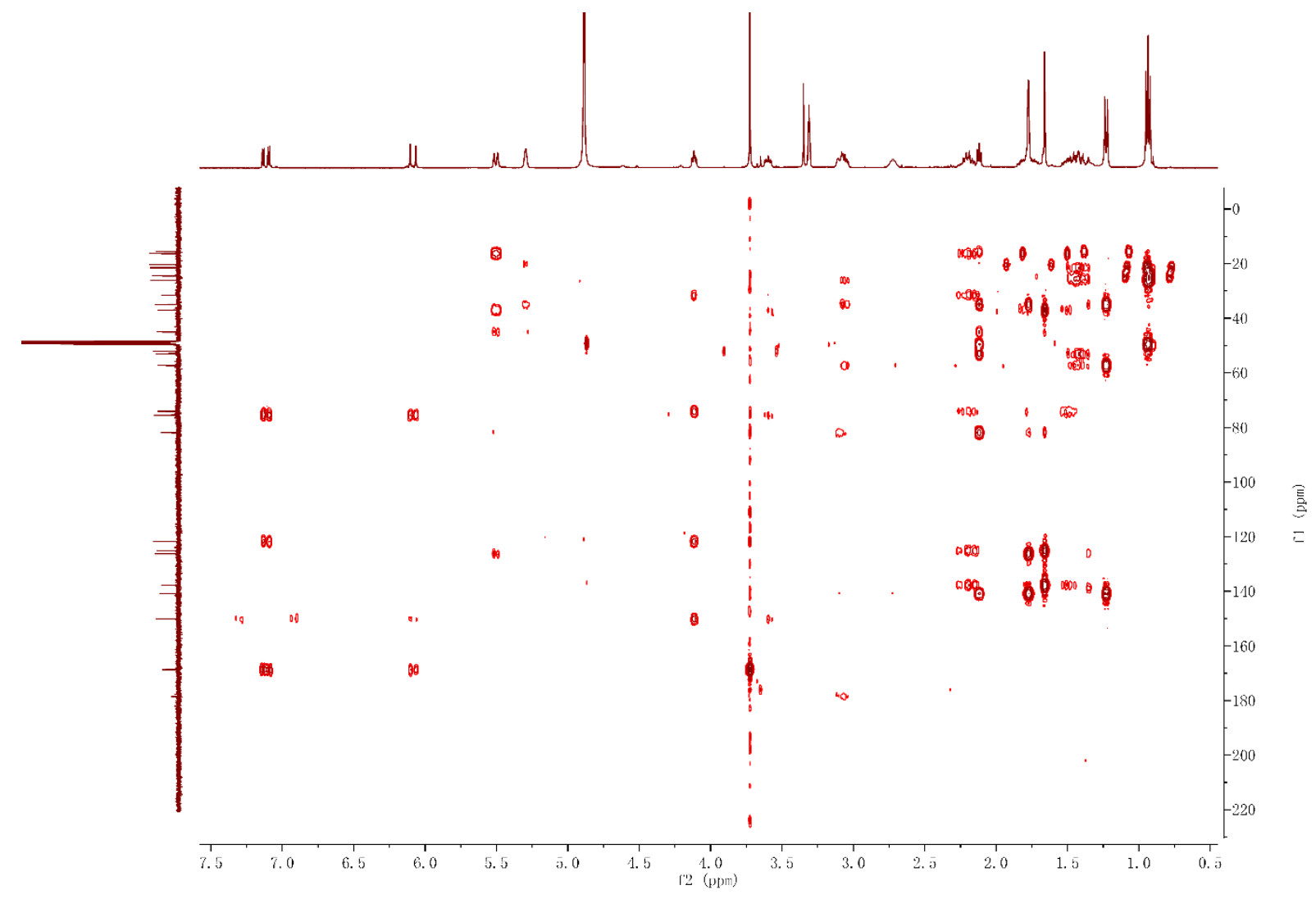




\section{${ }^{1} \mathrm{H}^{-1} \mathrm{H}$ COSY spectrum of compound 6}

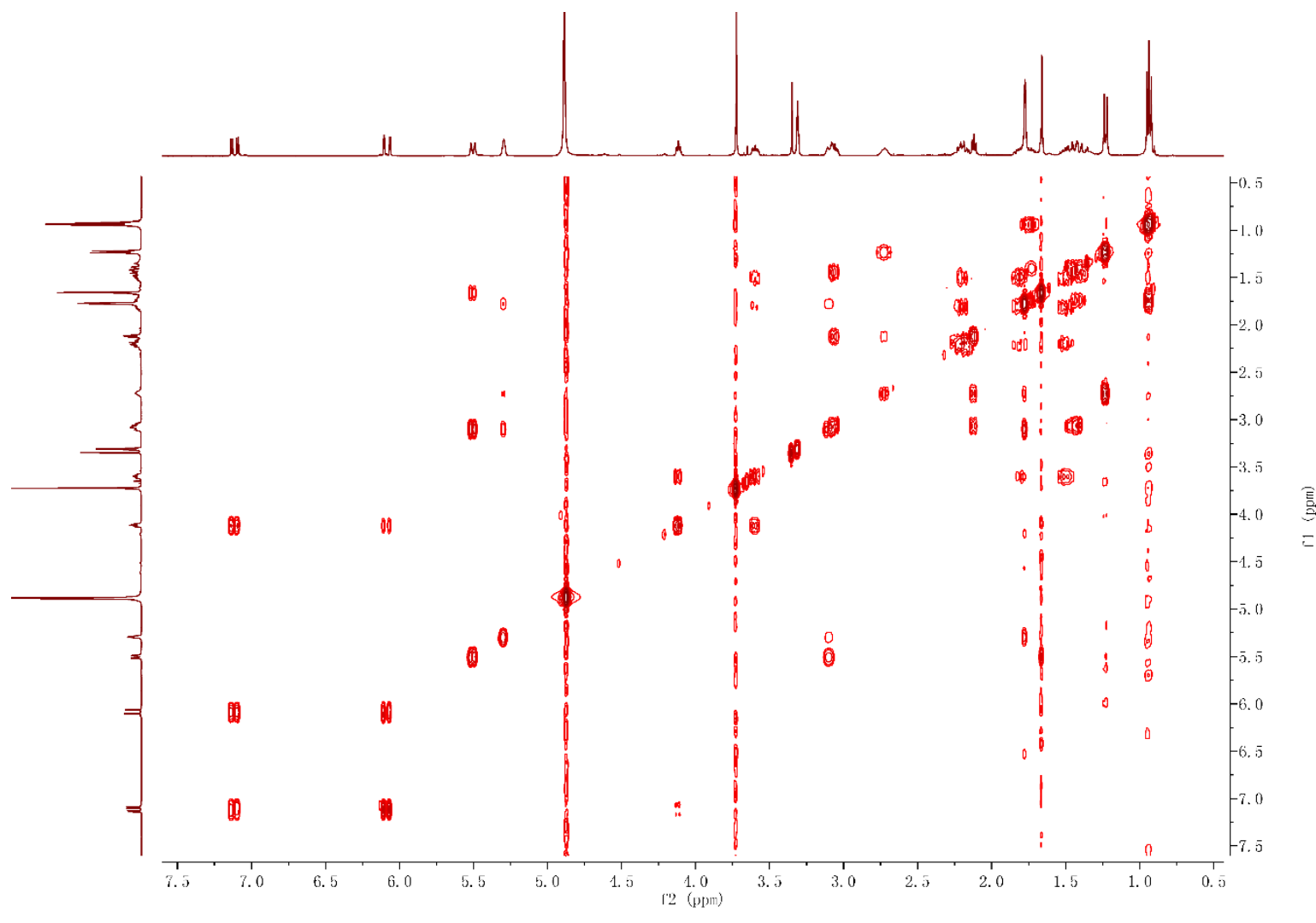

NOESY spectrum of compound 6

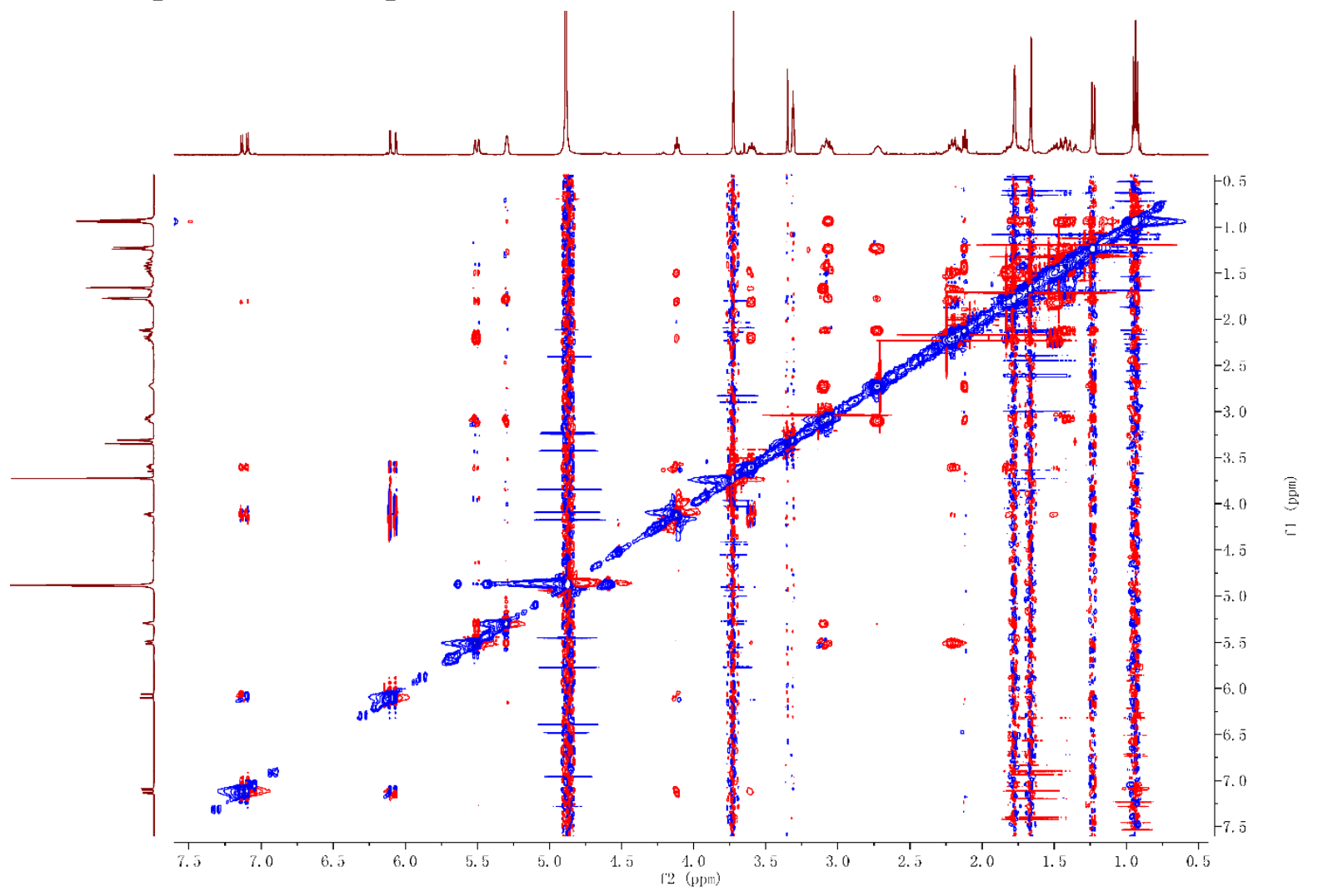




\section{HRESIMS spectrum of compound 7}

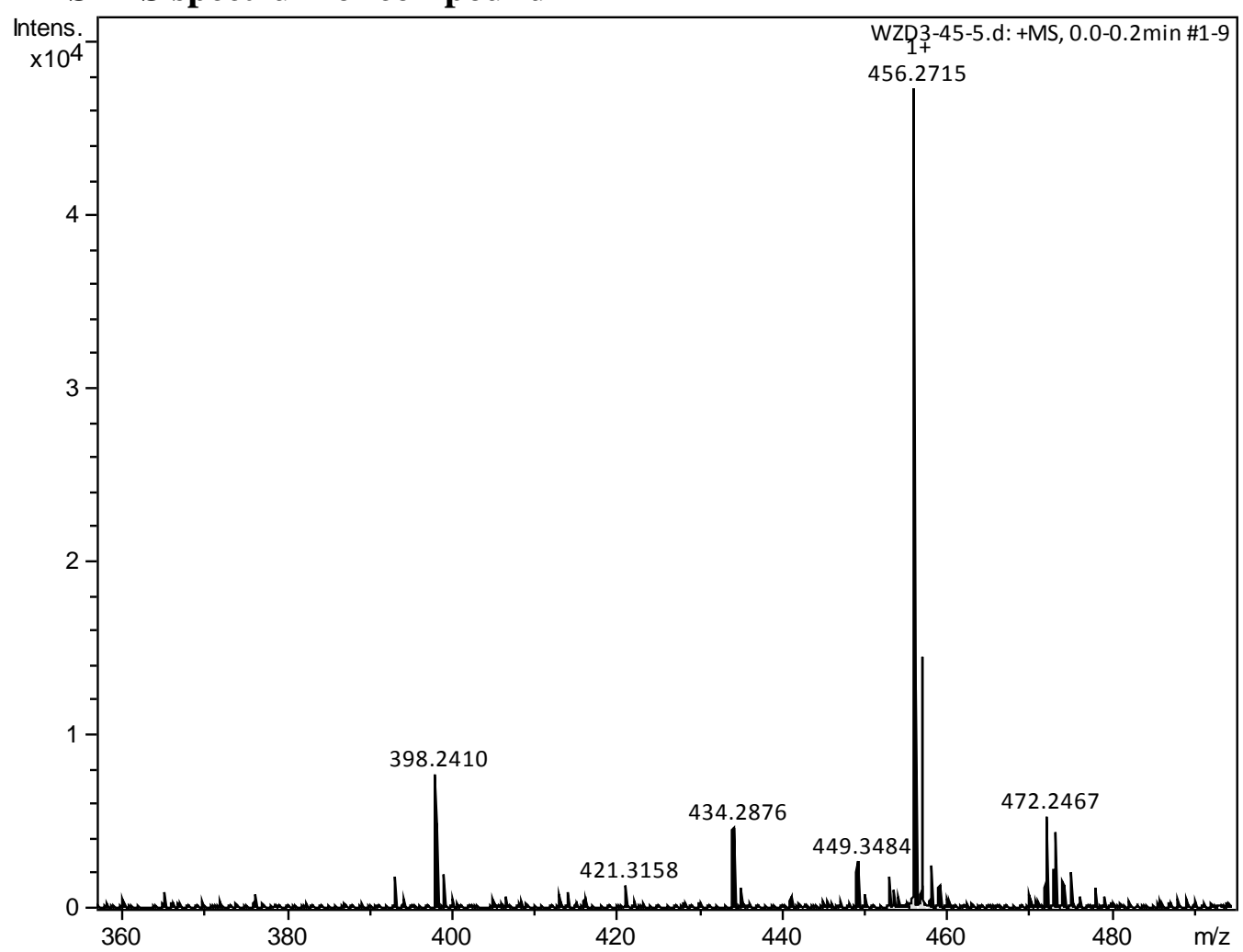

UV spectrum of compound 7

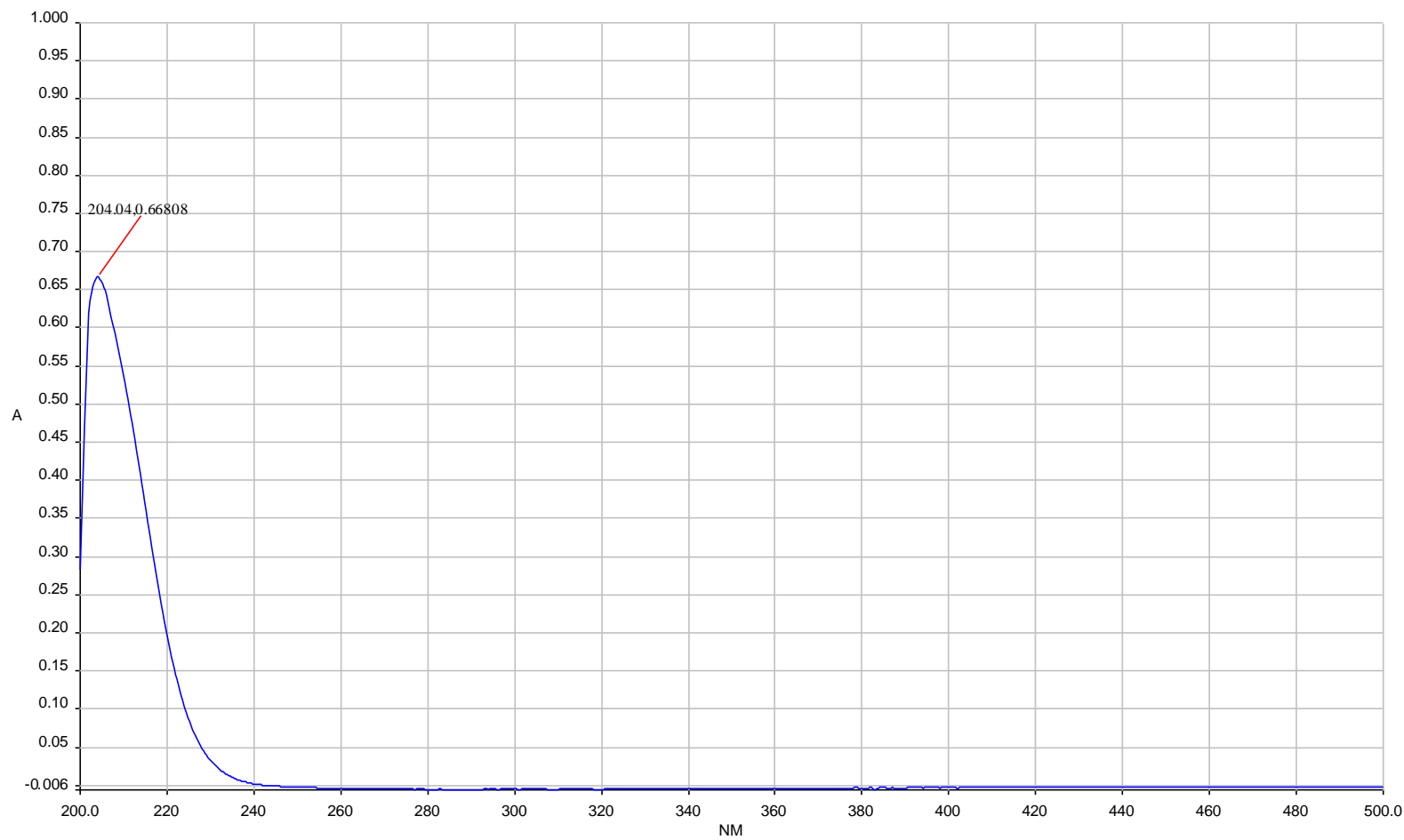


IR spectrum of compound 7

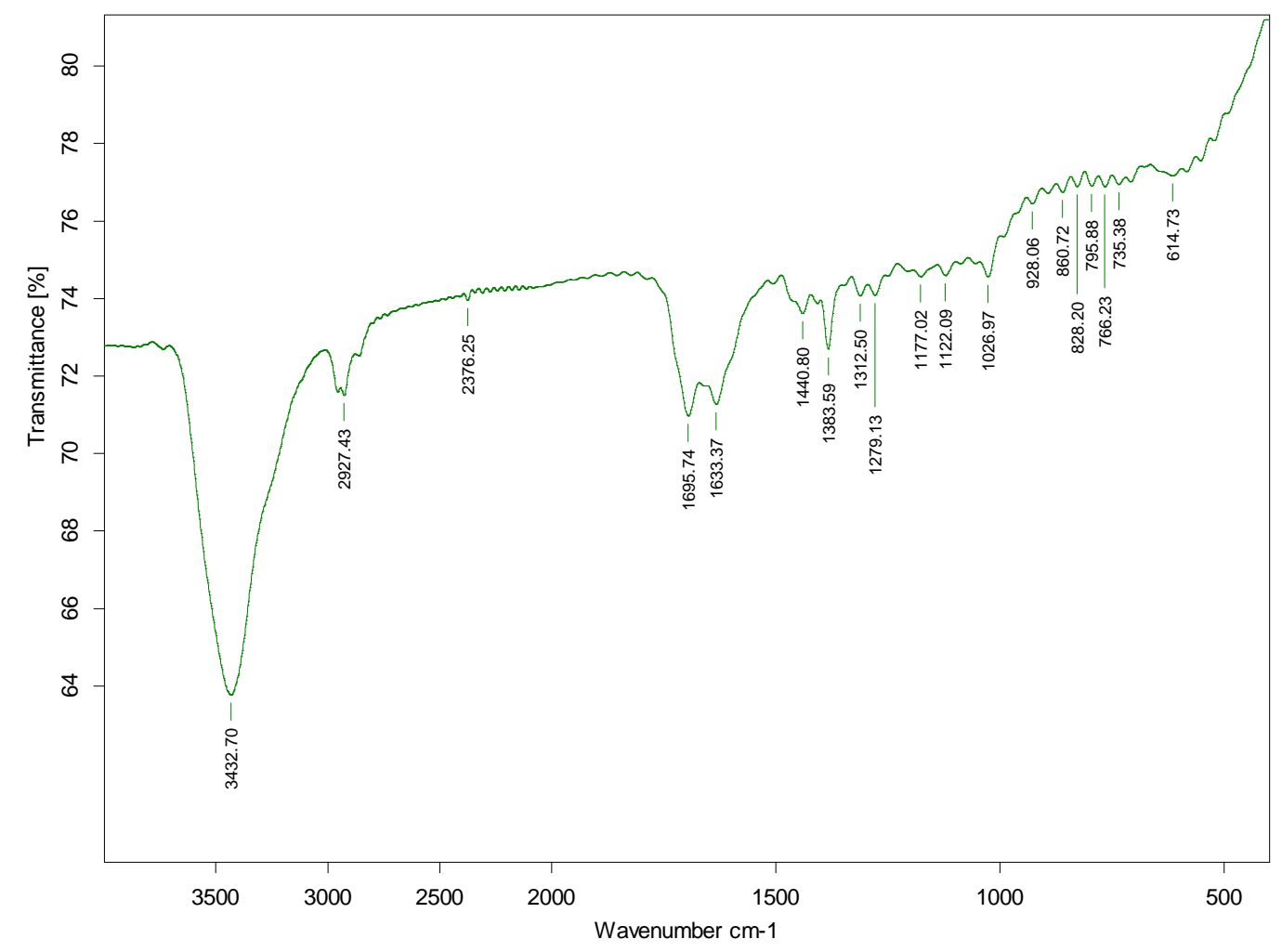

\section{${ }^{1} \mathrm{H}$ NMR spectrum of compound 7}

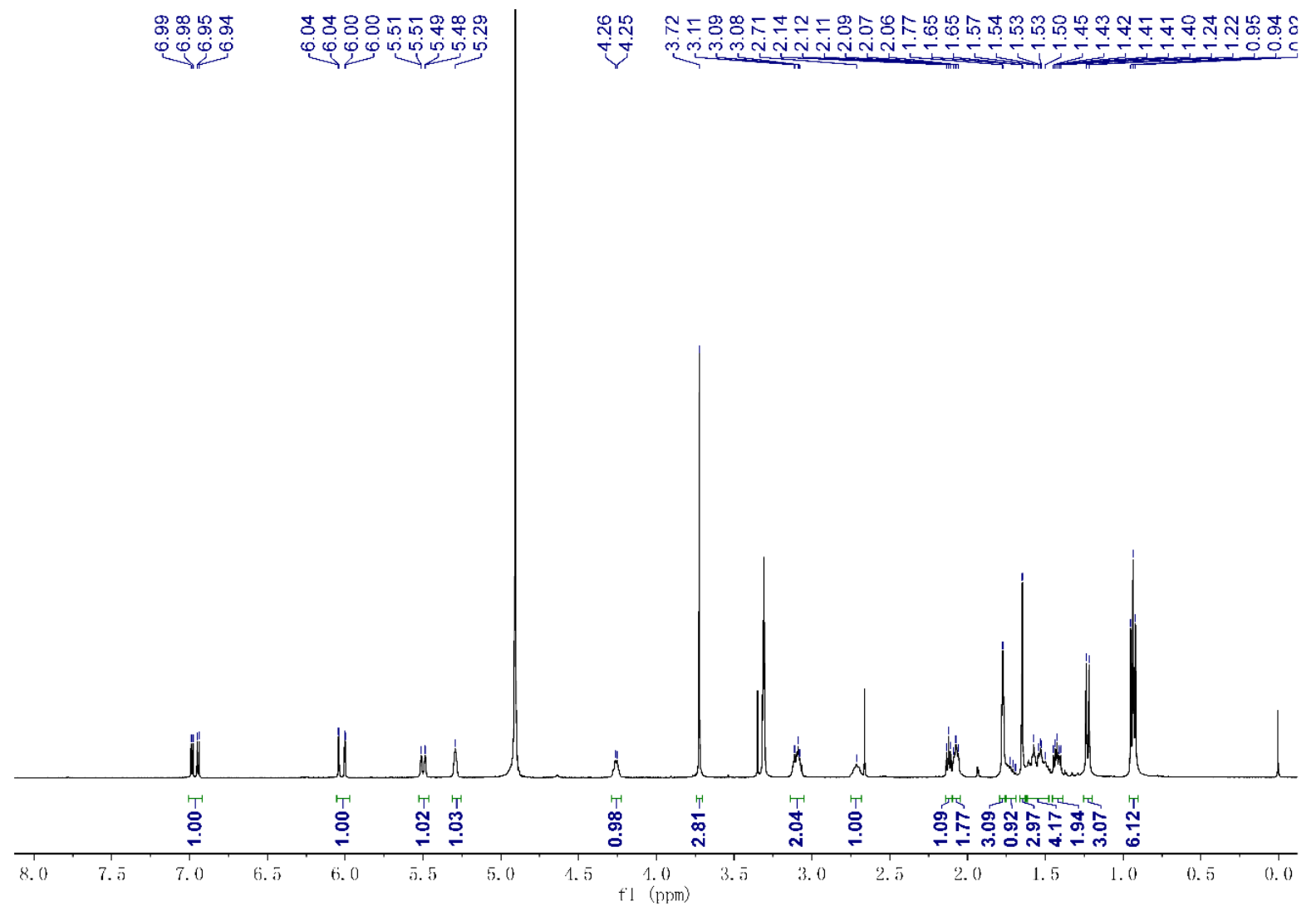


${ }^{13} \mathrm{C}$ NMR and DEPT spectra of compound 7
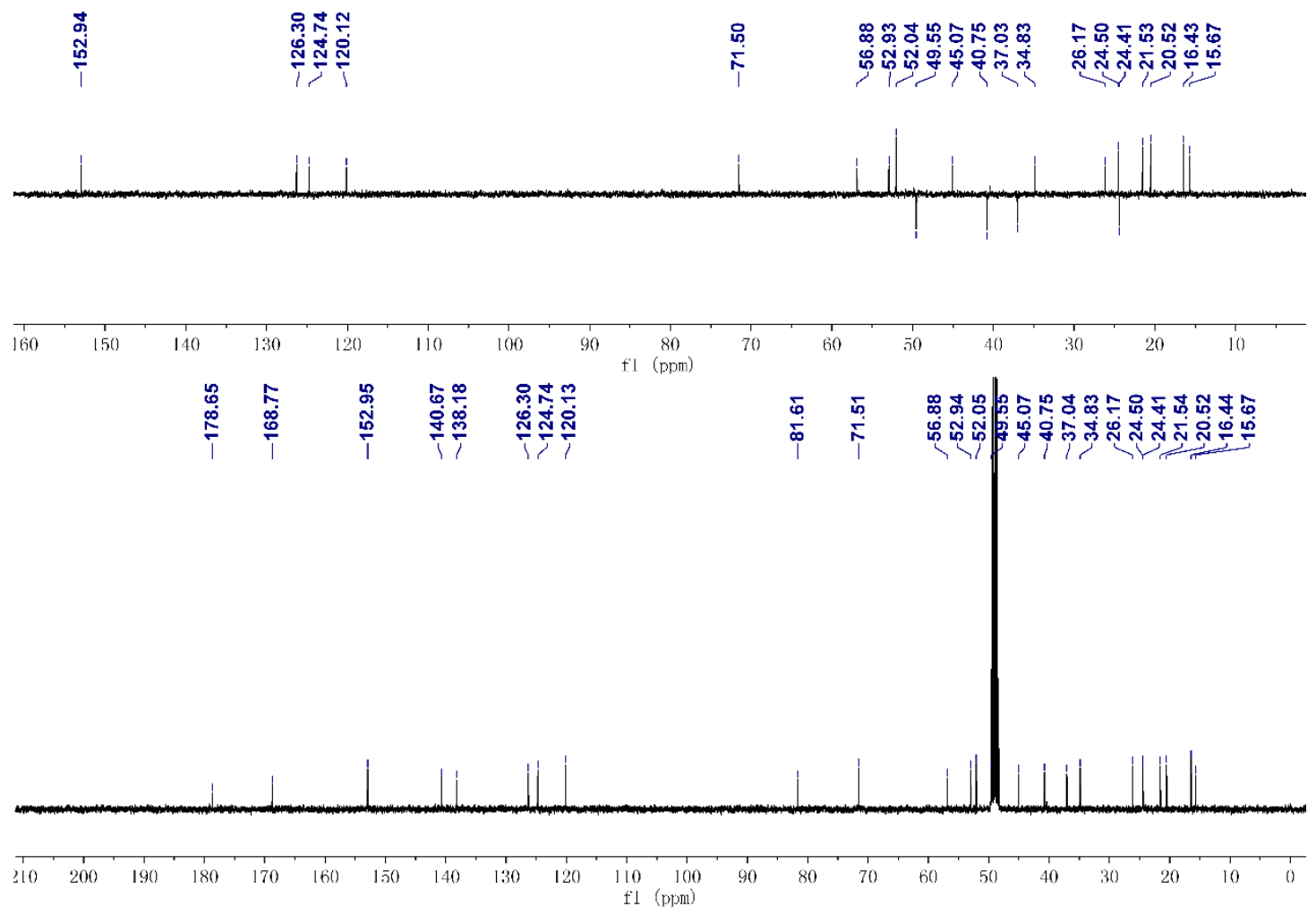

HSQC spectrum of compound 7

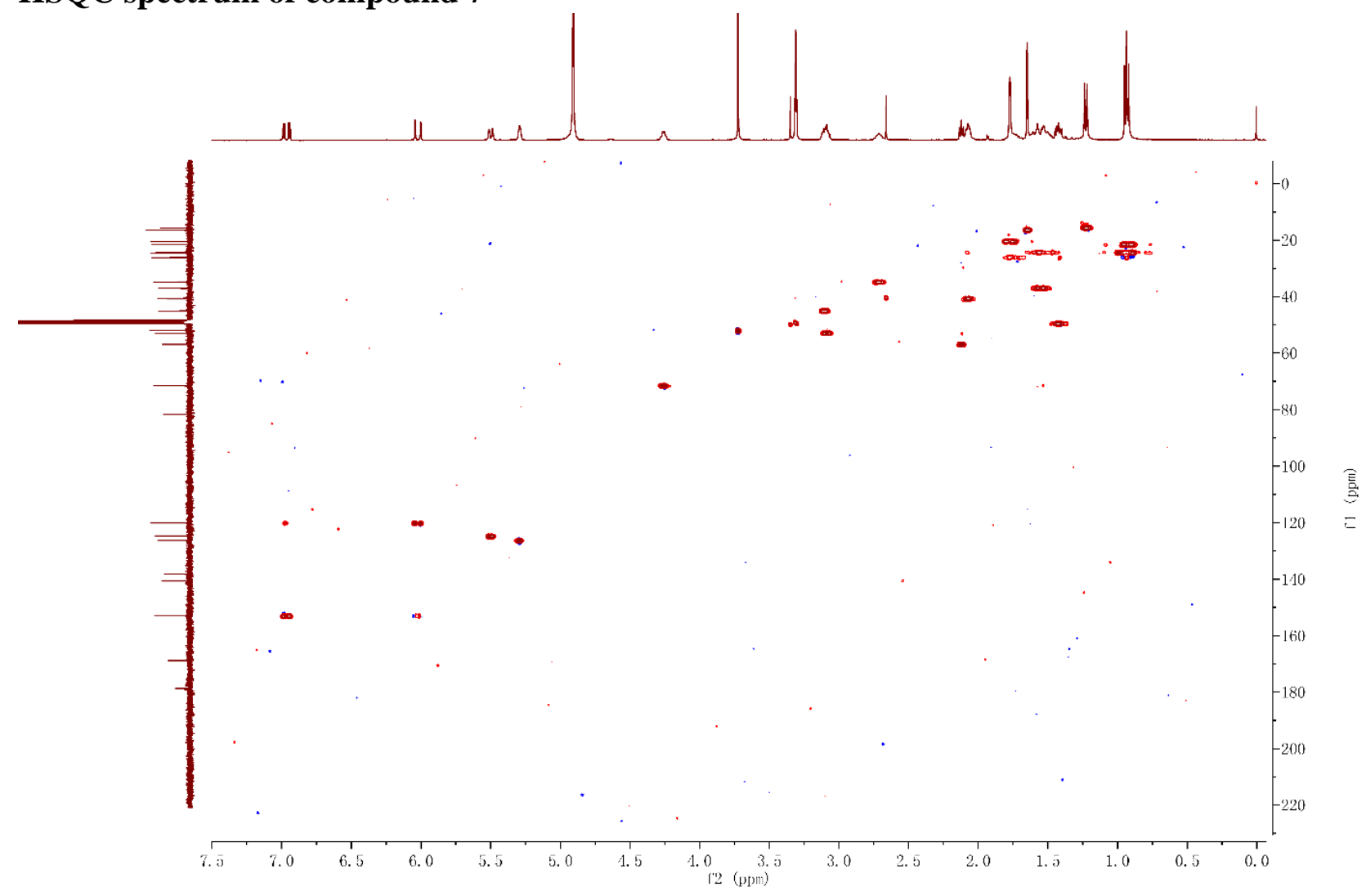


HMBC spectrum of compound 7

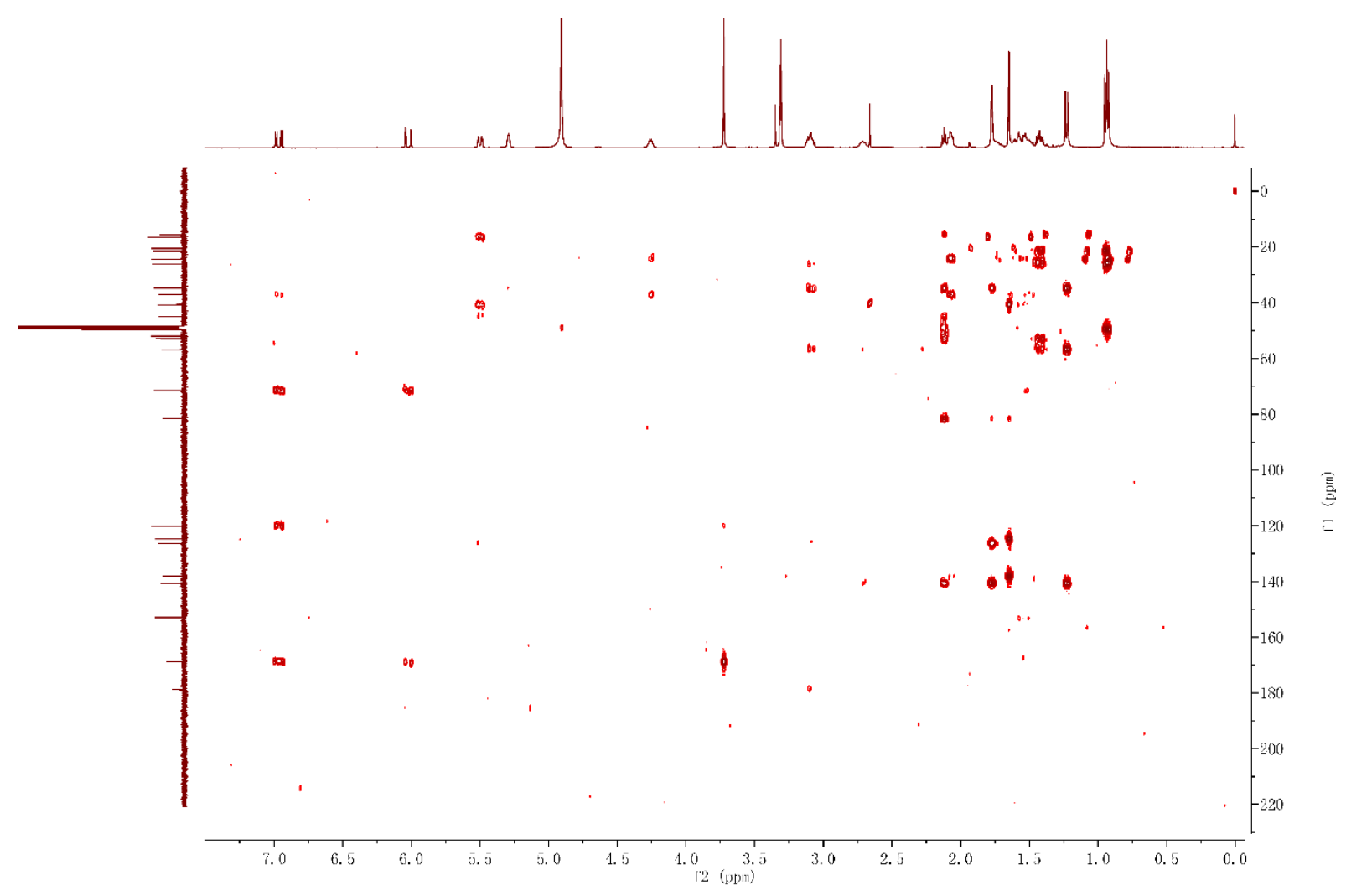

${ }^{1} \mathrm{H}-{ }^{1} \mathrm{H}$ COSY spectrum of compound 7

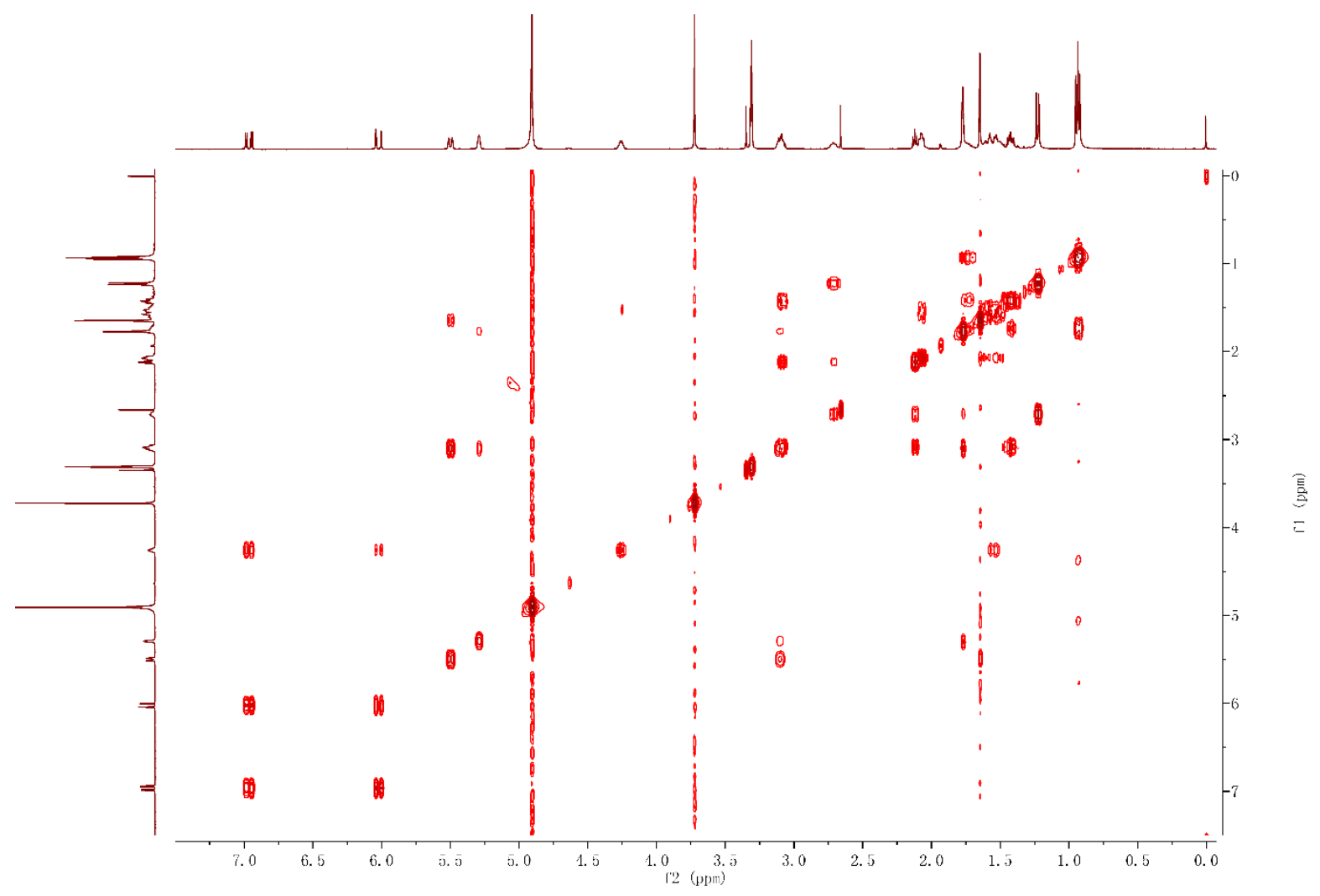

S47 


\section{NOESY spectrum of compound 7}

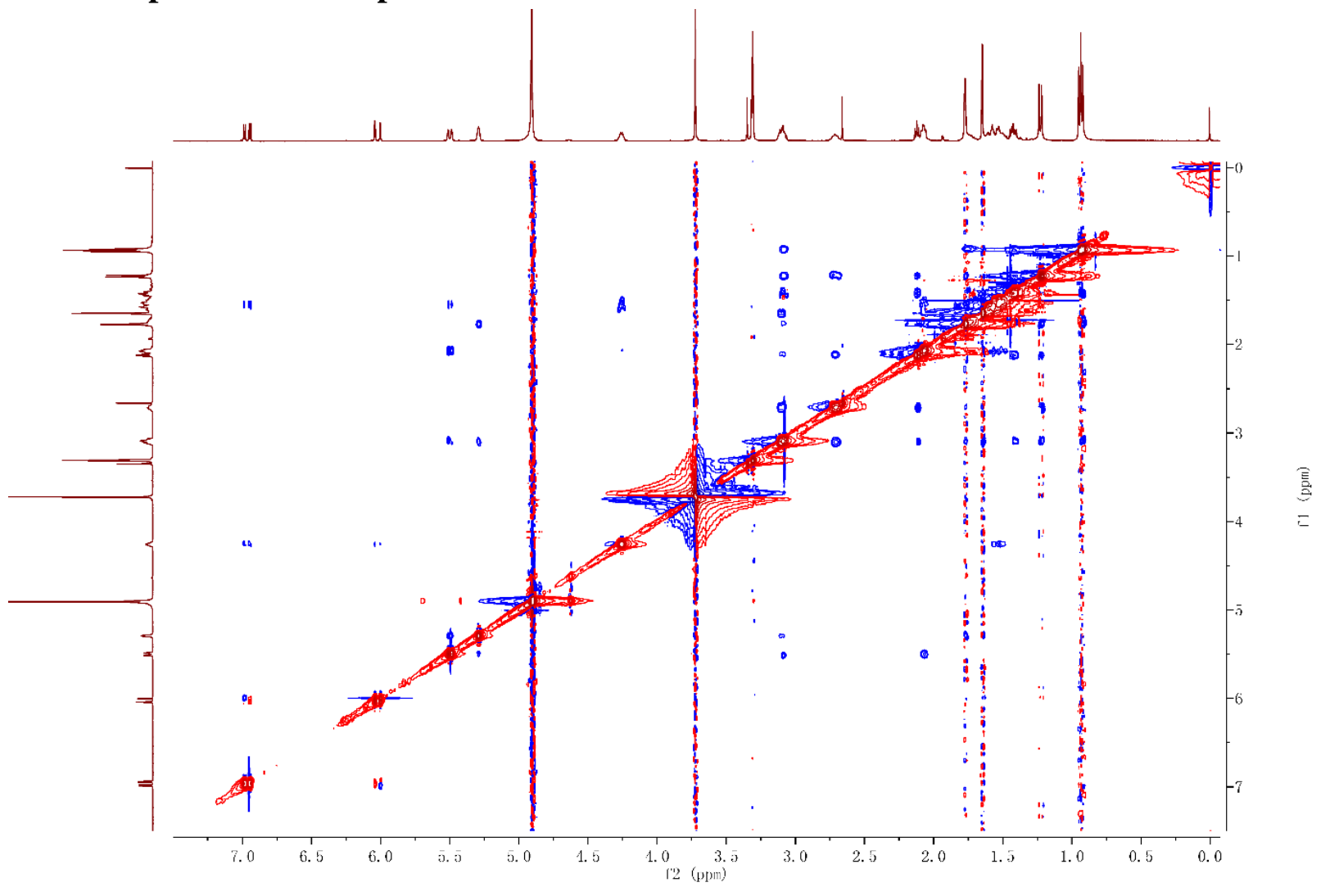

\section{HRESIMS spectrum of compound 8}

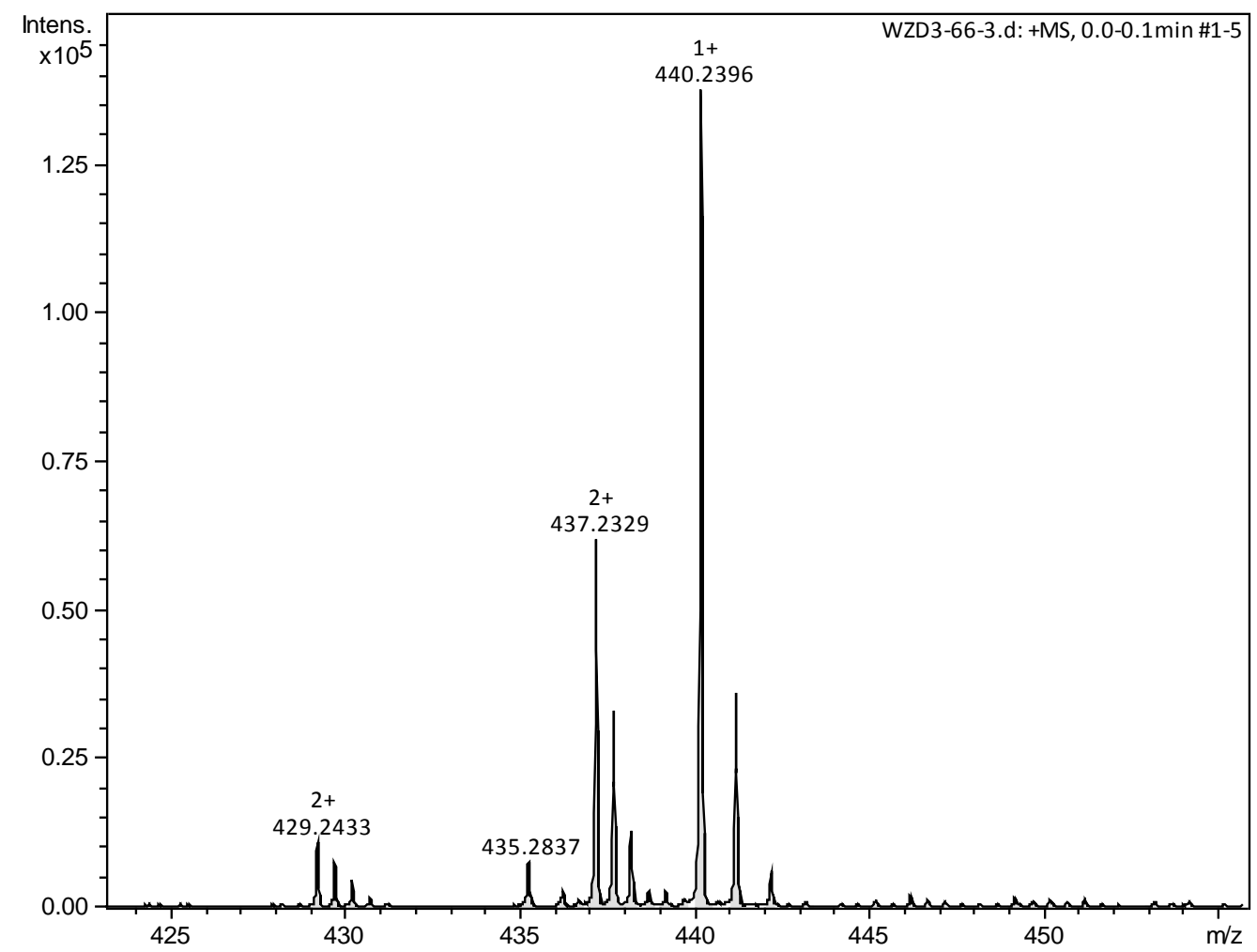




\section{UV spectrum of compound 8}

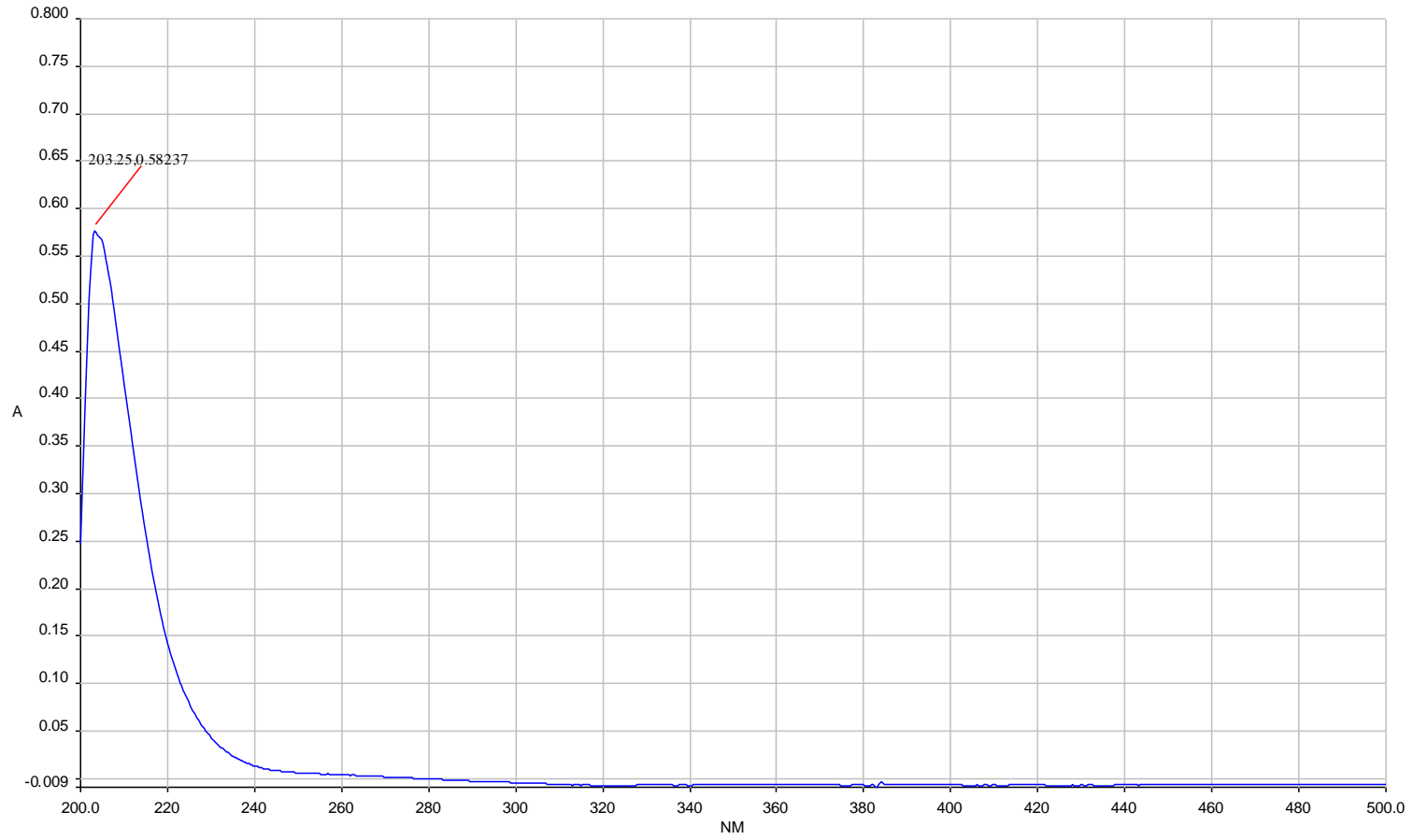

IR spectrum of compound 8

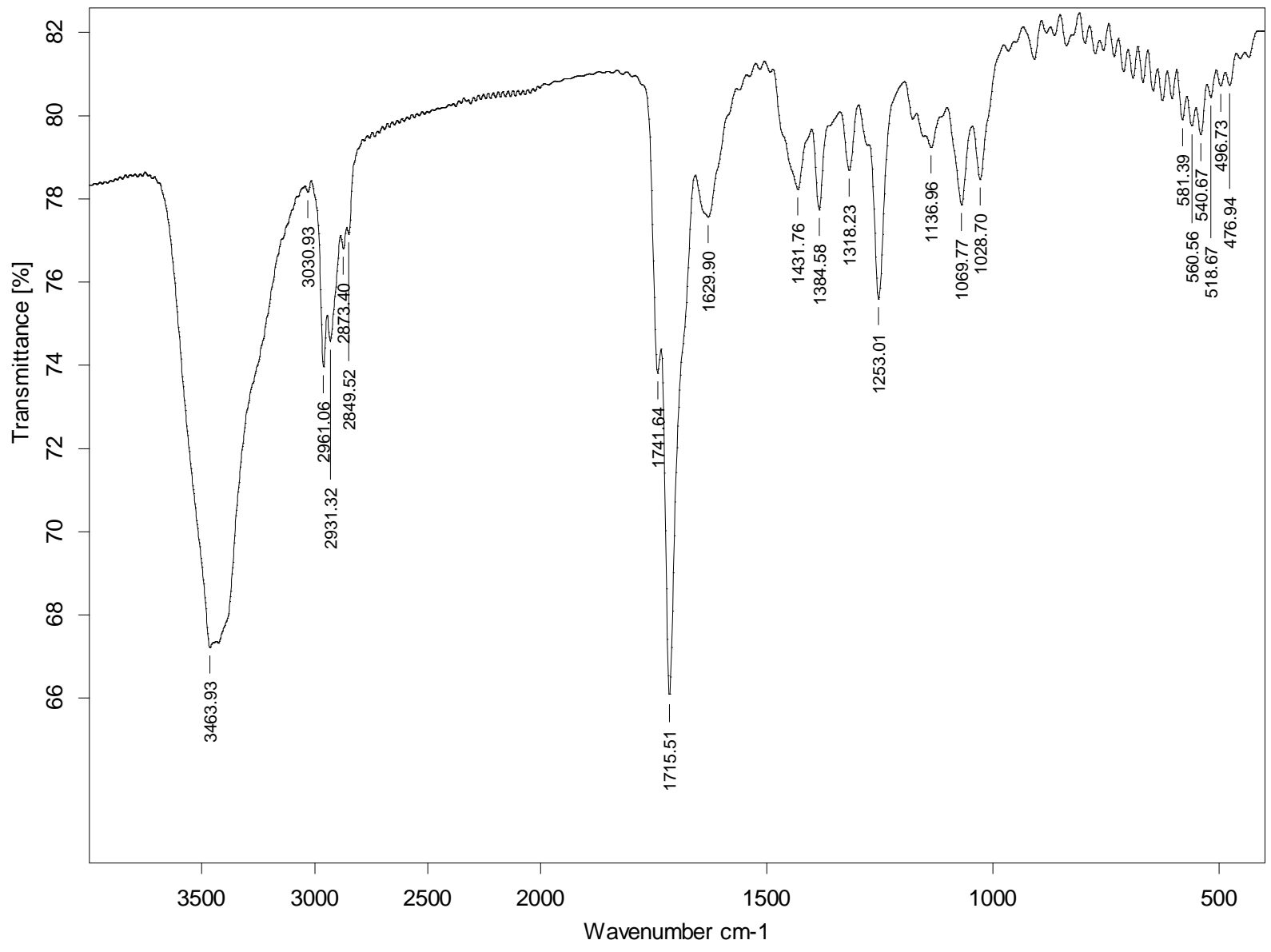




\section{${ }^{1}$ H NMR spectrum of compound 8}

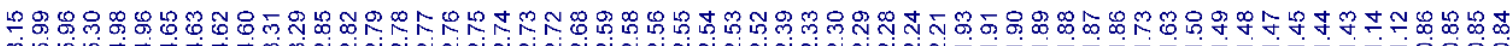

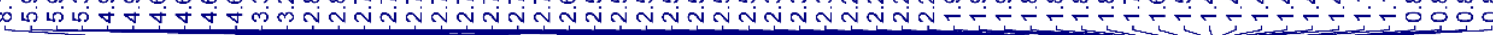

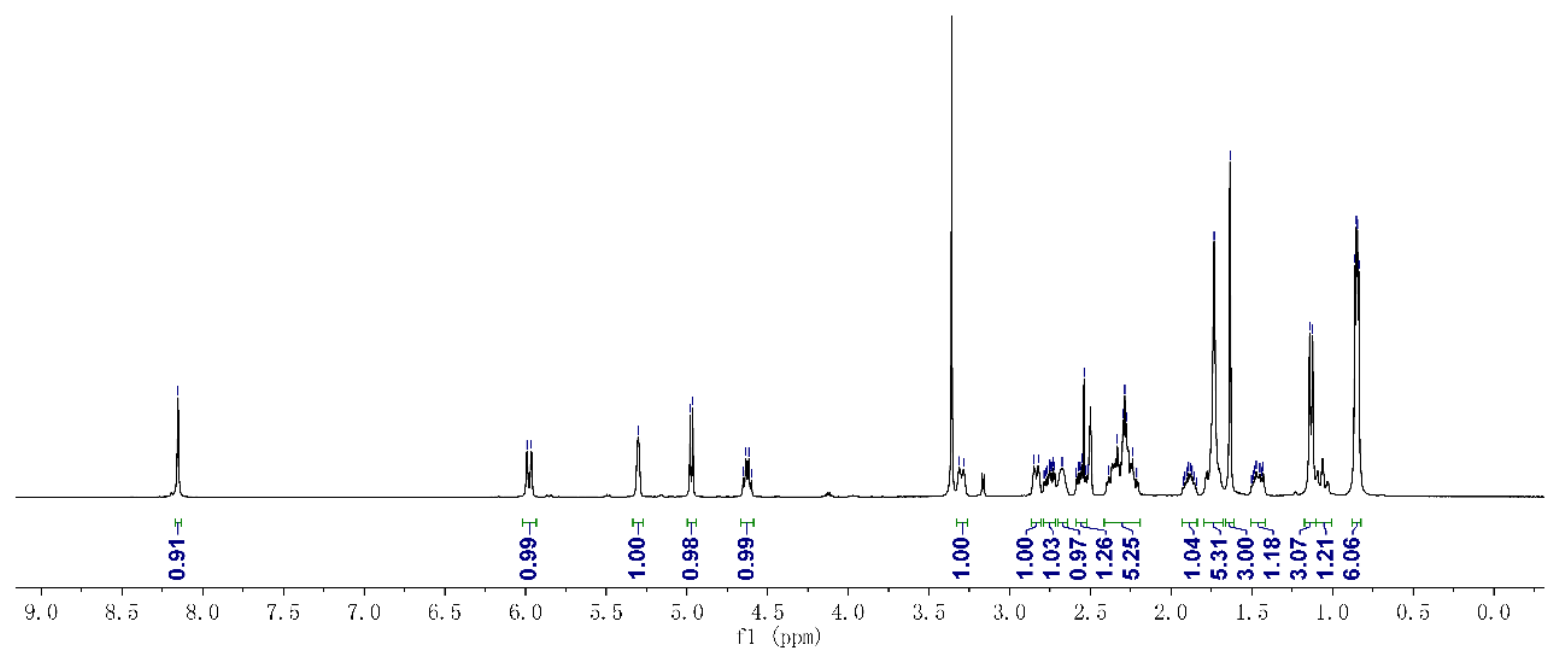

${ }^{13} \mathrm{C}$ NMR and DEPT spectra of compound 8
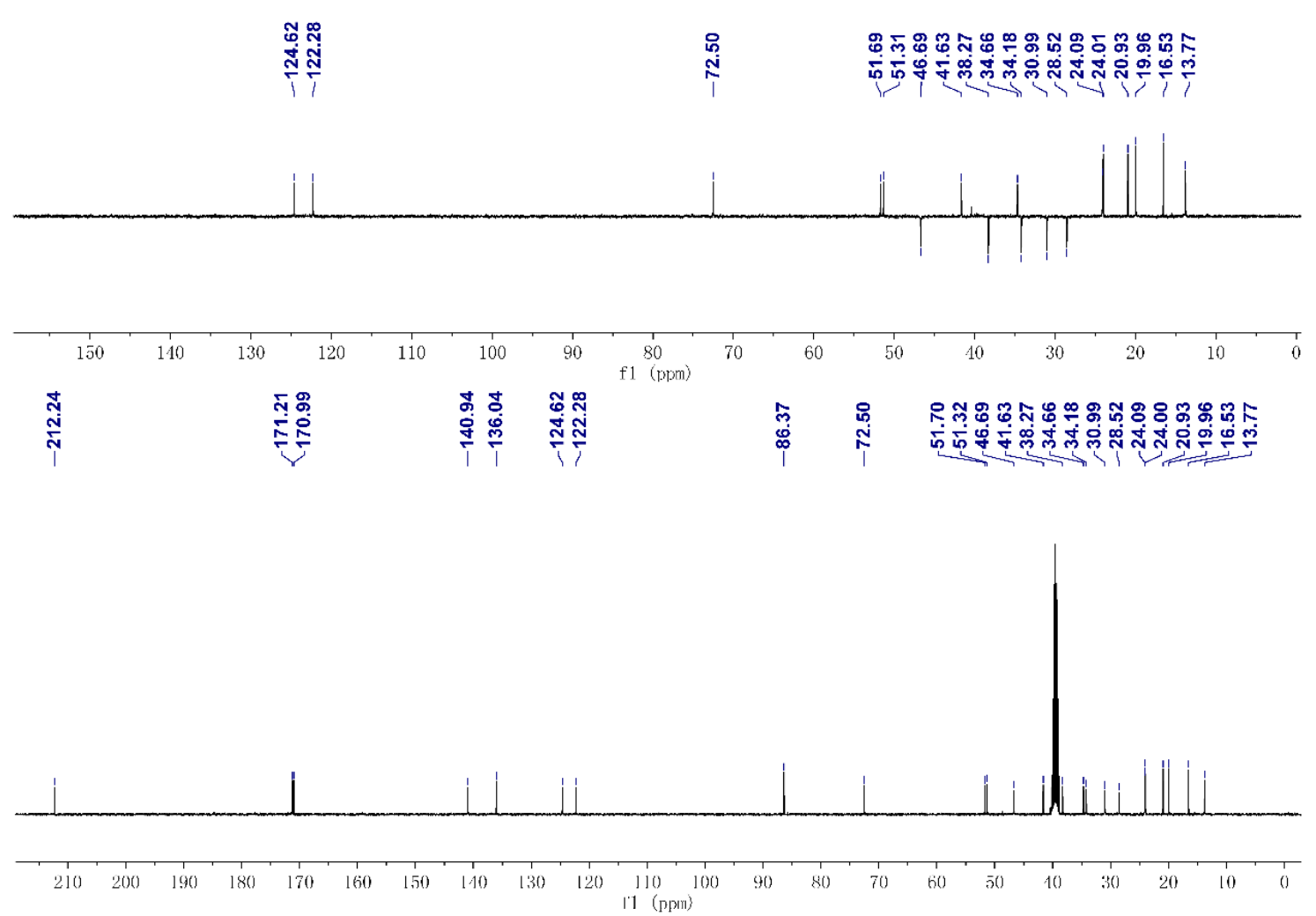


\section{HSQC spectrum of compound 8}

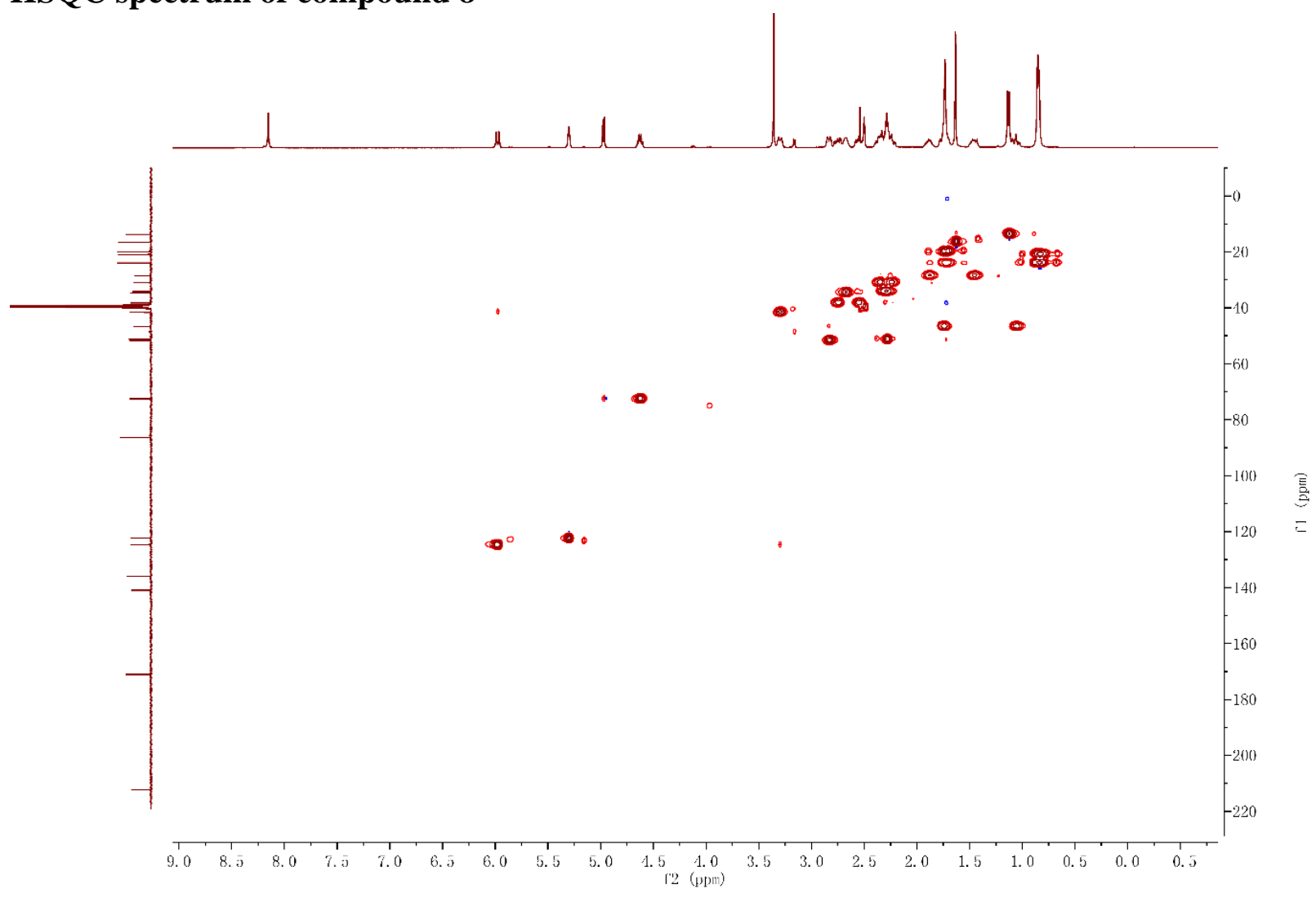

\section{HMBC spectrum of compound 8}

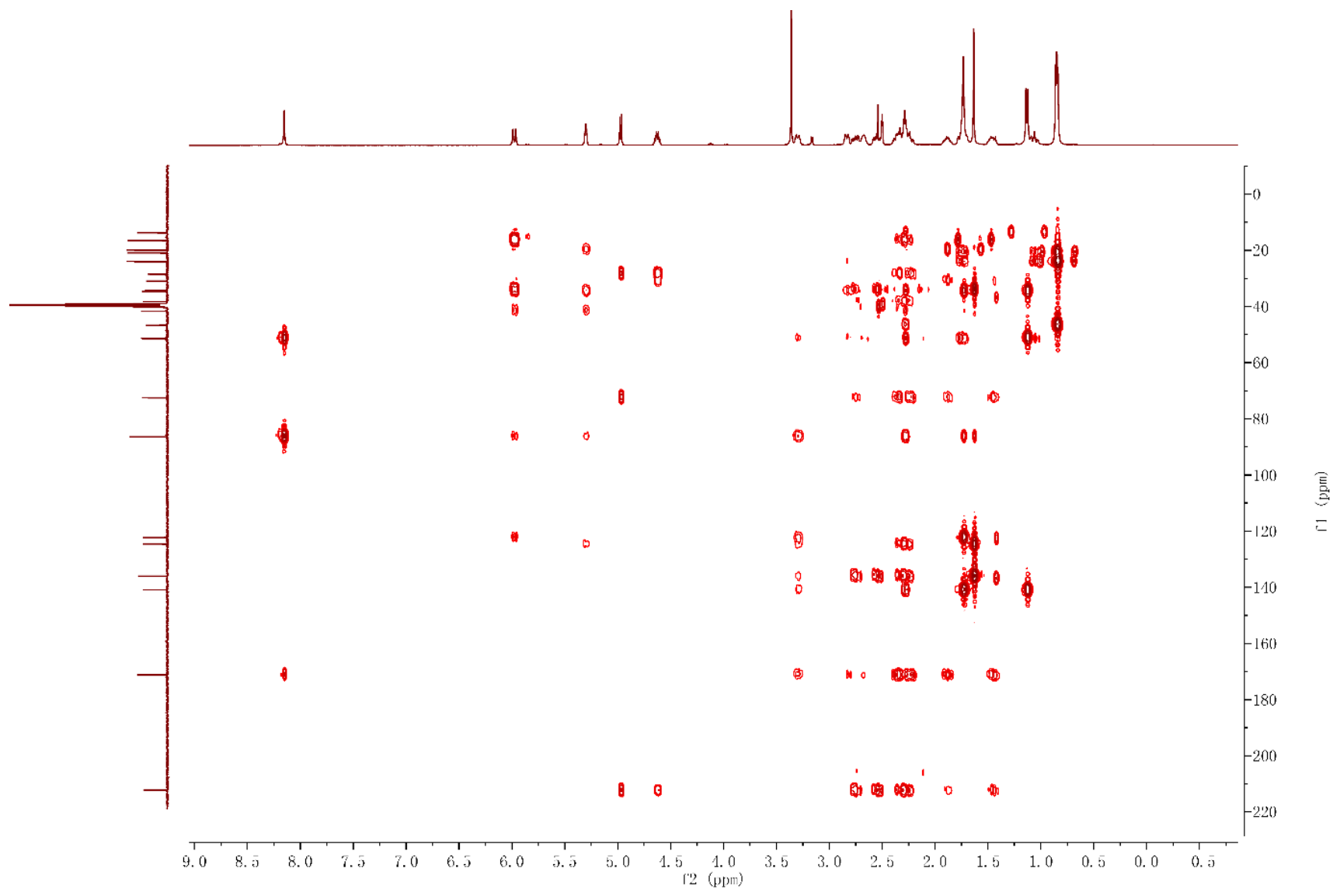


${ }^{1} \mathrm{H}-{ }^{1} \mathrm{H}$ COSY spectrum of compound 8

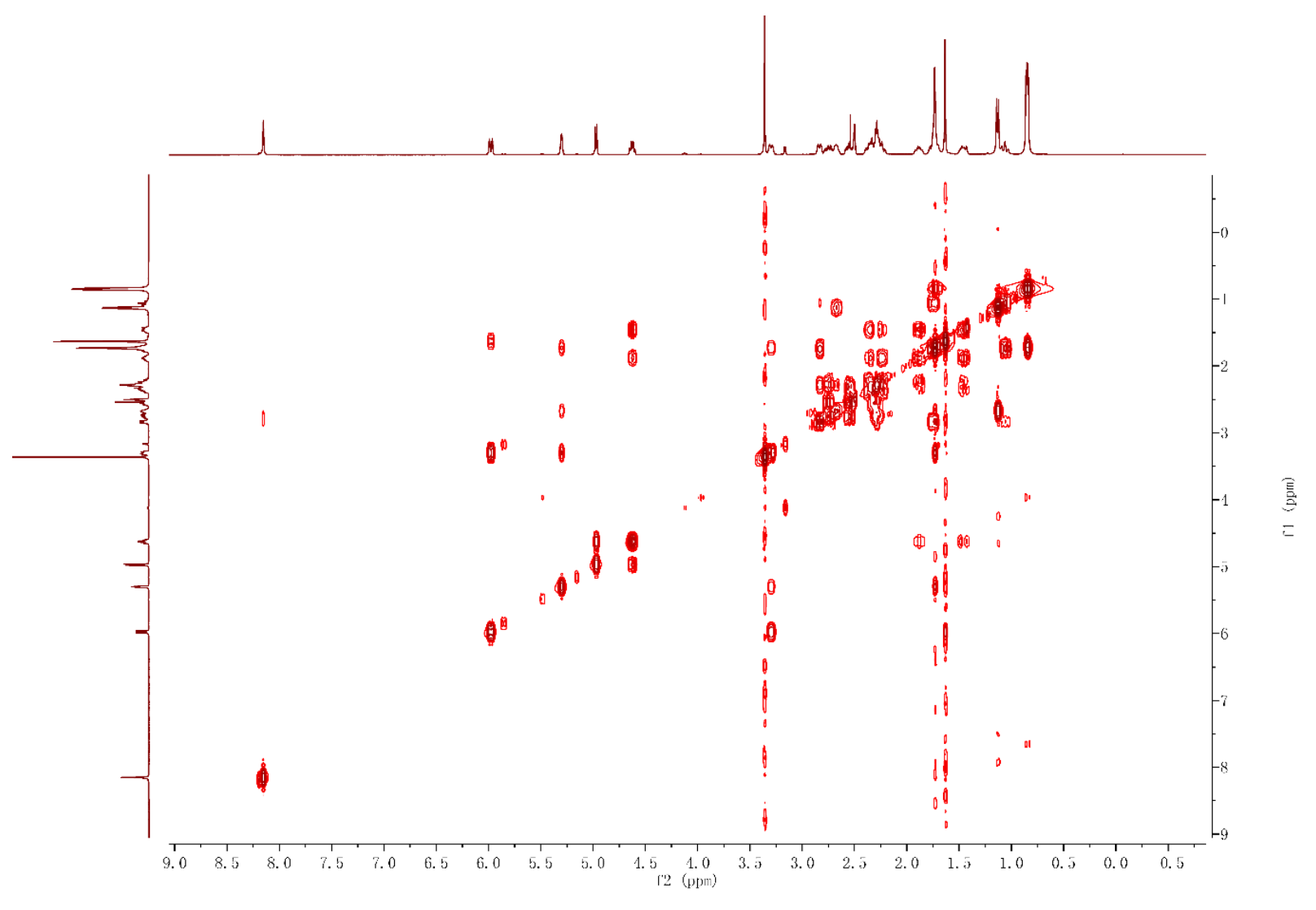

NOESY spectrum of compound 8

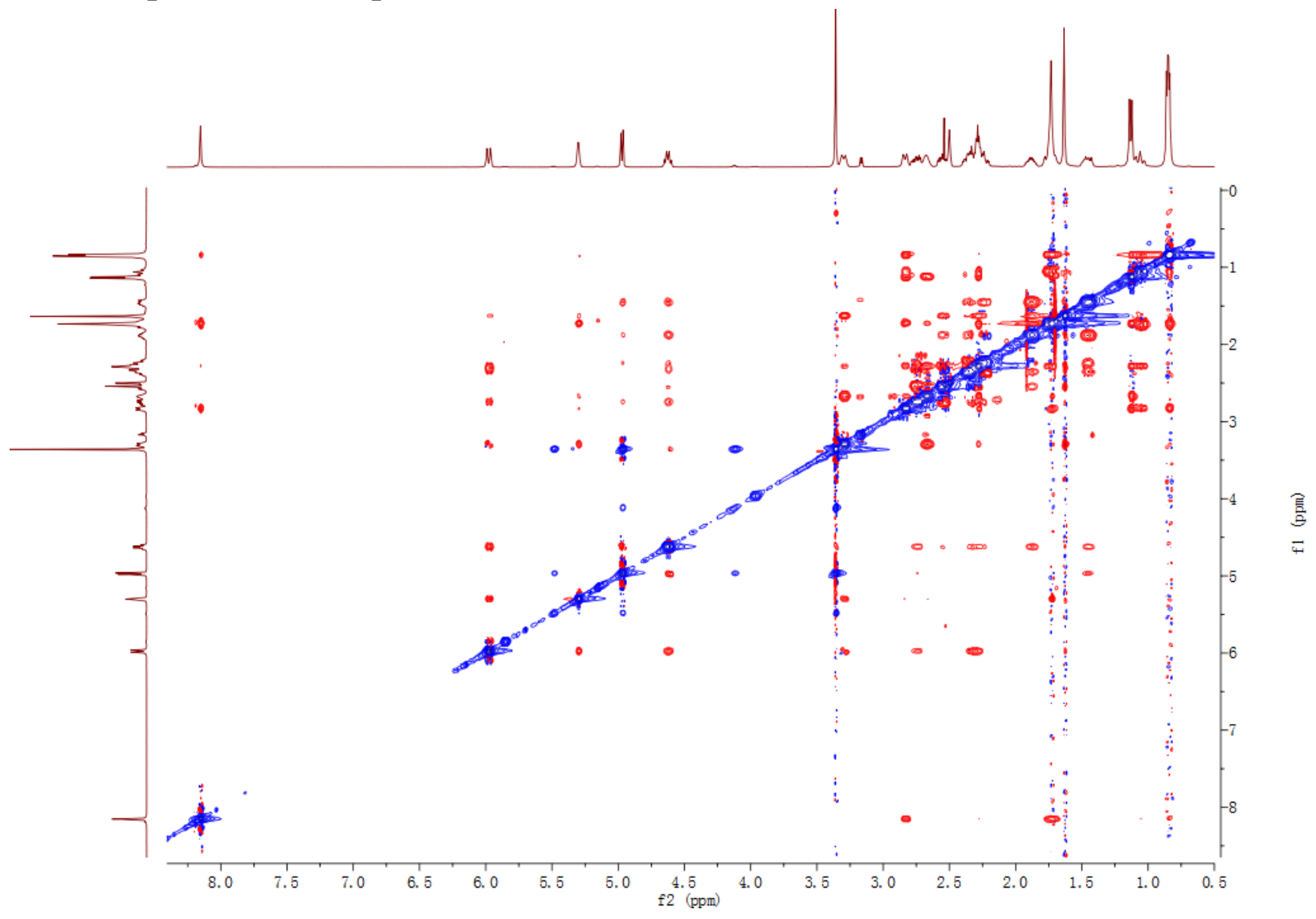




\section{${ }^{1} \mathrm{H}$ NMR spectrum of compound 9}

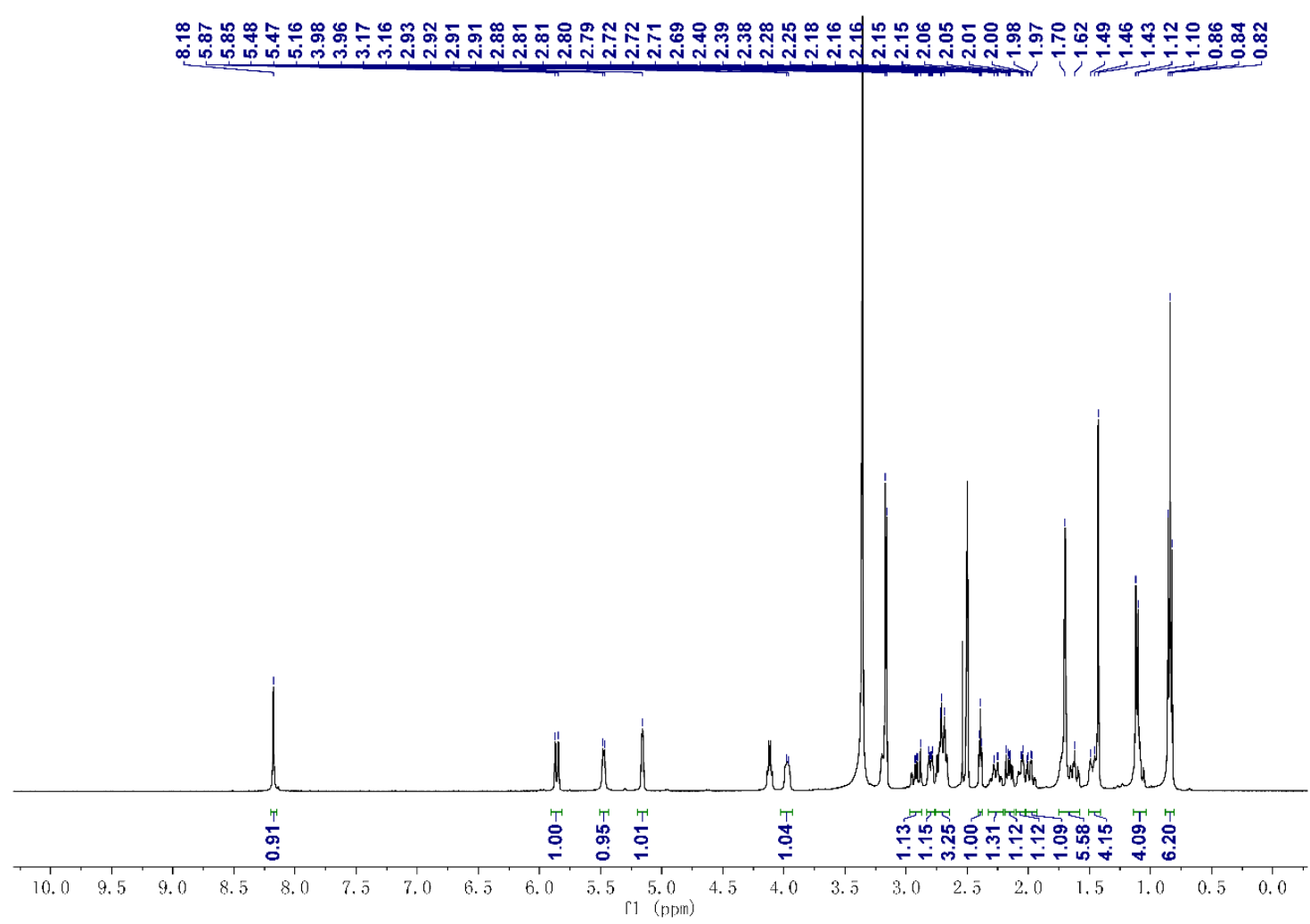

${ }^{13} \mathrm{C}$ NMR and DEPT spectra of compound 9
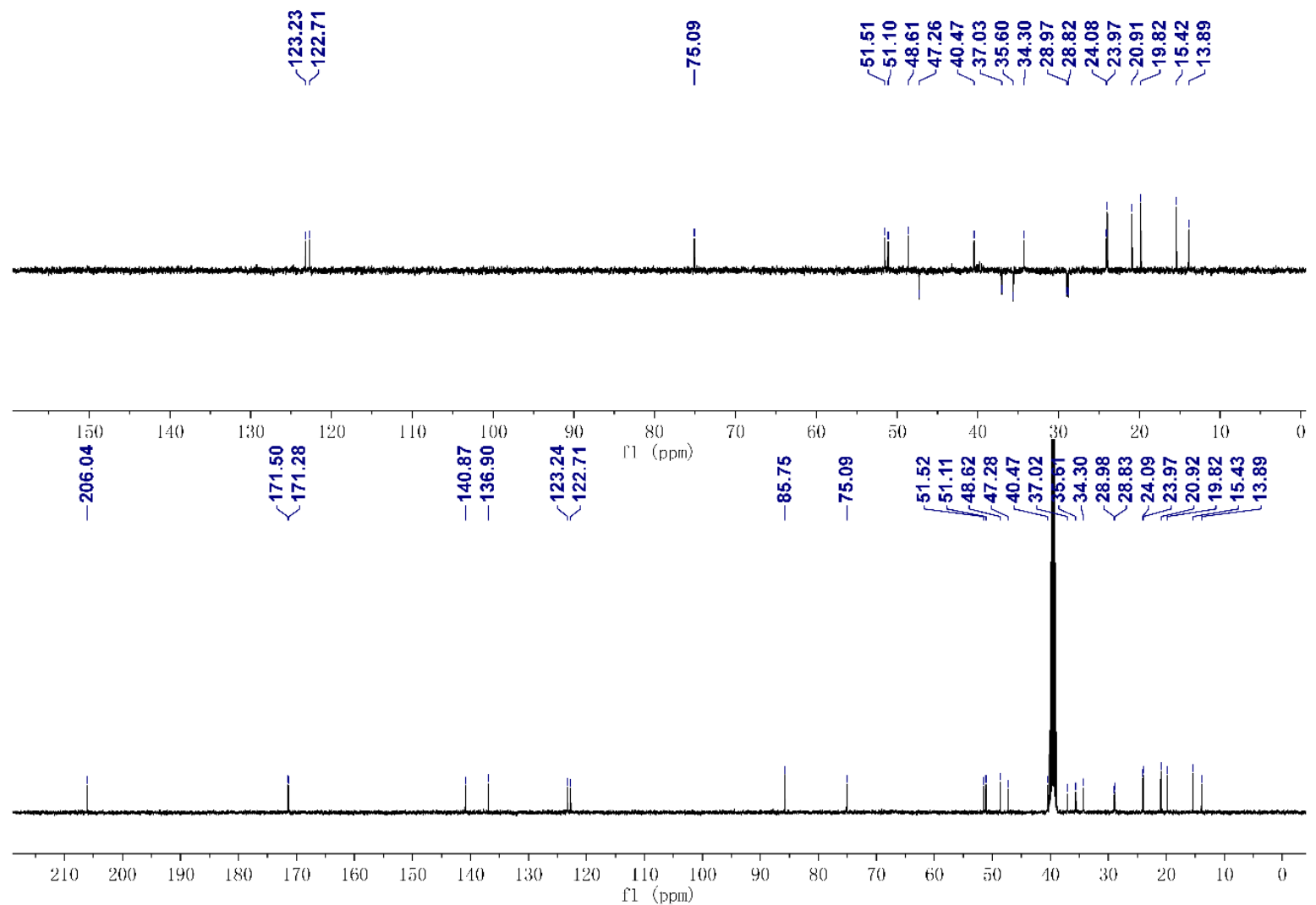